\title{
EFFECTS OF TETRACYCLINE AND IBUPROFEN ON THE RELATIVE ABUNDANCE OF PROTOZOAN AND BACTERIAL POPULATIONS IN WASTEWATER TREATMENT SEMI - BATCH REACTORS
}

by

\author{
Hossam Abdel Rahman \\ Bachelor of Science, General Science, \\ Athabasca University, 2014
}

\author{
A thesis \\ presented to Ryerson University \\ in partial fulfillment of the \\ requirement for the degree of \\ Master of Applied Science \\ In the program of \\ Environmental Applied Science and Management
}

Toronto, Ontario, Canada, 2017

(CHossam Abdel Rahman, 2017 


\section{AUTHOR'S DECLARATION}

I hereby declare that I, Hossam Abdel Rahman am the sole author of this thesis. This is a true copy of the thesis, including any final revisions as accepted by my examiners.

I hereby authorize the Ryerson University to lend this thesis to other institutions or individuals for the purpose of scholarly research.

I further authorize Ryerson University to reproduce this thesis by photocopying or by other means, in total or in part, at the request of other institutions or individuals for the purpose of scholarly research.

I understand that my thesis may be made electronically available to the public. 


\title{
EFFECTS OF TETRACYCLINE AND IBUPROFEN ON THE RELATIVE ABUNDANCE \\ OF PROTOZOAN AND BACTERIAL POPULATIONS IN WASTEWATER TREATMENT \\ SEMI - BATCH REACTORS
}

\author{
Hossam Abdel Rahman \\ Master of Applied Science, 2017 \\ Environmental Applied Science and Management \\ Ryerson University
}

\section{ABSTRACT}

The activated sludge process in Wastewater Treatment Plant (WWTPs) relies on the activities of microbes to reduce the organic and inorganic matter and produce effluent that is safe to discharge into receiving waters. This research examined the effects of non-steroidal antiinflammatory drug (NSAID) ibuprofen and the antibiotic tetracycline on the microbial population in activated sludge from the Humber WWTP. The current investigation was designated to observe the impact of these contaminants, at low (environmentally relative concentrations) as well as extremely high concentrations of tetracycline and ibuprofen. Using $16 \mathrm{~S}$ and $18 \mathrm{~S}$ rRNA gene primer sets, and qPCR the abundance of each population was monitored as well as the relative abundance of two populations under the various conditions. It was found that current environmental concentrations of ibuprofen stimulated protozoan growth but higher concentrations reduced their numbers especially in the presence of tetracycline. Finally using DGGE, the identity for some of the more abundant protozoa were identified and it was noted that high ibuprofen and tetracycline concentrations favored the abundance of some genera. 


\section{ACKNOWLEDGEMENTS}

I would like to start of by thanking my supervisor Dr. Kimberley Gilbride for offering me the privilege of being her student. Without her continuous patience, guidance and support, the field of research would have been difficult to navigate.

Second, I would like to thank my committee members Dr. Stephanie Melles and Dr. Otini Kroukamp. Your teachings have been a great addition to my arsenal of knowledge. I hope to continue building upon my teachings and to pass on the knowledge I have gained to others.

I would also like to take this opportunity to thank my mother, Nawal El Sayed, and father, Osama Abdel Rahman, for their love and support, I wouldn't have reached this far without your encouragement. I can spend lifetimes and wouldn't be able to repay back all they have done for me. I hope I can make you proud. I want to thank my brothers and friends for their support and encouragement.

I also want to thank everyone who has supported me throughout my research, GM Islam, Amir Tehrani, Ailiya Saeed, Brian Hanna, and Roshanak Pashang. Without your continuous help and support, my research would be at a stall.

I also thank all my lab colleagues from Kerr Hall North 301 and the volunteer students Farhan and Simon. I also thank the entire faculty and staff at Ryerson for providing me the opportunity to grow on the branches of Ryerson's endless tree of knowledge. 


\section{TABLE OF CONTENTS}

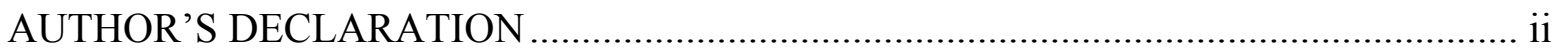

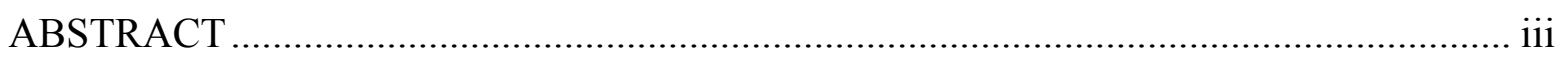

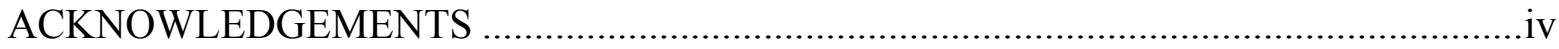

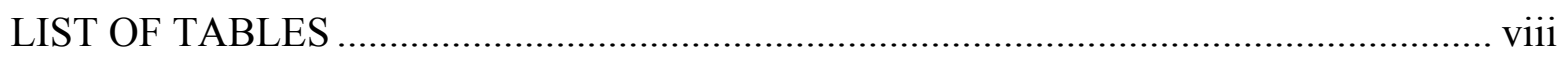

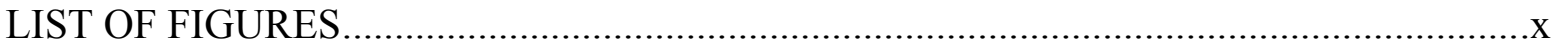

CHAPTER 1:

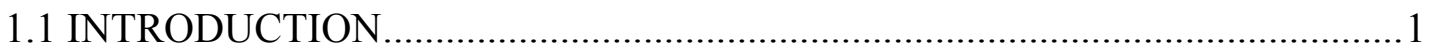

1.2 IBUPROFEN AS A CONTAMINANT OF WASTE WATER .............................2

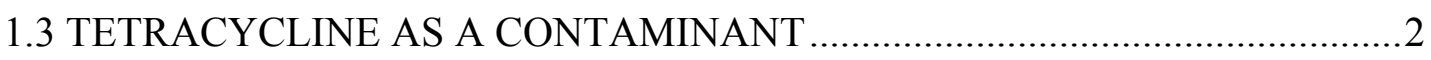

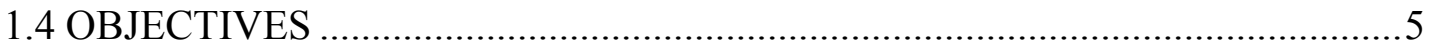

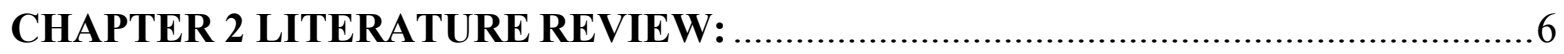

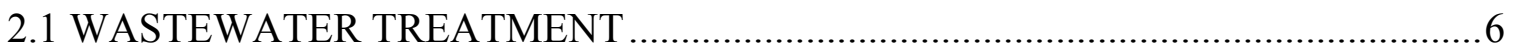

2.1.1 HUMBER WASTEWATER TREATMENT PLANT ....................................6

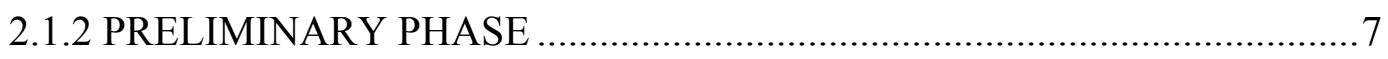

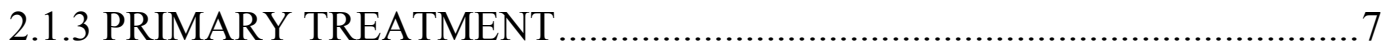

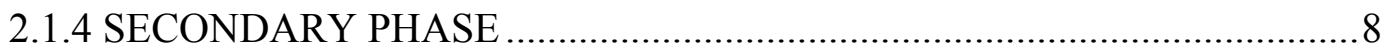

2.1.5 FINAL EFFLUENT QUALITY \& DISINFECTION ..................................

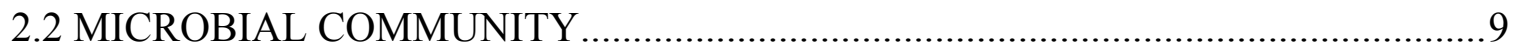

2.2.1 ACTIVATED SLUDGE, PARAMETERS AND EFFICIENCY .................11

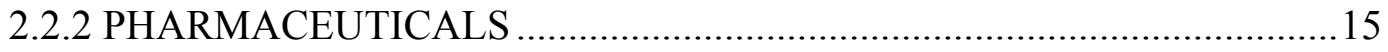

2.2.3 MAJOR PHARMACEUTICALS IN WASTEWATER ………………........17 
2.3.1 PROTOZOA RELATED RESEARCH..................................................28

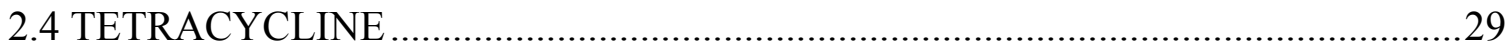

2.5 IBUPROFEN

2.6 16S rRNA gene AND 18S rRNA gene PRIMERS ……………………………........

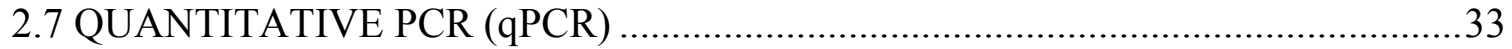

CHAPTER 3 MATERIALS AND METHOD:

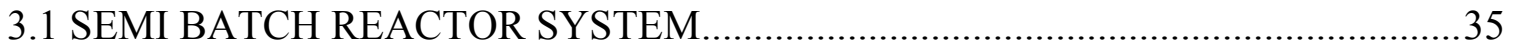

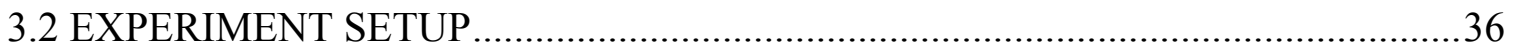

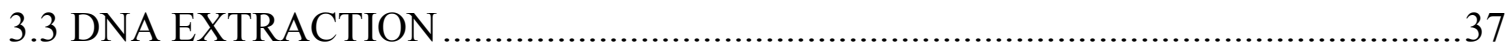

3.4 QUANTITATIVE POLYMERASE CHAIN REACTION ...........................................37

3.5 COMMUNITY PROFILES AND PROTOZOA IDENTIFICATION.........................39

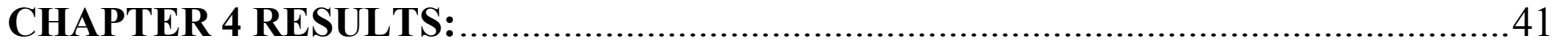

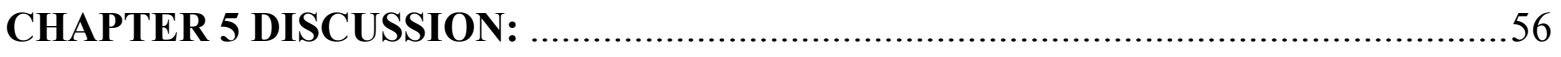

5.1 RESEARCH EXAMINATION ………………………….....................................56

5.2 PERFORMANCE OF THE SEMI-BATCH REACTORS …………………….........59

5.3 NON-STEROIDAL ANTI-INFLAMMATORY DRUGS ………………………....60

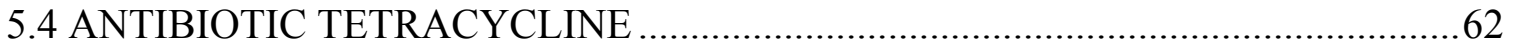

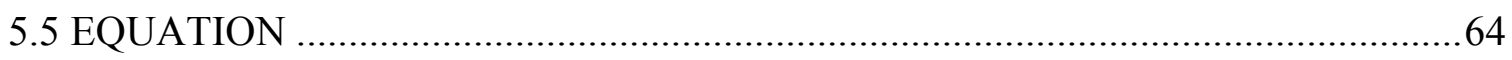

5.6 RESEARCH PROJECT APPLICATION AND FUTURE PROSPECTIVE .............64

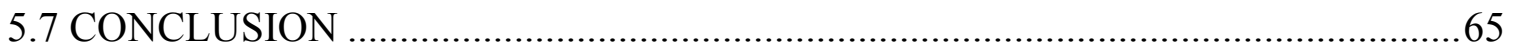

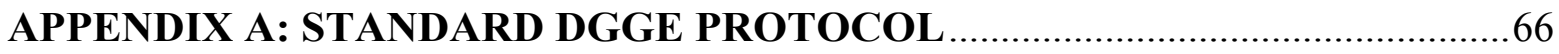

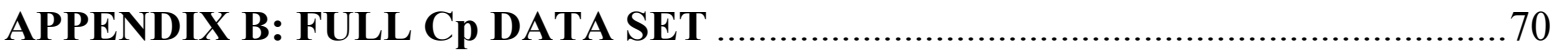


APPENDIX C: REAGENTS \& NUCLEIC ACID SEQUENCES

REFERENCES: 


\section{LIST OF TABLES}

Table 1: The range of removal rates (\%RE) for the most representative compounds of each therapeutic group, in the whole set of WWTP under investigation (Gros et al., 2010) ......20

Table 2: Various concentrations of ibuprofen found in influent, effluent, and their removal efficiency

Table 3: Activated sludge ciliates grouped by specialization. Categorized by Madoni 1994b ...26

Table 4 - Performance rating of ciliate groups and possible causes for performance rate (Madoni $1986,1988)$ 27

Table 5 - Cp values, standard deviation and relative abundance ratios for 16S rRNA gene and 18S rRNA gene for; day 0, no pharmaceuticals (control), tetracycline $(50 \mathrm{ng} / \mathrm{ml})$, Ibuprofen (100 ng/ml), and a combination of Ibuprofen $(100 \mathrm{ng} / \mathrm{ml})$ and tetracycline $(50 \mathrm{ng} / \mathrm{ml}) . \mathrm{Cp}$ values, standard deviation and relative abundance ratios for $16 \mathrm{~S}$ rRNA gene and $18 \mathrm{~S}$ rRNA gene; day 0 , no pharmaceuticals (control), ibuprofen $(100 \mathrm{ng} / \mathrm{ml})$ plus tetracycline $(50$ $\mathrm{ng} / \mathrm{ml})$, Ibuprofen $(2000 \mathrm{ng} / \mathrm{ml})$, a combination of Ibuprofen $(100,000 \mathrm{ng} / \mathrm{ml})$ and tetracycline $(50 \mathrm{ng} / \mathrm{ml})$ and a combination of Ibuprofen $(100,000 \mathrm{ng} / \mathrm{ml})$ and tetracycline $(500 \mathrm{ng} / \mathrm{ml})$.

Table 6 - Analyzed nucleotide sequences from DGGE samples 1-12 obtained from ACGT Inc. Using the Basic Local Alignment Search Tool (BLAST) from The National Center For Biotechnology Information (NCBI), a compiled list of possible species with their identity percentage is produced(Altschul et al., 1997) .54

Table 7 - Full experiment $1 \mathrm{Cp}$ values, standard deviation and relative abundance ratios for $16 \mathrm{~S}$ rRNA gene and 18S rRNA gene for; day 0, no pharmaceuticals (control), tetracycline (50 $\mathrm{ng} / \mathrm{ml})$, Ibuprofen $(100 \mathrm{ng} / \mathrm{ml})$, and a combination of Ibuprofen $(100 \mathrm{ng} / \mathrm{ml})$ and tetracycline 
(50 ng/ml). Experiment $2 \mathrm{Cp}$ values, standard deviation and relative abundance ratios for 16S rRNA gene and 18S rRNA gene; day 0, no pharmaceuticals (control), ibuprofen (100 $\mathrm{ng} / \mathrm{ml})$ plus tetracycline $(50 \mathrm{ng} / \mathrm{ml})$, Ibuprofen $(2000 \mathrm{ng} / \mathrm{ml})$, a combination of Ibuprofen $(100,000 \mathrm{ng} / \mathrm{ml})$ and tetracycline $(50 \mathrm{ng} / \mathrm{ml})$ and a combination of Ibuprofen $(100,000$ $\mathrm{ng} / \mathrm{ml})$ and tetracycline $(500 \mathrm{ng} / \mathrm{ml})$

Table 8 - Reagents and concentrations used for qPCR ……………………….........................

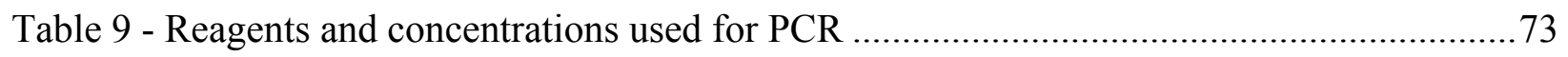

Table 10 - Synthetic Wastewater Composition (Liao et al., 2001) ................................................73 


\section{LIST OF FIGURES}

Figure 1 - Daily Consumption of tetracyclines and subclass agents in Canada from 1996 - 2013

("Do Bugs Need Drugs?", 2014).....................................................................................

Figure 2 - Daily prescription rates for tetracyclines and subclass agents in Canada from 1996 2013 ("Do Bugs Need Drugs?", 2014) .............................................................................

Figure 3 - Humber wastewater treatment process (City of Toronto, 2015) …..............................9

Figure 4 Diagram showing nitrogen cycle and the relationship of ammonification, nitrification, denitrification, and anammox process (Thomson et al., 2012)............................................13

Figure 5: A system showing potential sources and pathways for the occurrence of pharmaceuticals in the aquatic environment (Heberer, 2002).

Figure 6: One liter Reactors were set up on the bench at room temperature and aerated with aquarium bubblers. They were maintained for 15 days. a) top view, b) side view .36

Figure 7: Abundance of bacterial and protozoan populations in each reactors at time zero and then after 15 days after the addition of no pharmaceuticals (control), tetracycline $(50 \mathrm{ng} / \mathrm{ml})$, Ibuprofen $(100 \mathrm{ng} / \mathrm{ml})$, and a combination of Ibuprofen $(100 \mathrm{ng} / \mathrm{ml})$ and tetracycline (50 $\mathrm{ng} / \mathrm{ml})$

Figure 8A: The relative abundance of the bacterial and protozoan populations in each reactor compared to the abundance seen in the control. No pharmaceuticals (control), tetracycline (50 ng/ml), Ibuprofen $(100 \mathrm{ng} / \mathrm{ml})$, and a combination of Ibuprofen $(100 \mathrm{ng} / \mathrm{ml})$ and tetracycline $(50 \mathrm{ng} / \mathrm{ml})$. Ratios are relative to their own control and the control values are not 1:1 ratio 45

Figure 8B: Using the relative abundance of the bacterial and protozoan populations calculated using the relative expression formula for all day 15 reactors after the addition of no 
pharmaceuticals (control), tetracycline $(50 \mathrm{ng} / \mathrm{ml})$, Ibuprofen $(100 \mathrm{ng} / \mathrm{ml})$, and a combination of Ibuprofen $(100 \mathrm{ng} / \mathrm{ml})$ and tetracycline $(50 \mathrm{ng} / \mathrm{ml})$. Using the protozoa and bacterial ratios to calculate a single community ratio for each reactor 46

Figure 9: Relative abundance of the bacterial and protozoan populations in each reactor at time zero and then after 15 days after the addition of no pharmaceuticals (control), ibuprofen $(100 \mathrm{ng} / \mathrm{ml})$ plus tetracycline $(50 \mathrm{ng} / \mathrm{ml})$, Ibuprofen $(2000 \mathrm{ng} / \mathrm{ml})$, a combination of Ibuprofen $(100,000 \mathrm{ng} / \mathrm{ml})$ and tetracycline $(50 \mathrm{ng} / \mathrm{ml})$ and a combination of Ibuprofen $(100,000 \mathrm{ng} / \mathrm{ml})$ and tetracycline $(500 \mathrm{ng} / \mathrm{ml})$. 48

Figure 10A: Relative abundance of the bacterial and protozoan populations calculated using the relative expression formula for all day 15 reactors after the addition of no pharmaceuticals (control), Ibuprofen $(100 \mathrm{ng} / \mathrm{ml})$ and tetracycline $(50 \mathrm{ng} / \mathrm{ml})$, Ibuprofen $2000 \mathrm{ng} / \mathrm{ml}$ and tetracycline $(50 \mathrm{ng} / \mathrm{ml})$, Ibuprofen $(100,000 \mathrm{ng} / \mathrm{ml})$ and tetracycline $(50 \mathrm{ng} / \mathrm{ml})$, and Ibuprofen $(100,000 \mathrm{ng} / \mathrm{ml})$ and tetracycline $(500 \mathrm{ng} / \mathrm{ml})$. Ratios are relative to their own control and the control values are not 1:1 ratio

Figure 10B: Using the relative abundance of the protozoan population vs the bacterial population calculated using the relative expression formula for all day 15 reactors after the addition of no pharmaceuticals (control), Ibuprofen $(100 \mathrm{ng} / \mathrm{ml})$ and tetracycline $(50 \mathrm{ng} / \mathrm{ml})$, Ibuprofen $2000 \mathrm{ng} / \mathrm{ml}$ and tetracycline $(50 \mathrm{ng} / \mathrm{ml})$, Ibuprofen $(100,000 \mathrm{ng} / \mathrm{ml})$ and tetracycline $(50$ $\mathrm{ng} / \mathrm{ml}$ ), and Ibuprofen 100,000 $\mathrm{ng} / \mathrm{ml}$ and tetracycline (500 $\mathrm{ng} / \mathrm{ml})$. Using the protozoa and bacterial ratios to calculate a single community ratio for each reactor .50

Figure 11: The relative abundance of the bacterial and protozoan populations for day 0 and day 15 controls. Ratios are relative to their own control and the control values are not 1:1 ratio. 
Figure 12: DGGE profile of protozoan population in the reactors with various tetracycline and ibuprofen contractions. From right to left; MW marker ladder, control population, profile from reactors with $\mathrm{Ibu} 100,000 \mathrm{ng} / \mathrm{ml}$ and tet $50 \mathrm{ng} / \mathrm{ml}$, profile from reactors with $\mathrm{Ibu}$ $100,000 \mathrm{ng} / \mathrm{ml}$ and tet $500 \mathrm{ng} / \mathrm{ml}$. The bands present qPCR fragments generated with the

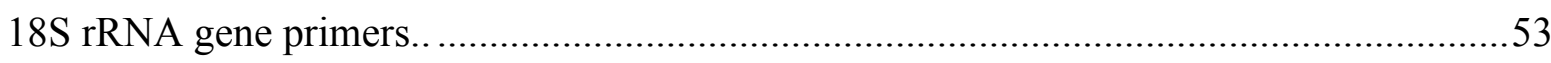

Figure 13: PCR gel image of isolated DNA bands cut from DGGE gel. Image shows DNA bands 1-6, ladder, 7-12. Bands show approximately 500 base pairs................................................53 


\section{CHAPTER 1:}

\subsection{INTRODUCTION}

Wastewater is a compilation of rainwater, agricultural, industrial, and municipal wastewater (Pauli et al., 2015). The city of Toronto houses four wastewater treatment plants (WWTP), Ashbridges Bay, Highland Creek, Humber, and North Toronto. The four plants jointly handle approximately 1,111.6 ML/day of wastewater and serve 2,773,000 residents in 2014 (City of Toronto, 2015). Wastewater can include organic and inorganic matter, nutrients, pathogens, synthetic chemicals, and heavy metals. In order to reduce harm and damages to the environment, and human society, as well as recycle fresh water, wastewater management is critical and their processes are vital to the operation.

The wastewater treatment process includes; i) preliminary, ii) primary, iii) secondary, sometimes a iv) tertiary treatment phase. A vital process of wastewater management is the secondary treatment phase, which operates with the usage of microorganism as clarifiers for waste decomposition. The importance of maintaining a proper environment for these microorganisms is critical for this process in order to maintain efficient biodegradation. Microorganisms are not immune to chemical and physical effects that may cause population reduction, subsequently reducing performance efficiency. The two significant microbial groups in the activated sludge are protozoa and bacteria. While bacteria biodegrade organic matter within the influent (wastewater entering), protozoa graze on free swimming bacteria and help clear the effluent (wastewater existing) (Pauli et al., 2015). 


\subsection{IBUPROFEN AS A CONTAMINANT OF WASTE WATER}

There are lots of contaminants that make their way into wastewater influent. One group are the non-steroidal anti-inflammatory drugs (NSAID) such as ibuprofen. Ibuprofen is an antipyretic and analgesic drug that is commonly used by children and adults (Aslam et al, 2010). Ibuprofen was developed in 1961 by the Boots Company and was approved by the FDA for over-the-counter use by 1984 (Rainsford, 2011). Ibuprofen was first introduced in 1969 in a study conducted by the University of Wollongong with evidence suggesting that some NSAIDs have the capabilities of antibacterial properties (Yin et al., 2014). Health Canada has recently reported that in Canada approximately 780,000 prescriptions of $600 \mathrm{mg}$ of ibuprofen were sold between 2010 and 2014 (Health Canada, 2015). This statistic does not include the over-thecounter ibuprofen sold, such as the regular strength $200 \mathrm{mg}$ and extra strength $400 \mathrm{mg}$.

\subsection{TETRACYCLINE AS A CONTAMINANT}

Another contaminant group in wastewater influent are antibiotics such as tetracycline. Tetracyclines are a group of broad-spectrum antibiotics first discovered in the early 1940s and were approved by the FDA in 1948 (Nelson et al., 2011). Tetracyclines also have sub classifications such as short acting (i.e. tetracycline), intermediate-acting (i.e. demeclocycline) and long-acting compounds (i.e. minocycline and doxycycline). Members of the tetracycline family share similar antibacterial effects against pathogens such as, Chlamydia, Mycoplasma and Rickettsia (Do Bugs Need Drugs?, 2014). Tetracyclines function by inhibiting protein synthesis by blocking aminoacyl tRNA and preventing it from binding to the 30S ribosome (Todar, 2002). Tetracyclines have been commonly used for both human and animal care, where the majority of 
use today is in veterinary medicine and animal husbandry, such as growth promotion and prevention of bacterial infections (Gujarathi et al., 2005).

According to a report by the BC Centre for Disease Control, from 1996 to 2009, the consumption rate of tetracyclines gradually declined from 3.34 to 2.66 defined daily dose (DDD)/1000 population/day, which was approximately a total percentage drop of $20 \%$. Conversely, an increase of $8 \%$ was witnessed from 2.66 in 2009 to $2.88 \mathrm{DDD} / 1000$ population/day in 2013 ("Do Bugs Need Drugs?", 2014). The reason for this change is that although tetracycline has declined, sub group doxycycline has significantly increased in use and is the major contributor for the overall tetracycline increase. The use of doxycycline decreased from 1.27 in 1996 to $1.06 \mathrm{DDD} / 1000$ population/day in 2003 , then had a steady increase to 1.78 DDD/1000 population/day up to 2013, which is most likely related to MRSA and treatment of skin and soft tissue infections (Do Bugs Need Drugs?, 2014). Usage of minocycline also increased from $0.43 \mathrm{DDD} / 1000$ population/day in 1996 to $0.82 \mathrm{DDD} / 1000$ population/day in 2013. Figure 1 and Figure 2 illustrate the change of DDD/1000 population/day and daily prescription rates for tetracyclines from 1996 to 2003. The Figures 1 and 2 demonstrate that, tetracycline has decreased while doxycycline and minocycline have steadily increased. Utilization of these antibiotic consumption in British Columbia were comparable in consumption to that of Ontario (Do Bugs Need Drugs?, 2014). 


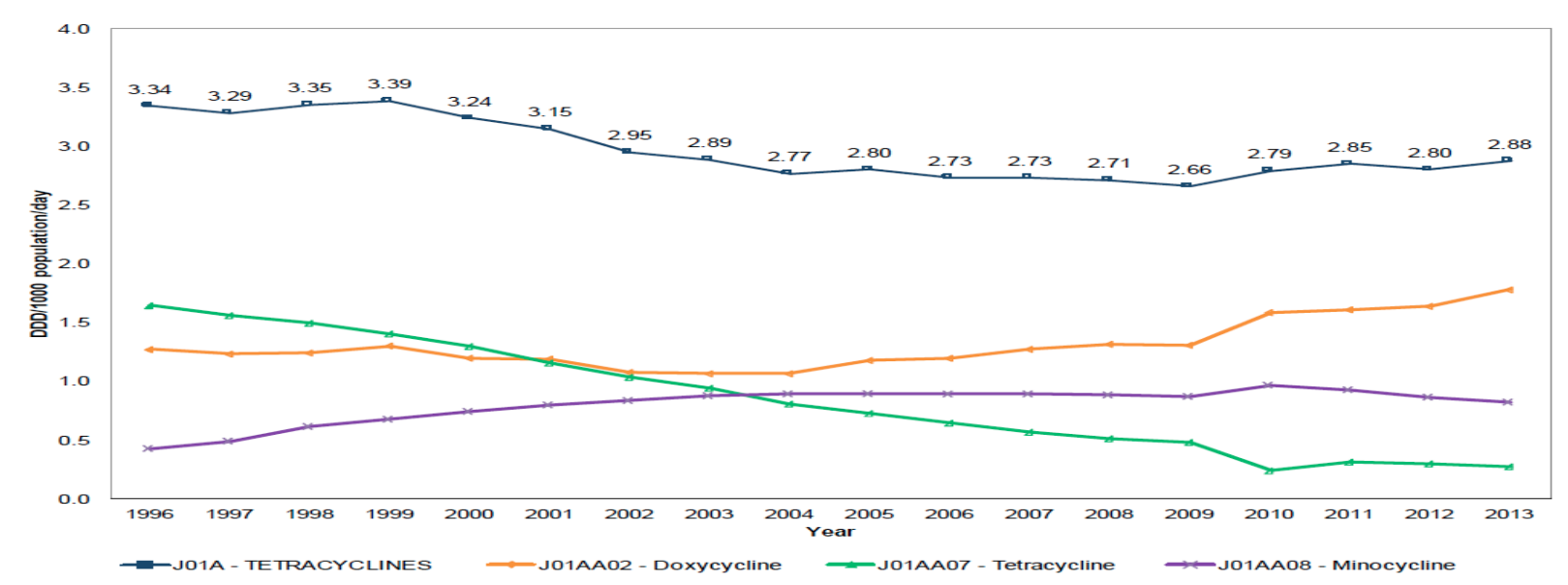

Figure 1 - Daily Consumption of tetracyclines and subclass agents in Canada from 1996 2013 (Do Bugs Need Drugs?, 2014)

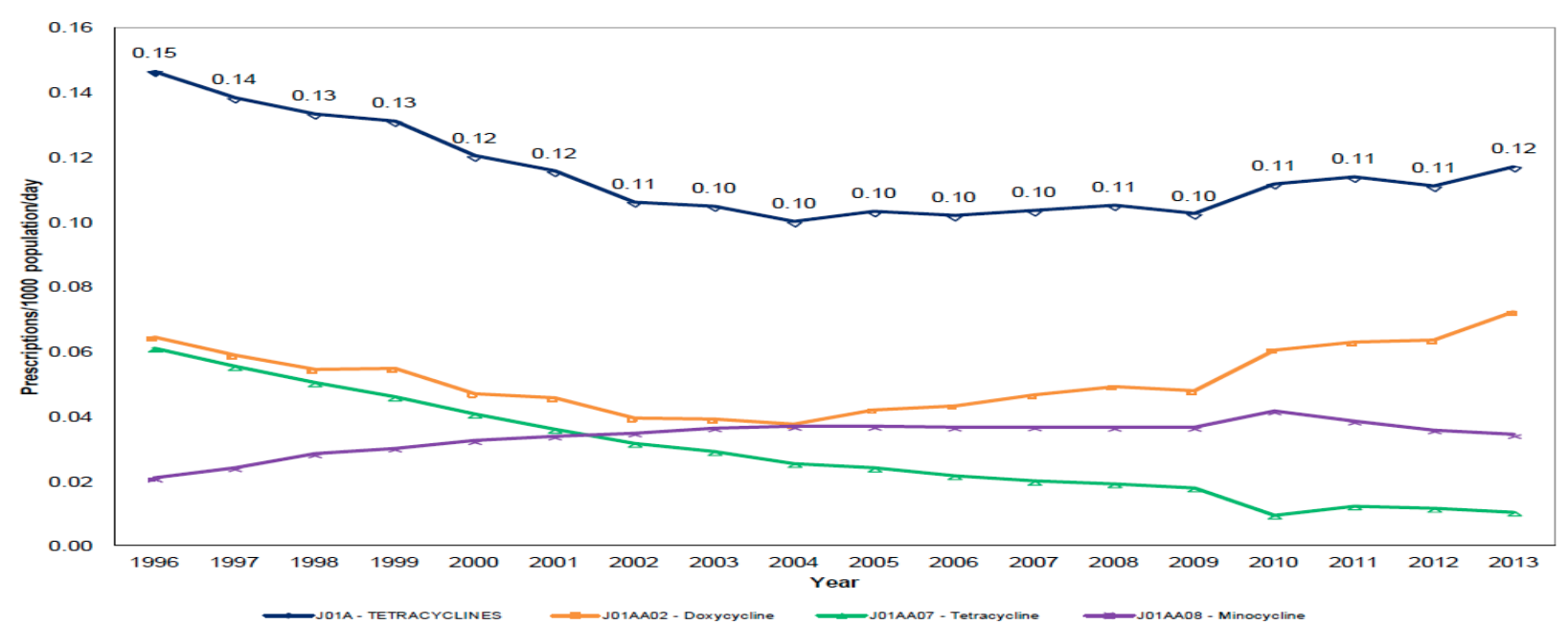

Figure 2 - Daily prescription rates for tetracyclines and subclass agents in Canada from 1996 - 2013 (Do Bugs Need Drugs?, 2014)

There are thousands of contaminants in wastewater, however, for this study tetracycline and ibuprofen were chosen as representatives of antibiotics and NSAIDS respectively because they are currently present in wastewater and it is very difficult to test all contaminants at the same time. In relation to the shown statistics, people are currently using ibuprofen and tetracycline in significant quantities. Although current activated sludge processes are working 
very well, microorganisms are being affected albeit on an insignificant scale but nonetheless still affected. This study will examine the effects of tetracycline and ibuprofen on the relative abundance of protozoan and bacterial populations because these two microorganisms play a vital role in the activated sludge process.

\subsection{OBJECTIVES}

In order to examine the effects of tetracycline and ibuprofen on the relative abundance of protozoan and bacterial populations, this study had the following three objectives.

I. Determine the abundance of protozoan and bacterial populations in presence of tetracycline and ibuprofen separately and simultaneously.

II. Comparison of the relative abundance of protozoan and bacterial populations separately and simultaneously through quantitative real-time polymerase chain reaction (qPCR).

III. Examine the eukaryotic community using $18 \mathrm{~S}$ rRNA gene primers to determine effects of pharmaceuticals. 


\section{CHAPTER 2 LITERATURE REVIEW}

\subsection{WASTEWATER TREATMENT}

The main objective of Toronto's wastewater treatment is to remove contaminants from wastewater before the effluent is released to Lake Ontario. Doing so will preserve Canadian water resources, the environment, and aquatic life. Wastewater is a combination of solids and liquids that derive from matter that has been flushed down toilets, drains and sinks daily (City of Toronto, 2015). The flushed matter travels through the sanitary sewer system throughout the city to one of the four WWTPs (City of Toronto, 2015). Toronto's WWTPs are designed to remove chemicals, solids and any other undesired contaminant in a cost effective, environmentally friendly and reliable approach (City of Toronto, 2015). A conventional wastewater treatment process is used for municipal sewage in Ontario, and its process involves a preliminary, primary, secondary and sometime a tertiary phase.

\subsubsection{HUMBER WASTEWATER TREATMENT PLANT}

Humber Wastewater Treatment Plant (HWWTP) is one of four WWTPs owned and operated by the City of Toronto. HWWTP is Toronto's second largest WWTP, located along the Queensway in Toronto's west end, near the mouth of the Humber River (City of Toronto, 2015). The HWWTP began operation in 1960 and its current capacity is 473,000 cubic meters. The facility serves a population of approximately 651,999, a population throughout the Etobicoke, a 
portion of North York, York and Toronto.

\subsubsection{PRELIMINARY PHASE}

The preliminary phase is designed to remove large debris from the wastewater before proceeding to the next phase (City of Toronto, 2015). The treatment process starts with raw wastewater entering the HWWTP Head House which functions to provide grit and screening removal processes. The plant has six inlet channels, four channels equipped with front raking mechanical bar screens and two with back raking mechanical bar screens (City of Toronto, 2015). The wastewater then splits into two streams, one stream is within the Head House and the other stream goes to another building, both used for grit removal (City of Toronto, 2015). In the Head House, ferrous chloride is added for phosphorus removal and the grit is removed using six vortex chambers, while in the other building the grit is removed using three Aerated Grit Channels (City of Toronto, 2015). The grit and screenings are than transported to a sanitary landfill location.

\subsubsection{PRIMARY TREATMENT}

The next step that precedes Preliminary Phase is the Primary Phase, also known as Primary Settling or Clarification. In this phase the flow velocity of the influent is reduced in the Primary Clarification Tanks, allowing for settlement of heavy solids and partially removing nonsoluble phosphorus (City of Toronto, 2015). Within the tanks, sludge collectors sweep the settled 
sludge into sludge hoppers that are located at the bottom of the tank, the sludge is then pumped to anaerobic digestion tanks. Unsettled, suspended, and dissolved effluent then proceeds to the secondary phase (City of Toronto, 2015).

\subsubsection{SECONDARY PHASE}

Secondary phase, also known as biological treatment phase, utilizes microorganisms to metabolize and dissolve organic and inorganic materials. These microorganisms can be used as part of processes such as activated sludge, rotating biological contactors, and bio-filtration. Activated sludge is the method of choice for municipal wastewater due to yielding the highest quality effluent at a reasonable maintenance and operating cost (Nesc, 2003). After microorganisms are added, with the addition of oxygen, the microorganisms break down organic solids, followed by flocculation. The effluent is then directed into a final sedimentation tank, where solid matter (a mixture of organic matter and microorganisms) is now heavy enough to settle in the tank and ready for discarding. Within the secondary phase, some of the returned activated sludge from final sedimentation or secondary clarification tanks is recycled back to the primary effluent in the aeration tank and the rest is sent to sludge thickening (City of Toronto, 2015).

Waste activated sludge from the final sedimentation that is sent to sludge thickening is dehydrated in order to reduce volume size and is then sent through the primary anaerobic digestion followed by secondary anaerobic digestion for energy production and other bio-solids use (City of Toronto, 2015). 


\subsubsection{FINAL EFFLUENT QUALITY \& DISINFECTION}

The final stage of treatment is chlorination in order to insure eradication of any microorganisms left in the effluent before discarding into bodies of water, in this case Lake Ontario. Figure 3 shows the Humber WWTP process.

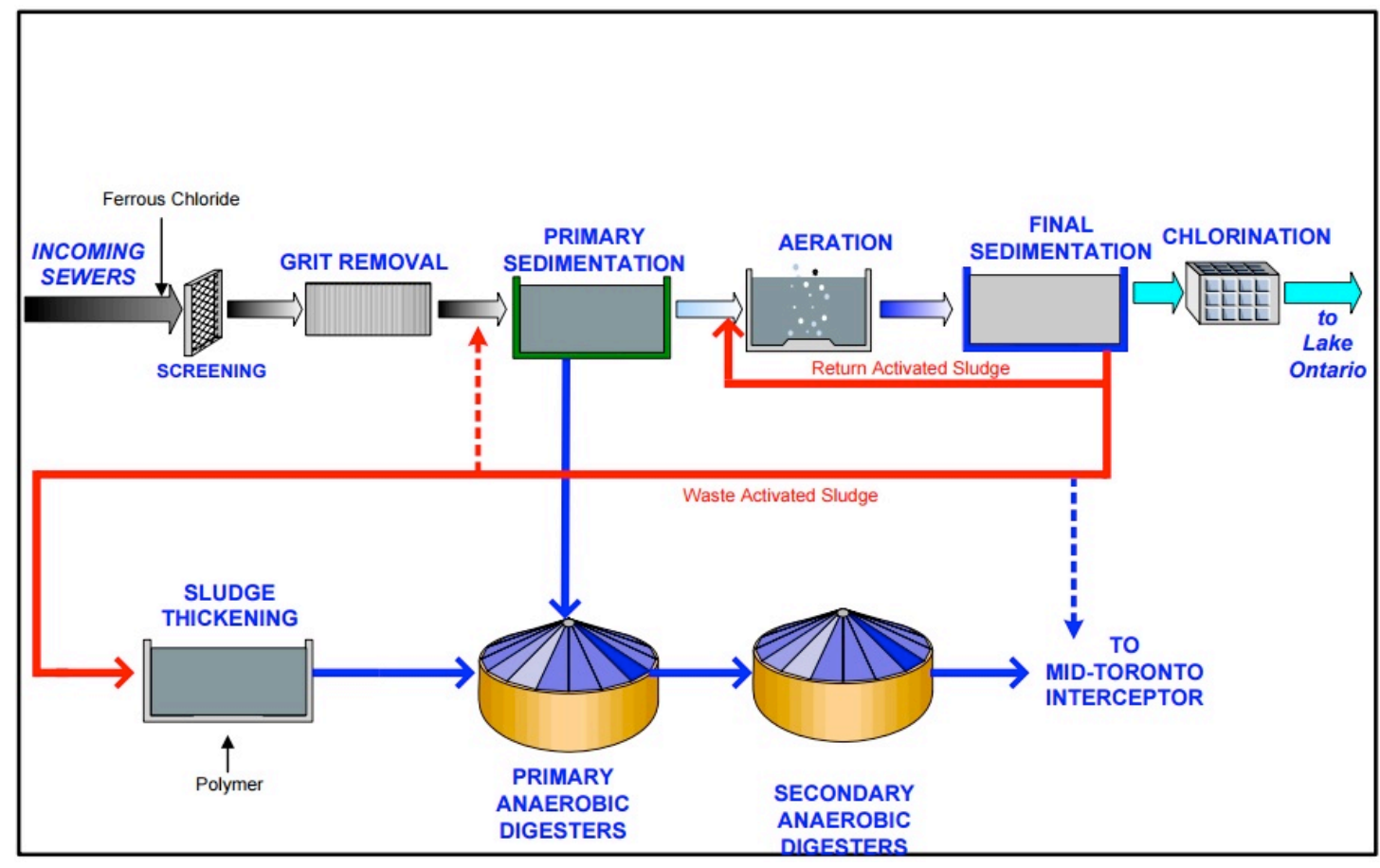

Figure 3 - Humber wastewater treatment process (City of Toronto, 2015)

\subsection{MICROBIAL COMMUNITY}

Microbial communities have been used for degradation since the discovery of bacteria in the nineteenth century (Pauli et al., 2015). Activated sludge was developed in 1913 in the United 
Kingdom by W.T. Lockett and Edward Ardern, utilizes suspended organisms and their selfpurification properties to transform the suspended and dissolved constituents into biomass, which then can be removed by sedimentation (Beychok 1967; Pauli et al., 2015). Activated sludge contains bacteria, filamentous bacteria, protozoa, metazoan (which includes rotifers, daphnia, other crustaceans, neatodes), algae, fungi and enteric viruses ( Pauli et al., 2015; Prado et al., 2014).

The most important group of microorganisms for wastewater treatment are bacteria, they are responsible for forming floc and degrading organic matter. There are many types of bacteria and their composition usually depends on the nature of the organic material present in wastewater (McKinney, 1962). Activated sludge tanks with suspended flocculate material can contain various amounts of bacteria. Pike, 1975, observed a population size approximately $6 \mathrm{x}$ $10^{9}$ individual bacteria per ml, while another study by Allen, 1944, examined samples presenting a population size between 9.5 to 48.5 millions per $\mathrm{ml}$, the difference in population size is due to different numeration procedures. The bacterial population represents approximately $90 \%$ of the total biomass of the activated sludge.

Although bacteria are the dominating microorganisms in activated sludge, there are other high forms of microorganisms, particularly protozoa, which help in clarifying the effluent. Protozoa are single celled eukaryotes that range from 5 to $1000 \mu \mathrm{m}$ in magnitude. Activated sludge is added to wastewater and in combination with aeration and agitation, the microorganisms are used for waste decomposition, this process is followed by sedimentation, where the sludge is either discarded or reused (Nesc, 2003). These microorganisms contribute to 
wastewater treatment in different forms. Prokaryotic communities are responsible for the removal of carbon, phosphorous and nitrogen from wastewater influent. Due to prokaryotes ability to mineralize inorganic and organic nutrients, it has been found that their population is greater in mass in comparison to other microorganisms and therefore represent an essential component of the activated sludge process (Madoni, 2011).

On the other hand, protozoa graze on free-swimming dispersed bacteria and other suspended particles, therefore contribute to the wastewater treatment processes by clarifying the effluent (Modoni, 2011). The high organic content in wastewater allows for biocoenosis of organisms to exist, with the primary members being decomposers, i.e., saprophytic (obtain nutrients from dead organic matter) bacteria. Bacteria biodegrades organic matter in the presence of oxygen and produces carbon dioxide and water; as well, nitrogen is released in the form of ammonia $\left(\mathrm{NH}_{3}\right)$ (Pauli et al., 2015). In wastewater treatment, bacteria are vastly greater in number and smaller in relative size than protozoa are ( Pauli et al., 2015). Bacteria and protozoa together form a closely related microbial system, this system allows for the "natural" selfpurification of wastewater (Pauli et al., 2015). Filamentous bacteria give awareness to activated sludge conditions; excessive amounts of filamentous bacteria in an activated sludge treatment systems can cause complications with sludge and floc settling (Pauli et al., 2015).

\subsubsection{ACTIVATED SLUDGE, PARAMETERS AND EFFICIENCY}

Activated sludge is the biomass in aeration tanks that is produced in settled or raw wastewater by the growth of microorganisms in the presence of dissolved oxygen. The sludge is 
deemed activated due to the presence of microorganism, particularly bacteria, protozoa and fungi. Wastewater is added to activated sludge in aeration tanks in combination with aeration and agitation, the microorganisms are used for waste decomposition, this process is followed by sedimentation, where the sludge is either discarded or reused (Nesc, 2003). During the activated sludge process, flocculation is induced by agitating wastewater in order to force suspended particles, bacteria, to group or clump together to produce heavier particles; these particles are termed floc. After the floc is formed, it becomes heavy and settles at the bottom of the tank (Wisconsin Department of Natural Resources, 2010).

Numerous parameters are used to describe activated sludge used in wastewater treatment. These parameters are, Sludge Volume Index (SVI), Mixed Liquor Volatile Suspended Solids (MLVSS), Mixed Liquor Suspension Solids (MLSS), and Oxygen Uptake Rate (OUR). These parameters are used to evaluate sludge condition and quality. Biochemical oxygen demand (BOD) can be examined in order to determine the efficiency of the activated sludge process before and after the treatment of wastewater. In aeration tanks, MLSS can be used as a measure of suspended organic and inorganic material (Wisconsin department of natural resources, 2010).

Microorganisms are an essential part of the activated sludge process; microorganisms help by removing nitrifying ammonia and carbonaceous organic material that is present in the secondary influent process. In the activated sludge process, biomass goes through a process of ammonification to form ammonia, which then proceeds to nitrification to form nitrite and then to form nitrate, which then produces nitrogen gas through denitrification. Anammox reaction is another method in which nitrogen is biologically removed; nitrite ions and ammonia ions form 
nitrogen gas (Basnyat, 2010). Below, figure 4 shows the nitrogen cycle and the relationship between the processes. Furthermore, some microorganisms, through nitrification, may use energy produced by oxidizing ammonia and nitrogen to nitrate. The major nutrients in wastewater that encourage growth of algae and other organic matter are phosphate and nitrogen. Biological removal of nitrogen and phosphorus is an essential function of the activated sludge process.

The most predominant microbe in activate sludge are heterotrophic bacteria. Heterotrophic bacteria use organic compounds for their carbon supply and energy source. Microbes are able to convert carbon into cell components as well as oxidize the end products, which include water and carbon dioxide (Hanrahan, 2012). Along with bacteria many other microbes are present.

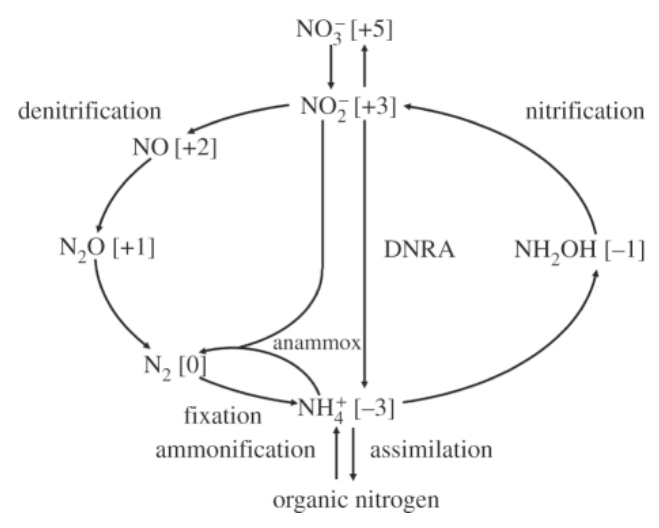

Figure 4 Diagram showing nitrogen cycle and the relationship of ammonification, nitrification, denitrification, and anammox process (Thomson et al., 2012).

In activated sludge, the microbial population exists in a heterogeneous community that is in equilibrium, which supports the treatment plant in adaptability with respect to plant operational changes. Such changes include temperature, flow and other wastewater composition 
changes. Perpetrations to the system, such as the presence of pharmaceuticals, may inhibit the performance of the activated sludge, which in turn can result in a loading shock to the system resulting in a decrease in treatment efficiency (Gutierrez et al., 2002).

Carvalho et al., (2013), evaluated the performance of activated sludge in the removal of frequently used veterinary medications, ceftiofur, enrofloxacin (ENR), and tetracycline (TET), from influent. The study was performed using $100 \mu \mathrm{g} / \mathrm{L}$ of the pharmaceutical and resulted in $68 \%$ removal for ENR and $77 \%$ for reactor containing TET in the aqueous stage. The research resulted in sorption of sludge having the most significant percent of drug removal.

Puigagut et al., (2007), tested soluble compounds on microfauna and the treatment efficiency of activated sludge. The experiment tested activated sludge containing domestic sewage supplemented with enriched starch or glucose over a period of five months. The study showed that the system with enriched starch presented a lower abundance of filamentous bacteria, which resulted in better sludge sedimentation. Although there was no difference in organic matter removal, a higher rate of nitrification and denitrification was observed which was most likely is a result of more compact flocs. Another observation was ciliated protozoa, specifically attached ciliates, were found to be the dominating microfuna in both tests whereas metazoan, in particular Lecanidae rotifers, were found to be more abundant in the enriched starch system. Furthermore, metazoan feeding caused a reduction in floc leading to a lower nitrogen quality in the effluent. 


\subsubsection{PHARMACEUTICALS}

The definition of pharmaceuticals as defined by the European Union is commonly known as drugs and medicine in real world, is defined as a chemical and biological product which are present in the form of different substances to cure diseases in human life (WHO, 2006). Several uses of pharmaceuticals in humans can be used to treat or correct physiological functions by applying immunological, pharmacological and metabolic action. In Europe, 3000 active components of pharmaceuticals are being used. Pharmaceuticals are classified differently and their structure of classification is usually defined by their chemical formula/structure, receptor interaction, pharmacological activity and physiological classification. An active pharmacological compound has been found in every pharmaceutical (WHO, 2006). Figure 5 shows a schematic figure of potential sources and pathways for the occurrence of pharmaceuticals in the environment. While some contaminants go through the wastewater treatment system, many contaminants go untreated from the source straight to the near by body of water which is often the drinking water source.

The Defined Daily Dose (DDD) and The Anatomical Therapeutic Chemical (ATC) are two main measuring units that are frequently used for drug utilization research on international level. The comparison and exchange of the data is occurred by ATC/DDD system on a major scale that includes local, national and international level around the globe (WHO, 2006). During the last decade, there has been an increase trend in terms of nature, type and presence of pharmaceuticals in wastewater. There are new pharmaceuticals in the market that are rapidly added to the large collection of chemical classes (Daughton et al., 1999; Heberer, 2002). 
Pharmaceuticals have been found in the water samples of groundwater, river water, wastewater and drinking water. Most common type of pharmaceuticals found in the water samples are lipid regulator, antibiotics, contraceptives, beta-blockers, anti-inflammatory drugs and tranquilizers (Daughton et al., 1999; Ternes, 2001; Heberer, 2002).

The classifications of pharmaceuticals are divided into various groups such as antibacterial, anti-inflammatory, antiepileptic's, antirheumatics, lipid modifying agents and betablocking agents. Antibacterial drugs are further classified into Fluoroquinolones, which are used to treat Urinary Tract Infections (UTI), gonorrhea, respiratory infections, cervicitis, bacterial prostatitis and anthrax. Ciprofloxacin, Ofloxacin and Norfloxacin, Sulamethoxazole and Sulfonamide are Fluoroquinolones. Antiepileptic drugs are used to cure manic-depressive illness and neuropathic pain, Carbamazepine is an example of a broadly researched antiepileptic drug (Rang et al., 2003).

Anti-inflammatory and antirheumatic drugs, also knows as non-steroidal antiinflammatory drugs (NSAIDS), help treat rheumatic musculoskeletal, pain and inflammation amgonst other bodily issues. Examples of these drugs are Ibuprofen, Ketoprofem, Diclofenac and Naproxen which are used worldwide (Rang et al., 2003). An example of an lipid modifying agent is Bezafibrate, which is commonly used to treat mixed dyslipidaemia that leads to atheromas disease (Rang et al., 2003). Beta - blockers, such as Atenol, Acebutolo and Metoprolol are drugs that help treat hypertension, dysrhythmias and angina (Rang et al., 2003). Therapeutic agent help treat muscle pain, Diclofenac and Ketoprofen in the form of different sprays and gels are examples of such agents (Rang et al., 2003). Osmerod and Efraimsen (1988) conducted 
research on the toxicity effects of phenols on heterotrophic microorganisms. Through microscopic examination, the research concluded that with increasing test compounds, ciliates were the first microbes to disappear.

\subsubsection{MAJOR PHARMACEUTICALS IN WASTEWATER}

Two major pharmaceuticals found in wastewater are Diclofenac and Carbamazepine. It has been found that during the wastewater treatment process (WWTP), pharmaceuticals are abundantly present and are not efficiently removed before effluent is released into water bodies. Pharmaceuticals are found in the waters of America, Asia and Europe (Zhang et al., 2008). The traces of pharmaceuticals are present mainly in wastewater treatment process (WWTP) effluents, ground water, surface water and in drinking water as well. Drugs like Diclofenac and Carbamazepine have different concentration in countries due to pharmaceutical consumption rates, as well as limited resources to conduct an investigation to find high concentration in the wastewater. The classification of Carbamzepine is anthropogenic and its concentration in wastewater effluent varies from nanogram per liter to microgram per liter in different countries (Heberer, 2002; Zhang et al., 2008).

Meige et al., (2009), conducted a study analyze the nature of pharmaceuticals, their occurrence, removal efficiency and their quantities. The list's allows the identification of commonly investigated PPCPs (pharmaceuticals and personal care products) and the most persistent of them present in the wastewater treatment process in order to obtain quantitative and reliable values of their concentrations as well as determine the removal efficiency and frequency of detection in WWTP. Meige and colleagues (2009) has detected and identified hundred's of 
pharmaceutical and PPCP'S through prescription drug classes which are measured in WWTPs of countries such as North America, Brazil and European countries. Anti-inflammatory and analgesics drugs, bacteriostatic and antibiotics, beta-blockers, anti-epileptics, contrast media, blood lipid regulators, hormones (including oral contraceptives) cytostatics, musk fragrances, antidepressants and anxiolytic, antiseptics and disinfectants are examples of drugs noted by the review to be in the WWTPs (Miège et al., 2009).

Microorganisms are used for mineralizing contaminants and breaking them down to an acceptable form for nutritional use and discharge. It is done through the activated sludge processes in WWTPs. Moreover, air stripping and then sorption onto sludge are to ways to remove the contaminants present in the wastewater. Overall the removal of pharmaceutical contaminants present in activated sludge process invloves four steps i.e. biotransformation, air stripping, sorption and photo transformation (Zhang, 2008). Table 1 shows an array of contaminants and their removal rates, and as shown, the removal rates are not always $100 \%$. Note that tetracycline has a removal rate between 40 and 89 percent with an average of 71 percent removal rate and ibuprofen has a removal rate between 65 and 100 with an average of 91 percent removal rate.

Ibuprofen, an NSAID, is an example of a commonly used pharmaceutical, it has a chemical structure that does not contain chlorine and double aromatic rings, which makes it easier to breakdown. Clofibric acid is a refractory contaminant, meaning difficult to treat, it contains chlorine in its chemical structure, which makes it harder to breakdown. Membrane bioreactors are considered highly effective in the removal of Clofibric acid in WWTPs (Kimura 
et al., 2005). Table 2 contains cited ibuprofen concentrations of varies influent, effluent and maximal removal rates.

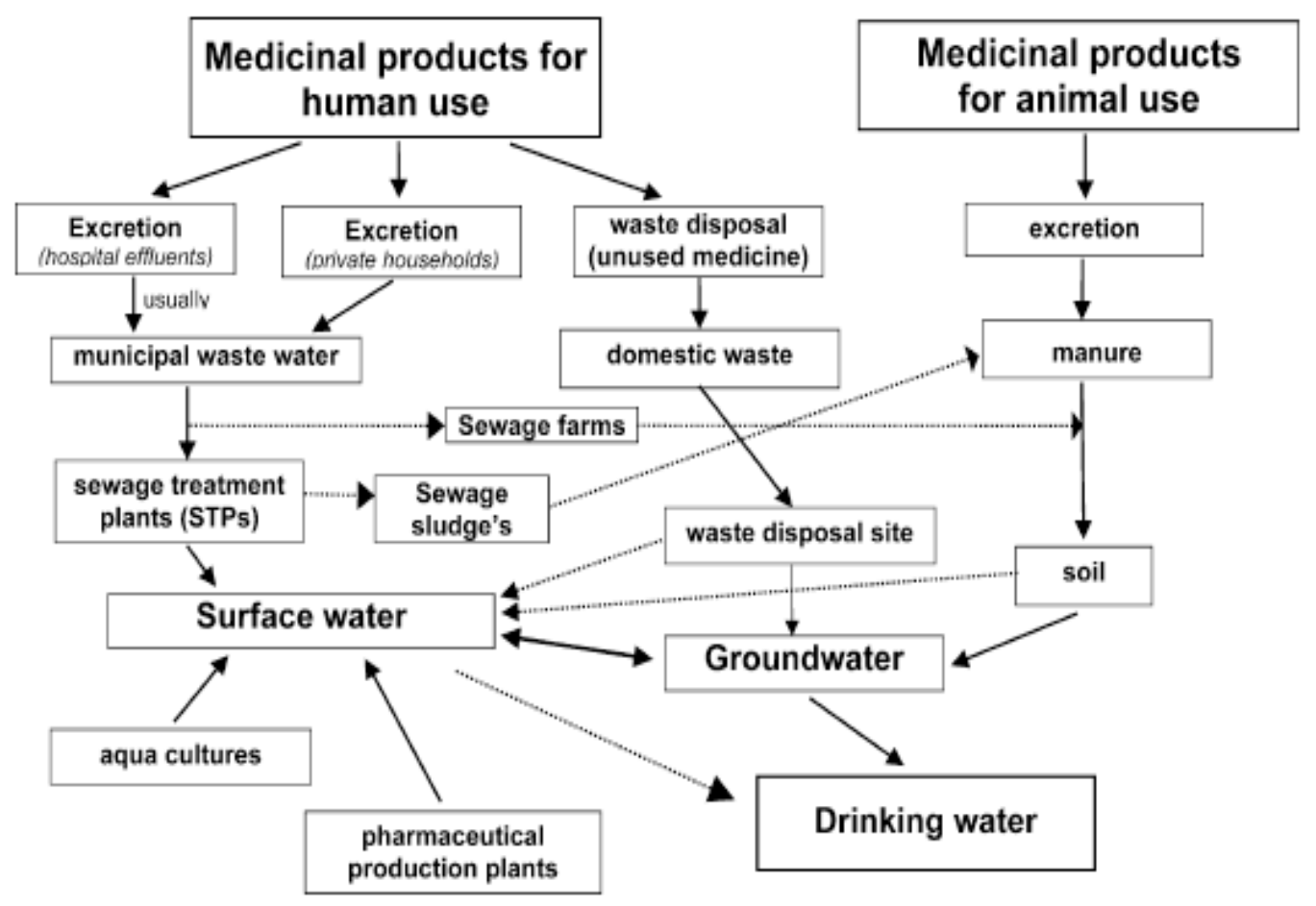

Figure 5: A system showing potential sources and pathways for the occurrence of pharmaceuticals in the aquatic environment (Heberer, 2002) 
Table 1: The range of removal rates (\%RE) for the most representative compounds of each therapeutic group, in the whole set of WWTP under investigation. (Gros et al., 2010)

\begin{tabular}{|c|c|c|}
\hline Compounds & Range of \%RE & Average \%RE ( \pm RSD) \\
\hline Sulfadiazine & $\lceil 43-98\rceil$ & $69( \pm 32)$ \\
\hline Sulfamethoxazole & {$[30-92]$} & $74( \pm 22)$ \\
\hline Norfloxacin & [30-98] & $57( \pm 54)$ \\
\hline Ofloxacin & $\lceil 20-99\rceil$ & $40( \pm 64)$ \\
\hline Ciprofloxacin & $\lceil 37-99\rceil$ & $66( \pm 35)$ \\
\hline Tetracycline & [40-89] & $71( \pm 33)$ \\
\hline Enalapril & 「83-99] & $96( \pm 11)$ \\
\hline Salbutamol & [20-99] & $60( \pm 44)$ \\
\hline Famotidine & $\lceil 30-99\rceil$ & $50( \pm 59)$ \\
\hline Ranitidine & $\lceil 50-98\rceil$ & $66( \pm 39)$ \\
\hline Cimetidine & [30-99] & $50( \pm 64)$ \\
\hline Glibenclamide & {$[22-75]$} & $46( \pm 39)$ \\
\hline Nadolol & $\lceil 25-99\rceil$ & $60( \pm 51)$ \\
\hline Atenolol & [20-97] & $59( \pm 50)$ \\
\hline Bezafibrate & [23-99] & $69( \pm 39)$ \\
\hline Gemfibrozil & [30-99] & $67( \pm 48)$ \\
\hline Atorvastatin & $\lceil 40-80\rceil$ & $58( \pm 44)$ \\
\hline Propyphenazone & $\lceil 30-87\rceil$ & $44( \pm 68)$ \\
\hline Ketoprofen & $\lceil 40-100\rceil$ & $69( \pm 40)$ \\
\hline Naproxen & {$[60-100]$} & $86( \pm 13)$ \\
\hline Ibuprofen & {$[65-100]$} & $91( \pm 13)$ \\
\hline Diclofenac & {$[30-100]$} & $58( \pm 53)$ \\
\hline Acetaminophen & 「96-100] & $99( \pm 1)$ \\
\hline Salicylic acid & [82-99] & $96( \pm 8)$ \\
\hline Furosemide & [20-96] & $50( \pm 59)$ \\
\hline
\end{tabular}


Table 2: Various concentrations of ibuprofen found in influent, effluent, and their removal efficiency.

\begin{tabular}{|l|l|l|l|}
\hline Influent Conc. $\mu \mathrm{g} / \mathrm{L}$ & Effluent Conc. $\mu \mathrm{g} / \mathrm{L}$ & Maximal removal \% & Reference \\
\hline 3 & & 96 & (Buser et al., 1999) \\
\hline 38.7 & 4 & $>90$ & (Metcalfe et al., (2003) \\
\hline $9.5-14.7$ & $0.01-0.02$ & 99 & (Thomas \& Foster 2004) \\
\hline 1.5 & 0.01 & $12-86$ & (Strenn et al., 2005) \\
\hline $2.6-5.7$ & $0.9-2.1$ & $60-70$ & (Carballa et al., 2004) \\
\hline 5.7 & 0.18 & 97 & (Quintana et al., 2005) \\
\hline 28 & 3.0 & 98 & (Roberts \& Thomas 2005) \\
\hline $2-3$ & $0.6-0.8$ & $53-79$ & (Tauxe-Wuersch et \\
\hline 13.1 & & & 2005) \\
\hline
\end{tabular}




\subsection{PROTOZOA}

Protozoa are mostly found in biofilms, activated sludge, sedimentation tanks and are associated with aerobic processes, thus they are restricted to certain areas of the wastewater treatment plant. However, there are a few specialists amongst the protozoan species that take part in anaerobic processes (Pauli et al., 2015).

Literature regarding protozoa in wastewater mainly focuses on activated sludge and aerobic processes. Protozoa are a common constituent of the wastewater ecosystem (Madoni, 2011). Studies show that over 200 protozoan species are present in percolating filters, it has been established that the most common groups of protozoa detected in wastewater treatment plants are amoebae, ciliates, and flagellates, whereby ciliates produce the largest fraction with regards to population and biomass, ranging from 500 - 10,000 individuals per ml of liquor (Madoni, 2011; Pauli et al., 2015). Protozoa comprise of about 5\% of the dry weight of suspended solids in the mixed liquor (Curds, 1973, 1975, 1982).

Most protozoa such as ciliates often graze on suspended particles and bacteria, subsequently having a significant effect on the quality of effluent and clarification of effluent (Madoni, 2003). It has also been observed that in the presence of ciliates, a decrease in the density of viable Escherichia coli occurred (Curds et al., 1969; Mallory et al. 1983). In rotating biological contactors (RBC), there is a correlation between the distribution of microorganisms and the organic load. Free-swimming ciliates and heterotrophic flagellates are dominant in early stages due to the higher organic load, whereas attached ciliates and testate amoebae are dominant 
in the final stages containing low biochemical oxygen demand (BOD) (Curds \& Cockburn, 1970 I). In activated sludge, free-living protozoa have been found to have a population size of $3-20 \mathrm{x}$ $10^{6}$ cells/1, as well in biomass they can have values of $250 \mathrm{mg} / 1$ in dry weight (Madoni, 1994a). Curds (1975), compiled a list of 228 species of protozoa found in activated sludge.

Within wastewater treatment systems, the formation of the protozoan biocoenosis, in addition to that of the total biomass involved in the purification process, is essentially dependent on factors such as wastewater composition, physical conditions, and factors resulting from technologies involved (Pauli et al., 2015). Research has found that depending on the wastewater treatment plant, different protozoa dominated. A study by Sydenham (1971) showed amoebae to be the dominant group with regard to biomass while another study by Curds and Cockburn (1970) demonstrated that sludge with a high organic content showed flagellates to be a higher population density.

Protozoa positively affect bacterial carbon mineralization in activated sludge (Ratsak et al., 1996). Protozoa excrete growth-stimulating compounds and nutritional minerals that result in enhanced bacterial activity and accelerated use of carbon by bacteria (Madoni, 2011). Additionally, it has been discovered that due to influence on bacterial growth, protozoa causes an increase in the per-cell nitrification rates (Madoni, 2011). Research conducted by Curds et al., (1968), found that without the presence of protozoa in the mixed liquor, the effluent parameters such as BOD, organic carbon, and mixed liquor suspended solids (MLSS), were higher. Protozoa are found to be the most important bacterivorous grazers. Various studies have researched and established the relationship between the presences of particular species of ciliates in relation to 
the performance of activated sludge process (Madoni et al., 1993; Madoni, 1994). Jenkins and colleagues (1993) noted that stalked ciliates are suggestive of stable activated sludge process.

A side from heavy metals, there are numerous toxic substances entering the WWTP that can damage the protozoan community. The shock load effect of sodium chloride $(\mathrm{NaCl})$ in the protozoan community has been evaluated in (Salvadò et al. 2001), the observations have shown that concentrations from 3000 to $10,000 \mathrm{mg} / 1$ gradually affected the microbial community with few protozoa surviving (Madoni, 2011).

Concentration of protozoan population are typically larger than $10^{6}$ protozoa/L under normal conditions, $10^{7}$ protozoa/L represents very good pollution reduction. As well, protozoan population that is $10^{6}$ organisms/L is approximately 6 orders of magnitude less than the total number of bacteria in activated sludge. Concentrations that are found lower than $10^{5}$ protozoa/L suggests a low efficiency of the plant (Madoni, 2011).

Ciliates the most often found protozoa in sludge, and they can be classified in four principal groups: crawling, free-swimming, attached and carnivorous (Madoni, 2011). With regards to crawling ciliates, they crawl over the surface of the sludge floc and or attach themselves to the sludge floc by a stalk. As for free-swimming ciliates, they swim through the liquid stage of the mixed liquor (Curds, 1973; Madoni, 1986). It was showed that effluent from activated sludge lacking protozoa was found to be more turbid than those containing protozoa. It is concluded that protozoa play a significant role in the effluent quality of the activate sludge process (Curds 1973; Curds 1975). Table 3 is a listing by Madoni (1994b) of ciliated protozoa 
commonly found in activated sludge and grouped by specialization. Table 4 , constructed by Madoni $(1986,1988)$ describes the ciliated group performance and possible causes for the rated performance. 
Table 3: Activated sludge ciliates grouped by specialization. Categorized by Madoni 1994b

\begin{tabular}{|l|l|l|l|}
\hline Carnivorous & Free-swimming & Crawling & Attached \\
\hline Holotrichs & Colpoda sp. & Aspidisca cicada & Carchesium spp \\
\hline Acineria incuroata & Colpidium colpoda & Aspidisca lynceus & Epistylis spp \\
\hline Amphileptus sp. & Colpidium campylum & Chilodonella uncinata & Opercularia coarctata \\
\hline Coleps hirtus* & Cinetochilum margaritaceum & Euplotes affinis & Opercularia microdiscus \\
\hline Litonotus spp & Cyclidium glaucoma & Euplotes moebiusi & Opercularia minima \\
\hline Spathidium spp & Dexiotricha sp. & Euplotes patella & Stentor spp \\
\hline Suctorians & Glaucoma scinti/lans & Stylonychia spp & Vaginicola crystallina \\
\hline Acineta spp & Loxocephalus sp. & Trithigmostoma cucul/ulus & Vorticella conrnllaria \\
\hline Metacineta sp. & Paramecium spp & Trochi/ia minuta & Vorticella microstoma octam \\
\hline Podophrya spp & Pseudocohnilembus pusillus & & Zoothamnium spp \\
\hline Tokophrya spp & Sathrophilus sp. & & \\
\hline & Spirostomum teres & \\
\hline & Tetrahymena pyriformis complex & & \\
\hline & Uronema nigricans Drepanomonas revoluta \\
\hline & \multicolumn{2}{|c|}{ Trachelophyllum pusillum } \\
\hline
\end{tabular}

*Omnivorous; Incertae sedis: these species are free-swimming forms but their grazing activity seems to be linked to the Hoc. 
Table 4: Performance rating of ciliate groups and possible causes for performance rate (Madoni 1986, 1988)

\begin{tabular}{|l|l|l|}
\hline Dominant group & Performance & Possible causes \\
\hline Small flagellates & Low & Poorly aerated sludge; overloading; fermenting substances involved \\
\hline Small swimming ciliates & Mediocre & Too short sewage retention time; poorly aerated sludge \\
\hline Large swimming ciliates & Mediocre & Overloading; poorly aerated sludge \\
\hline Crawling ciliates & Good & \\
\hline Sessile and crawling ciliates & Good & \\
\hline & & \\
\hline Sessile ciliates & Decreasing & Transient phenomena (discontinuous load, recent sludge extraction) \\
\hline Small naked amoebae and flagellates & Poor & Very high load, not easily degradable \\
\hline Testate amoebae & Good & \\
\hline
\end{tabular}




\subsubsection{PROTOZOA RELATED RESEARCH}

Petropoulos et al., (2005), studied effects of protozoan grazing on nitrification process in activated sludge. It was concluded that with the reduction of grazing protozoan, nitrification rates declined. This result suggests that a reduction in either protozoan or bacterial concentrations may be the cause of nitrification decline (Petropoulos \& Gilbride, 2005). This research relates to the current study with respect to protozoan and bacterial relationship.

Pogue et al., (2007) reported protozoan grazing on the ammonia and nitrite-oxidizing bacterial communities in activated sludge concluded that without the presence of protozoan grazing, the nitrification rates would be lower. Inhibition in ammonia oxidation also lowered the amount of nitrate and nitrite accumulation. Introducing deflocculation led to high levels of nitrate accumulation, which is an indication of high levels of nitrification. This effect was less pronounced in the absence of protozoan grazing. In addition, nitrite oxidizing bacteria (NOB) and ammonia oxidizing bacteria (AOB) were found clustered in the floc. Inhibiting protozoa and ammonia oxidation, as well inducing deflocculation did not reduce NOB and AOB presence or have influence on their position within the floc. These conclusions suggest that nitrite-oxidizing bacteria and ammonia-oxidizing bacteria are present but less active in the absence of protozoa (Pogue \& Gilbride, 2007). This study shows that protozoa play an important role in WWTPs and thus if impacted in a way to reduce their function and abilities then consequential affects may occur. 
A third study conducted by Islam 2013, examined the impacts of tetracycline on the composition and function of microbial communities with respect to nitrification and the effect of tetracycline under low and high nutrient replacement conditions. The study concluded that with lower rate of nutrient replacement, tetracycline was observed to have a positive effect on ammonia removal and nitrification than at a higher rate. In addition, under lower nutrient replacement, Kjeldahl nitrogen concentrations increased in the presence of tetracycline, which suggested a potential inhibitory effect on de-nitrification. Finally, at higher nutrient replacement rates, tetracycline had no inhibitory effect on either de-nitrification and nitrification functions (Islam, 2013). In relation to my research, this study shows a causal effect of tetracycline on the microbial system, as well there is a significant protozoan and bacterial relationship with wastewater treatment dependent on their condition.

\subsection{TETRACYCLINE}

As previously stated, tetracyclines are a group of broad-spectrum antibiotics discovered in the early 1940s and were approved by the FDA in 1948 (Nelson et al., 2011). Tetracyclines affect a wide range or both Gram-positive and Gram-Negative bacteria (Wang et al., 2010). Tetracyclines are used by humans to fight bacterial infections and by veterinarians to treat or fight against bacterial infections. Tetracyclines are also added to food producing animals as well as honeybees as a result of their broad antibiotic spectrum and its advantage of preventing wide spread diseases (Kazemifard, 1997; Oka et al, 2000). Furthermore, they are used to promote growth as well as disease prevention in livestock and aquatic agriculture (Boxall et al, 2003; Kay et al, 2005). Since the discovery of chlortetracycline in 1948, its family has grown with the 
addition of eight other tetracyclines that are now commercially accessible. Of those, tetracycline, oxytetracycline, doxycycline, and chlortetracycline are frequently used as veterinary medicines (Chopra \& Roberts, 2001). Tetracycline not only encompasses antibacterial properties but also contains antiprotozoal capabilities (Chopra \& Roberts, 2001). Tetracycline functions by binding to the $30 \mathrm{~S}$ ribosomes in the mitochondrial organelle or by thus inhibiting protein syntheses. Examples of protozoan parasites affected by tetracyclines are Entamoeba histolytica, Plasmodium falciparum, Trichomonas vaginalis, Leishmania major, Giardia lamblia, and Toxoplasma gondii, though further research into specific organelles affected by tetracycline still requiring further research (Chopra \& Roberts, 2001).

Due to the large quantities of tetracycline used and released into the environment, it can be passed along with wastewater into wastewater treatment facilities. A study in 2005 stated that $0.2 \mu \mathrm{g} / \mathrm{L}$ of tetracycline was measured in WWTP influent in Canada, however the study only tested for tetracycline and not its sub-classes (Yang et al., 2005). Deblonde et al. (2011) reported tetracycline levels of $48 \mu \mathrm{g} / \mathrm{L}$ in influent and $2.375 \mu \mathrm{g} / \mathrm{L}$ in effluent. Due to tetracyclines antibacterial capabilities, bacterial biodegradation may play a negligible role in the removal of the antibiotic. To this point, no evidence of microbial degradation of tetracyclines in the environment has been seen (Alexy et al, 2004).

\subsection{IBUPROFEN}

As previously mentioned in the introduction, ibuprofen was developed by the Boots Company in 1961 and approved by the FDA for over-the-counter use by 1984 (Rainsford, 2011). 
Ibuprofen was first introduced in 1969 in a study conducted by the University of Wollongong with evidence suggesting that some NSAIDs have the capabilities of antibacterial properties (Yin et al., 2014). NSAIDs have been show to have antibacterial capabilities with a mechanism to still be discovered. Yin et al. (2014) showed results in regards to testing the NSAIDs bromfenac, carprofen, and vedaprofen and discovered that Escherichia coli DNA polymerase III b subunit was inhibited (Yin et al., 2014). The DNA polymerase III subunit is the primary enzyme responsible for DNA replication. By inhibiting this subunit, bacterial reproduction is also inhibited. A study conducted in Spain by Ferrando-Climent and colleagues (2012) showed that ibuprofen concentrations of $13.74 \mu \mathrm{g} / \mathrm{L}$ were found in wastewater influent. A study showed an average of $38.7 \mu \mathrm{g} / \mathrm{L}$ and a maximum of $75.8 \mu \mathrm{g} / \mathrm{L}$ of ibuprofen collected from 14 sewage treatment plants in Canada between 1998 through 1999 (Metcalfe et al., 2003). In another study, ibuprofen was detected at levels of $13.482 \mu \mathrm{g} / \mathrm{L}$ in influent and $3.480 \mu \mathrm{g} / \mathrm{L}$ in effluent (Deblonde et al., 2011).

Due to dependence on protozoa and bacteria for wastewater purification processes, dependence of protozoa on bacteria for grazing and other sources, and bacterial benefits from protozoa for nutrients and function enhancement, it is vitally important to keep their ecosystem satisfied. If commonly used compounds such as ibuprofen and tetracycline severely affect either of these organisms, the ecosystem balance will be affected and their purification performance will be compromised. 


\subsection{S rRNA gene AND 18S rRNA gene PRIMERS}

A primer is a single stranded oligo-nucleotide sequence. The strand length can vary based on its function. A primer consisting of 18 to $24 \mathrm{bp}$ is considered appropriate for a standard PCR (Dieffenbach \& Dveksler, 1995). PCR uses a set of two primers, a forward primer and a reverse primer. The forward primer is a sequence that is complementary to a section on the anti-sense strand that follows $3^{\prime}$ to $5^{\prime}$ in the forward direction whereas the reverse primer is complementary to the section on the sense strand that follows $3^{\prime}$ to $5^{\prime}$ in the reverse direction of a double stranded DNA fragment. The primers are synthesized in order to target specific DNA fragments to identify a specific species. The $16 \mathrm{~S}$ rRNA gene is a component of the prokaryotic ribosomes whereas the $18 \mathrm{~S}$ rRNA gene is a component of the eukaryotic ribosomes. Some primers such as universal primer sets can target a diverse array of species while some primers are used to only target a minor set of species (Yu et al., 2013).

Lin et al, (2014), studied the diversity of microbial communities in each step of treatment plant for potable water generation. The $16 \mathrm{~S}$ rRNA gene is universal amongst bacteria, and thus their relationships can be measured with a universal 16S rRNA gene primer. By comparing the 16S rRNA gene sequences, differentiation between organisms at the genus level across the phyla of prokaryotes is possible. Furthermore, organism can be identified and classified at multiple strain levels including species and subspecies (Jill, 2004). The ribosomal subunits vary between prokaryotes and eukaryotes, and where $16 \mathrm{~S}$ rRNA gene is prokaryotic, 18S rRNA gene is the eukaryotic nuclear homologue similar to that of the 16S rRNA gene in prokaryotes. 
In order to identify the different bacterial communities, the V1-V3 region of the bacterial 16S rRNA gene was amplified using forward primer F341 (5'- CCT ACG GGA GGC AGC AG-3') and reverse primer V3R (5'- ATT ACC GCG GCT GCT GG -3') (Muyzer et al. 1993). For eukaryotes such as protozoa, a qPCR approach was used to amplify the variable V4 region of the $18 \mathrm{~S}$ rRNA gene. The primers used to examine eukaryotes were $3 \mathrm{NDF}$ ( $5^{\prime}-$ GGCAAGTCTGGTGCCAG-3') and reverse primer V4_euk_R2 (5'ACGGTATCT(AG)ATC(AG)TCTTCG-3') (Lin et al., 2014).

\subsection{QUANTITATIVE PCR (qPCR)}

Quantitative real-time Polymerase Chain Reaction (qPCR), is a widely used molecular method for microbial detection in real-time (Girones et al., 2010). The qPCR method measures the amplification of a nucleic acid (DNA, RNA) target sequence in the presence of a fluorescent dye. Through the process, fluorescence increases indicating amplification of nucleic acid and is measured in real-time. The crossing point $(\mathrm{Cp})$ is the cycle number at which the targeted sample begins to amplify exponentially, the $\mathrm{Cp}$ value is then compared to a standard curve from which a quantitative value is calculated.

An advantage to using qPCR is the quantification of very minuscule samples; an example is the detection of a single microbe such as anamoeba in a water sample (Qvarnstrom et al., 2006). Furthermore, qPCR does not take long and within approximately 3 hours results can be attained. There are a number of studies that have used qPCR for analyzing microbial species, one particular study previously mentioned that stands out in relation to this research is Lin et al., 
(2014), which also utilized qPCR to study microbials within potable water generation treatment plant. Other studies have shown the potential of qPCR procedures in monitoring the quality of recreational waters, focusing on bacteria, such as Enterococcus spp. and E. coli (Haugland et al., 2005; Bartrand et al., 2010; Noble et al., 2010; Wade et al., 2010).

\subsection{RESEARCH OBJECTIVE}

The objective of this research is to examine the affects of tetracycline and ibuprofen on the relative abundance of the bacterial and protozoan community present in activated sludge in a semi-batch reactor system. The study will examine the effects of the pharmaceuticals at different concentrations, tetracycline: $50 \mathrm{ng} / \mathrm{ml}, 500 \mathrm{ng} / \mathrm{ml}$, ibuprofen: $100 \mathrm{ng} / \mathrm{ml}, 2000 \mathrm{ng} / \mathrm{ml}, 10^{5} \mathrm{ng} / \mathrm{ml}$. The semi-batch reactors will run for 15 days and samples will be extracted on days, $0,5,10$ and 15. Synthetic nutrient supplements every 5 days and bubbling stones for aeration in order to simulate wastewater treatment plant conditions. Following the samples extractions from each reactor, DNA extraction is performed on day 0 and day 15 samples. Following DNA extraction, qPCR is performed to determine abundance of bacterial and protozoan populations using $16 \mathrm{~S}$ rRNA gene and 18S rRNA gene primers. Using $\mathrm{Cp}$ values obtained from the $\mathrm{qPCR}$, relative quantification of $\mathrm{Cp}$ values will be calculated using $\mathrm{R}=2^{\text {(control - sample) }}$ formula to normalize the $\mathrm{Cp}$ values. In order to examine the effects of the pharmaceuticals on the eukaryotic community, DDGE and 18S rRNA gene primers are used to observe change in community compositions. 


\section{CHAPTER 3 MATERIALS AND METHOD}

\subsection{SEMI BATCH REACTOR SYSTEM}

The semi batch reactors were constructed and filled with activated sludge mixture from the secondary-treatment aeration tanks 2, 4, 6, and 8 from the Humber Wastewater Treatment Plant. Approximately $1 \mathrm{~L}$ from each aeration tank was collected from the WWTP and transported to the lab in plastic containers. Within approximately 3 hours the containers of activated sludge sample were combined for a collective of $4 \mathrm{~L}$, which was then divided to produce $500 \mathrm{ml}$ reactors (Figure 6). The batch reactors are oxygenated using aquarium bubbler through a flask containing deionized water in order to minimize evaporation. An aliquot of the combined activated sludge was taken and centrifuged at $7000 \mathrm{rcf}$ for 15 minutes to achieve a pellet which was then stored at $-20^{\circ} \mathrm{C}$. This was considered the time zero sample. At days 5 and $10,10 \%$ of the volume for the reactor was replaced with synthetic wastewater to maintain nutrients but no microbes were added (Liao et al. 2001). The reactors were also topped up to $500 \mathrm{ml}$ to account for any evaporation. Aliquots from each reactor were collected after 15 days and used for analyses. 
Figure 6. One liter Reactors were set up on the bench at room temperature and aerated with aquarium bubblers. They were maintained for 15 days. a) top view, b) side view.

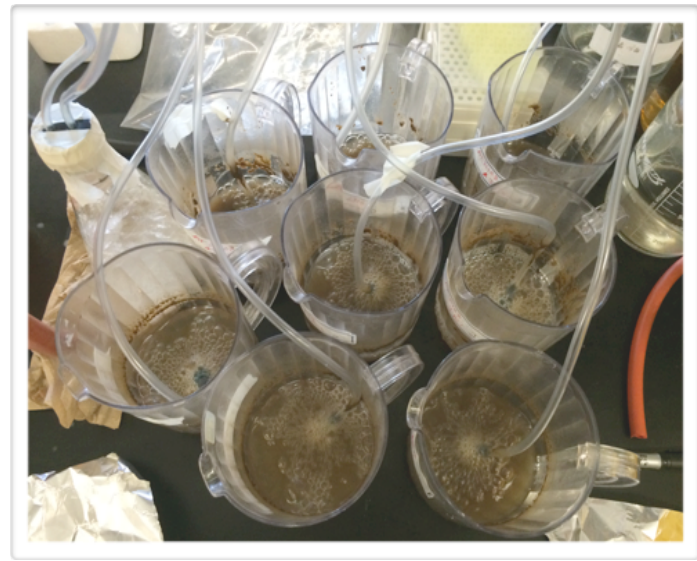

A.

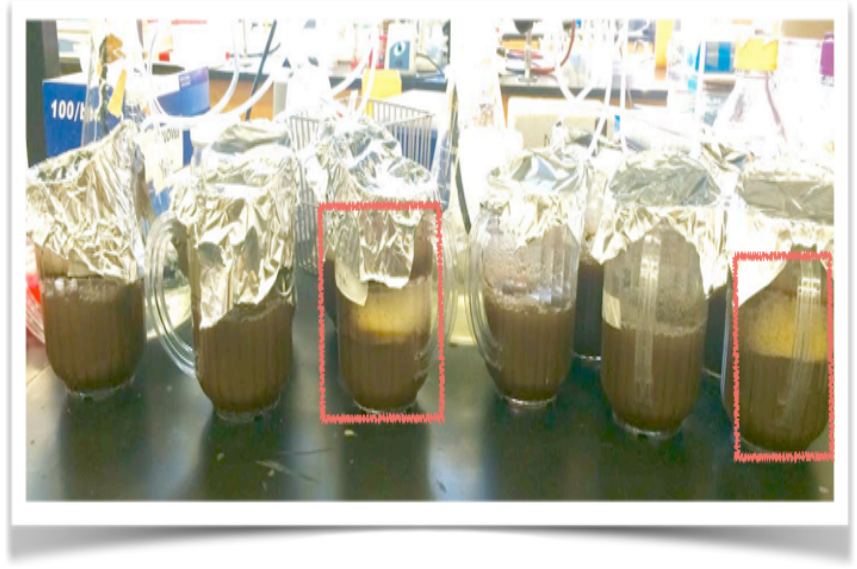

B.

\subsection{EXPERIMENT SETUP}

The batch reactors contained $500 \mathrm{ml}$ per reactor of activated sludge from the Humber Wastewater Treatment Plant. Eight batch reactors were set up at a time to simulate aeration tanks from WWTP. Three sets of experiments were carried out. The first two sets contained 8 reactors; two reactors that were set up as a control where no pharmaceutical was added. Two reactors were supplemented with $100 \mathrm{ng} / \mathrm{ml}$ of ibuprofen, two were supplemented with $50 \mathrm{ng} / \mathrm{ml}$ of tetracycline and two were supplemented with both ibuprofen and tetracycline. The third set of reactors consisted of 10 reactors, each condition in duplicate; control: $100 \mathrm{ng} / \mathrm{ml}$ of ibuprofen and $50 \mathrm{ng} / \mathrm{ml}$ of tetracycline: $2000 \mathrm{ng} / \mathrm{ml}$ of ibuprofen and $50 \mathrm{ng} / \mathrm{ml}$ of tetracycline: 100,000 $\mathrm{ng} / \mathrm{ml}$ ibuprofen and $50 \mathrm{ng} / \mathrm{ml}$ tetracycline, and 100,000 ng/ml ibuprofen and $500 \mathrm{ng} / \mathrm{ml}$ tetracycline. 
Tetracycline:

A stock solution of tetracycline $(30 \mathrm{mg} / \mathrm{ml})$ was made using milli $\mathrm{q}$ water as a solvent and it was stored at $4^{\circ} \mathrm{C}$ in foil until needed since daylight can cause breakdown of the chemical structure. Final concentration of $50 \mathrm{ng} / \mathrm{ml}$ and $500 \mathrm{ng} / \mathrm{ml}$ were added to the appropriate reactors.

Ibuprofen:

A stock solution of Ibuprofen $(0.1 \mathrm{mg} / \mathrm{ml})$ was made using milli $\mathrm{q}$ water as a solvent and stored at $4^{\circ} \mathrm{C}$. Final concentrations of $100 \mathrm{ng} / \mathrm{ml}, 2000 \mathrm{ng} / \mathrm{ml}$ and $100 \mathrm{mg} / \mathrm{ml}$ were added to the appropriate reactors.

\subsection{DNA EXTRACTION}

Reactor samples were processed for community DNA using the PowerSoil DNA Isolation Kit (Mo Bio Laboratories, USA). A NanoDrop spectrophotometer (Thermo Scientific, USA) was used to measure the concentrations of each DNA sample in order to determine the concentrations of DNA to adjust volume quantity accordingly for qPCR reactions.

\subsection{QUANTITATIVE POL YMERASE CHAIN REACTION}

Primers for prokaryotic and eukaryotic rRNA genes were used to quantify the amount of each population that was present in the samples. Primers and protocol for qPCR are followed according to Lin et al., (2014). The $16 \mathrm{~S}$ rRNA gene bacterial genes were amplified using $200 \mu \mathrm{M}$ of the forward primer F341 (5'- CCT ACG GGA GGC AGC AG-3') and $200 \mu \mathrm{M}$ of 
the reverse primer V3R (5'-ATT ACC GCG GCT GCT GG -3') (Muyzer et al. 1993). The qPCR protocol for $16 \mathrm{~S}$ rRNA gene prokaryotic amplification was as follows, hot start at $95{ }^{0} \mathrm{C}$, followed by 25 cycles at $92{ }^{\circ} \mathrm{C}$ for $45 \mathrm{~s}, 55{ }^{\circ} \mathrm{C}$ for $45 \mathrm{~s}, 72{ }^{0} \mathrm{C}$ for $90 \mathrm{~s}$ with a final extension at 72 ${ }^{0} \mathrm{C}$ for $7 \mathrm{~min} .$. For the $18 \mathrm{~S}$ rRNA protozoan gene, $5 \mu \mathrm{M}$ forward primer 3NDF (5'GGCAAGTCTGGTGCCAG-3') and $5 \mu \mathrm{M}$ reverse primer V4_euk_R2 (5'ACGGTAtCT(AG)ATC(AG)TCTTCG-3') were used (Lin et al., 2014). The qPCR protocol for 18S rRNA gene eukaryotic amplification was as follows $95{ }^{0} \mathrm{C}$ for $2 \mathrm{~min}$, followed by 25 cycles at $95{ }^{0} \mathrm{C}$ for $30 \mathrm{~s}, 55{ }^{0} \mathrm{C}$ for $30 \mathrm{~s}, 72{ }^{0} \mathrm{C}$ for $60 \mathrm{~s}$ with a final extension at $72{ }^{0} \mathrm{C}$ for 5 min. These primers have been chosen because they produce amplicons equal to or less than $500 \mathrm{bp}$, which is ideal for qPCR. Due to the various concentrations of DNA in each sample, $50 \mathrm{ng} / \mu \mathrm{l}$ of DNA was chosen to be added to each reaction to standardize the procedure therefore different volumes of the DNA solution were used and the total volume of the reaction adjusted with Milli-Q $\mathrm{H}_{2} \mathrm{O}$ in order to obtain a final reaction sample of $20 \mu \mathrm{l}$. For full procedure and reagents setup up for qPCR refer to Appendix C.

Following the qPCR protocol, the LightCycler software was used to analyze the tested sample and provided information such as amplification curves, melting curves, and Cp values for each sample. The $\mathrm{Cp}$ values were then collected and organized on excel, averages of the same samples was calculated, standard deviation was calculated and the normalization equation $\mathrm{R}=2^{\Delta \mathrm{Cp}}$ ("Real-Time", 2006) where $\Delta \mathrm{Cp}=(\mathrm{Cp}$ control $-\mathrm{Cp}$ test), was used to calculate the relative abundance ratio for each sample. In order to perform relative quantification, an experimental control is required; in this case it's the day 15 control sample. The test samples are expressed as an increase or decrease relative to the experimental control. 
Graphs were then produced using the calculated information. The ratio, $\mathrm{R}$, is calculated by using efficiency value 2, which assumes a PCR performance that achieves perfect doubling with each amplification cycle.

\subsection{COMMUNITY PROFILES AND PROTOZOA IDENTIFICATION}

The Standard Operating Protocol Denaturing Gradient Gel Electrophoresis System (DGGE) was used to analysis the community profiles for protozoa. The gel was performed in a DCode Universal Mutation Detection System (BioRad Laboratories, Mississauga, ON). The PCR products used for DGGE were the Day 15 control: $100 \mathrm{ng} / \mathrm{ml}$ of ibuprofen and $50 \mathrm{ng} / \mathrm{ml}$ of tetracycline: $2000 \mathrm{ng} / \mathrm{ml}$ of ibuprofen and $50 \mathrm{ng} / \mathrm{ml}$ of tetracycline: 100,000 $\mathrm{ng} / \mathrm{ml}$ ibuprofen and $50 \mathrm{ng} / \mathrm{ml}$ tetracycline, and 100,000 $\mathrm{ng} / \mathrm{ml}$ ibuprofen and $500 \mathrm{ng} / \mathrm{ml}$ tetracycline. After gel preparation, the gel was run using standard procedures as instructed by the DCode protocol manual (BioRad Laboratories, Mississauga, ON). The denaturing gradient used was 40-70\%. The samples were loaded into the gel wells with $30 \mu$ of PCR products and $30 \mu 1$ (1:1 ratio) of loading dye $(2 \mathrm{x})$. DGGE gel ran with the denaturing gradient parallel to the direction of the electrophoresis for 16 hours at 80 volts in a tank containing 6 liters of $1 \mathrm{X}$ TAE buffer at $60{ }^{0} \mathrm{C}$. DGGE gel was stained with Sybr Gold (Thermo Fisher Scientific Invitrogen, USA) for 30 min, the de-stained for $15 \mathrm{~min}$ in in $250 \mathrm{ml}$ of $1 \mathrm{X}$ TAE. The gel was then placed in a UV trans illuminator for viewing. Each DNA fragment on the gel was then cut out and placed in different eppendorf tubes obtaining a total of 12 samples. Each fragment was submerged in $30 \mu 1$ of

deionized water and left to elute for 3 days at $4{ }^{0} \mathrm{C}$. Afterwards, $1 \boldsymbol{\mu l}$ of the fragment was used for PCR to determine product quality. The PCR products were purified using the PCR purification 
kit (Qiagen, Germany). Following a successful PCR purification, the product was sent to ACGT Corp (Toronto, ON) for DNA sequencing. For full procedure and reagents setup refer to Appendix A.

In order to identify the $18 \mathrm{~S}$ rRNA gene species, Basic Local Alignment Search Tool (BLAST), was utilized. BLAST is a database and its function is to find sections of local similarity between sequences. In order to do so, the program compares proteins or nucleotide sequences to its sequence database and calculates a significance of possible matches. BLAST can also distinguish between sequences in order to identify members of the same gene family (Altschul et al., 1997). The sequences retrieved from ACGT Corp were entered into the BLAST database and a statistical comparison of each species was determined and the ideal identities were collected and charted in Table 6 . 


\section{CHAPTER 4 RESULTS}

Semi- batch reactors were maintained for 15 days at a temperature range between 20 and $22{ }^{0} \mathrm{C}$. It was observed that the color and consistency of the sludge did not change over the duration of the experiment except in those that contained the largest amount of Ibuprofen $(100,000 \mathrm{ng} / \mathrm{ml})$. It appeared that at this concentration the pharmaceutical caused some foaming in the reactors.

Samples from the reactors were collected on day $0,5,10$, and 15 , (only day 0 and day 15 samples were analyzed for this project) and the microbial community DNA was extracted. To measure the relative amount of the bacterial population compared to the protozoan population, qPCR was performed with primer sets that could distinguish between prokaryotic and eukaryotic DNA. The primers used were specific to rRNA gene sequence for the 16S rRNA gene sequences in bacteria and the $18 \mathrm{~S}$ rRNA gene sequences in eukaryotes. Although the primers for the 18S rRNA gene were not specific to protozoa, a previous study by Ovez and Orhon (2005), have shown that the majority of the eukaryotic community in wastewater is composed of protists with concentrations ranging from 500 to 1000 cell/ml during optimal conditions to over 5000 cell/ml during bulking conditions. Therefore, it is assumed that the $18 \mathrm{~S}$ rRNA gene signal will represent the protozoan population.

The PCR experiments were carried out to determine the crossing point $(\mathrm{Cp})$ values that can be used as a measure of the abundance of the target sequences in a DNA sample. The Cp values were measured in triplicate for each reactor sample for both $16 \mathrm{~S}$ rRNA gene and $18 \mathrm{~S}$ rRNA gene qPCR reactions. 
The averages and standard deviations were calculated for combined reactor sets 1 and 2 . Ratio of 16S rRNA gene and 18S rRNA gene sequences were calculated using the relative quantification formula $\mathrm{R}=2^{\Delta \mathrm{Cp}}$ ("Real-Time", 2006). The final values are listed in Table 5, for a complete listing of all values refer to Appendix B. For experiment 1 and the 16S rRNA gene set, the average $\mathrm{Cp}$ values were between 13.77 and 14.61. With respect to the 18S rRNA gene Cp values, the average was between 17.69 and 19.44. These averages show that there was a higher 18S rRNA gene Cp values than 16S rRNA gene, meaning the need for more cycles for the florescent signal were required to cross the threshold or simply there was less 18S rRNA gene present at the start of the reaction. A variation in the standard deviation was observed, possibly due to numerous qPCR trials for both set 1 and set 2 in experiment 1 . For experiment 2, $16 \mathrm{~S}$ rRNA gene Cp averages are between 13.94 and 15.23, 18S rRNA gene Cp averages are between 17.25 and 20.00. Similar to experiment 1, the standard deviation varied. All control ratios were normalized to a value of 1.00 , in accordance to the formula used. 
Table 5: Normalization using relative abundance formula of $\mathrm{Cp}$ values, normalization of protozoan to bacterial ratio and standard deviation for $16 \mathrm{~S}$ rRNA gene and $18 \mathrm{~S}$ rRA gene for; day 0 , no pharmaceuticals (control), tetracycline (50 $\mathrm{ng} / \mathrm{ml})$, Ibuprofen $(100 \mathrm{ng} / \mathrm{ml})$, and a combination of Ibuprofen $(100 \mathrm{ng} / \mathrm{ml})$ and tetracycline $(50 \mathrm{ng} / \mathrm{ml})$. Cp values, standard deviation and relative abundance ratios for $16 \mathrm{~S}$ rRNA gene and $18 \mathrm{~S}$ rRA gene; day 0 , no pharmaceuticals (control), ibuprofen (100 $\mathrm{ng} / \mathrm{ml})$ plus tetracycline $(50 \mathrm{ng} / \mathrm{ml})$, Ibuprofen $(2000 \mathrm{ng} / \mathrm{ml})$, a combination of Ibuprofen $(100,000 \mathrm{ng} / \mathrm{ml})$ and tetracycline $(50$ $\mathrm{ng} / \mathrm{ml})$ and a combination of Ibuprofen $(100,000 \mathrm{ng} / \mathrm{ml})$ and tetracycline $(500 \mathrm{ng} / \mathrm{ml})$

\begin{tabular}{|c|c|c|c|c|c|}
\hline & $\begin{array}{l}\text { Normalization } \\
\text { Bacteria } \mathrm{Cp}\end{array}$ & $\begin{array}{l}\text { Normalization } \\
\text { Protozoa } \mathrm{Cp}\end{array}$ & Normalization P:B & S.D. Bacteria & S.D. Protozoa \\
\hline Day 0 & 0.63 & 3.09 & & 0.02 & 1.97 \\
\hline Control & 1.00 & 1.00 & 1.00 & & \\
\hline Tet $50 \mathrm{ng}$ & 0.93 & 0.84 & 0.91 & 0.14 & 0.05 \\
\hline Ibu 100 ng & 1.01 & 1.73 & 1.71 & 0.01 & 0.94 \\
\hline Ibu 100 ng / tet 50 ng & 0.89 & 0.77 & 0.86 & 0.04 & 0.08 \\
\hline Day 0 & 1.92 & 7.35 & & 0.22 & 3.74 \\
\hline Control & 1.00 & 1.00 & 1.00 & & \\
\hline Ibu $100 \mathrm{ng} /$ tet $50 \mathrm{ng}$ & 0.81 & 0.70 & 0.87 & 0.05 & 0.26 \\
\hline Ibu 2000 ng / tet 50 ng & 0.99 & 0.65 & 0.65 & 0.09 & 0.12 \\
\hline Ibu 100000 ng / tet 50 ng & 0.98 & 0.16 & 0.17 & 0.13 & 0.08 \\
\hline Ibu 100000 ng / tet 500 ng & 1.28 & 0.16 & 0.13 & 0.18 & 0.08 \\
\hline
\end{tabular}




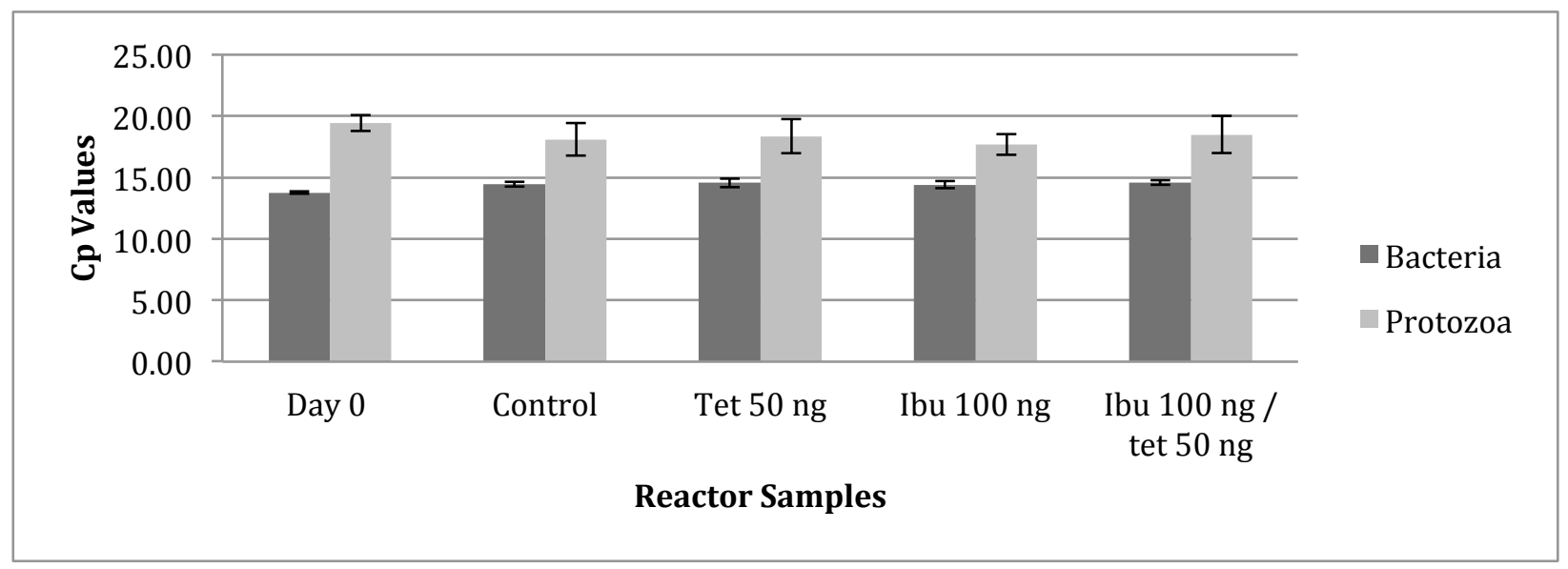

Figure 7: Abundance of bacterial and protozoan populations in each reactors at time zero and then after 15 days after the addition of no pharmaceuticals (control), tetracycline (tet) $(50 \mathrm{ng} / \mathrm{ml})$, ibuprofen (ibu) $(100 \mathrm{ng} / \mathrm{ml})$, and a combination of ibuprofen $(100 \mathrm{ng} / \mathrm{ml})$ and tetracycline $(50 \mathrm{ng} / \mathrm{ml})$.

Figure 7, shows a comparison of absolute $\mathrm{Cp}$ values for each population on day 0 and day 15. Day 0 and day 15 control did not contain tetracycline or ibuprofen, tetracycline contained 50 $\mathrm{ng} / \mathrm{ml}$ of tetracycline, ibuprofen contained $100 \mathrm{ng} / \mathrm{ml}$ of ibuprofen and tetracycline/ibuprofen contained $50 \mathrm{ng} / \mathrm{ml}$ of tetracycline and $100 \mathrm{ng} / \mathrm{ml}$ of ibuprofen. A higher $\mathrm{Cp}$ value represents a lower detection level while a lower $\mathrm{Cp}$ value represents a higher detection level of rRNA gene associated with the primer set. Very little change in the absolute Cp values was observed for the abundance of the day $1516 \mathrm{~S}$ rRNA and $18 \mathrm{~S}$ rRNA genes in comparison to the day 0 sample.

Figures $8 \mathrm{~A}, 8 \mathrm{~B}, 9 \mathrm{~A}$ and $9 \mathrm{~B}$ show a control ratio of 1:1 for the bacterial and protozoan population. However, that is not a true ratio, the 1:1 ratio is simply a reference to compare the change of the other reactors, in order to determine if an increase or decrease has occurred in comparison to their own control. 


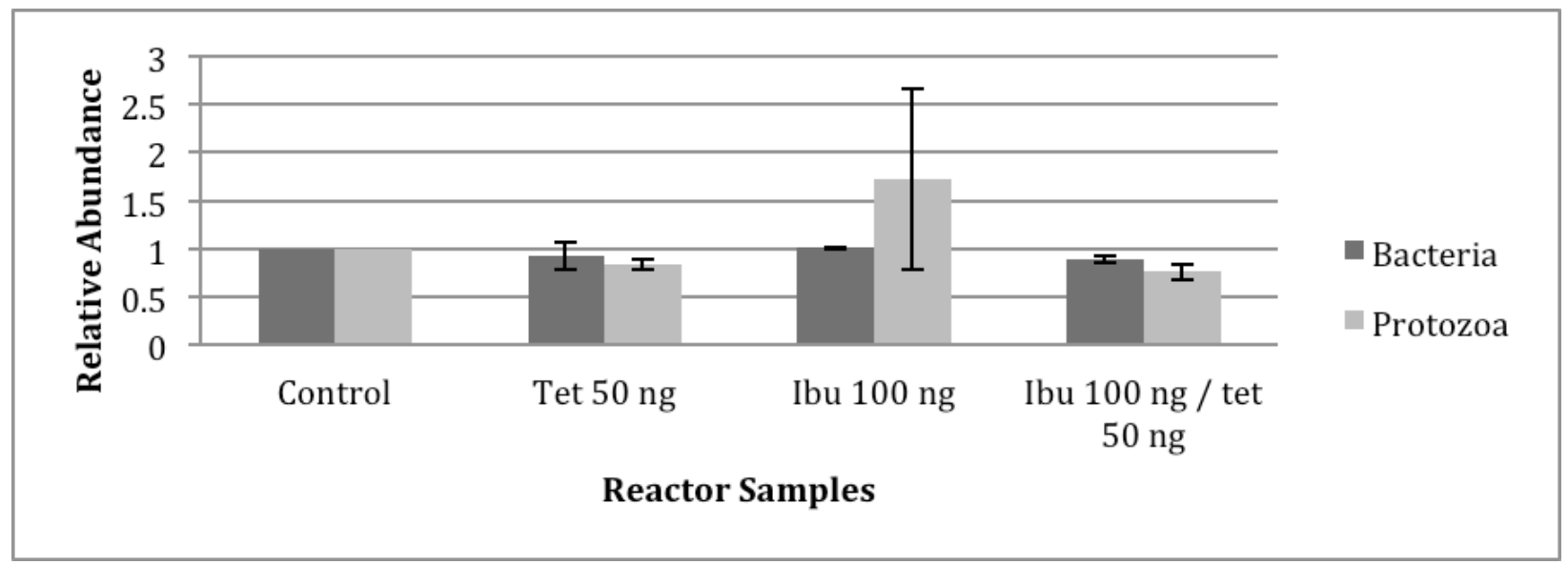

Figure 8A: The relative abundance of the bacterial and protozoan populations in each reactor compared to the abundance seen in the control. No pharmaceuticals (control), tetracycline $(50 \mathrm{ng} / \mathrm{ml})$, Ibuprofen $(100 \mathrm{ng} / \mathrm{ml})$, and a combination of Ibuprofen $(100 \mathrm{ng} / \mathrm{ml})$ and tetracycline $(50 \mathrm{ng} / \mathrm{ml})$. Ratios are relative to their own control and the control values are not 1:1 ratio.

Figure 8A shows a comparison of the abundance of each population for control and reactors with pharmaceuticals. In order to calculate the ratios of each sample, a reference sample was used. The day 15 control (no pharmaceuticals) sample was used as a reference in order to determine if a change has occurred. Calculations are not calculated for an absolute quantification but rather a relative expression.

The formula $\mathrm{R}=2^{\Delta \mathrm{Cp}}$ expressed by "Real-Time" (2006), incorporates an experiment

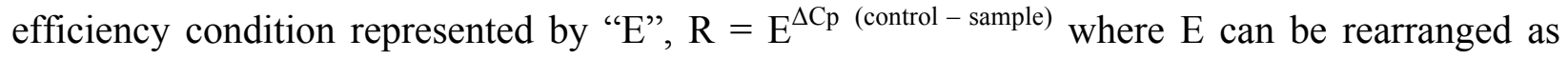
$\mathrm{R}=2^{\text {(control - sample) }}$. Arrangement of the formula assumes a perfect doubling efficiency $(E=2)$ for each cycle. The standard deviations were calculated for the triplicate sets of the Cp values for both 16S rRNA gene and 18S rRNA gene. Same calculation approach was followed for Figure 10A. With regards to the relative abundance of bacteria, observations show a change (decrease) 
in the abundance of bacteria in the reactor containing $50 \mathrm{ng} / \mathrm{ml}$ of tetracycline and in the reactor containing $100 \mathrm{ng} / \mathrm{ml}$ of ibuprofen and $50 \mathrm{ng} / \mathrm{ml}$ of tetracycline. In the case of protozoa, observations show a change (decrease) has occurred with $100 \mathrm{ng} / \mathrm{ml}$ of ibuprofen and $50 \mathrm{ng} / \mathrm{ml}$ of tetracycline.

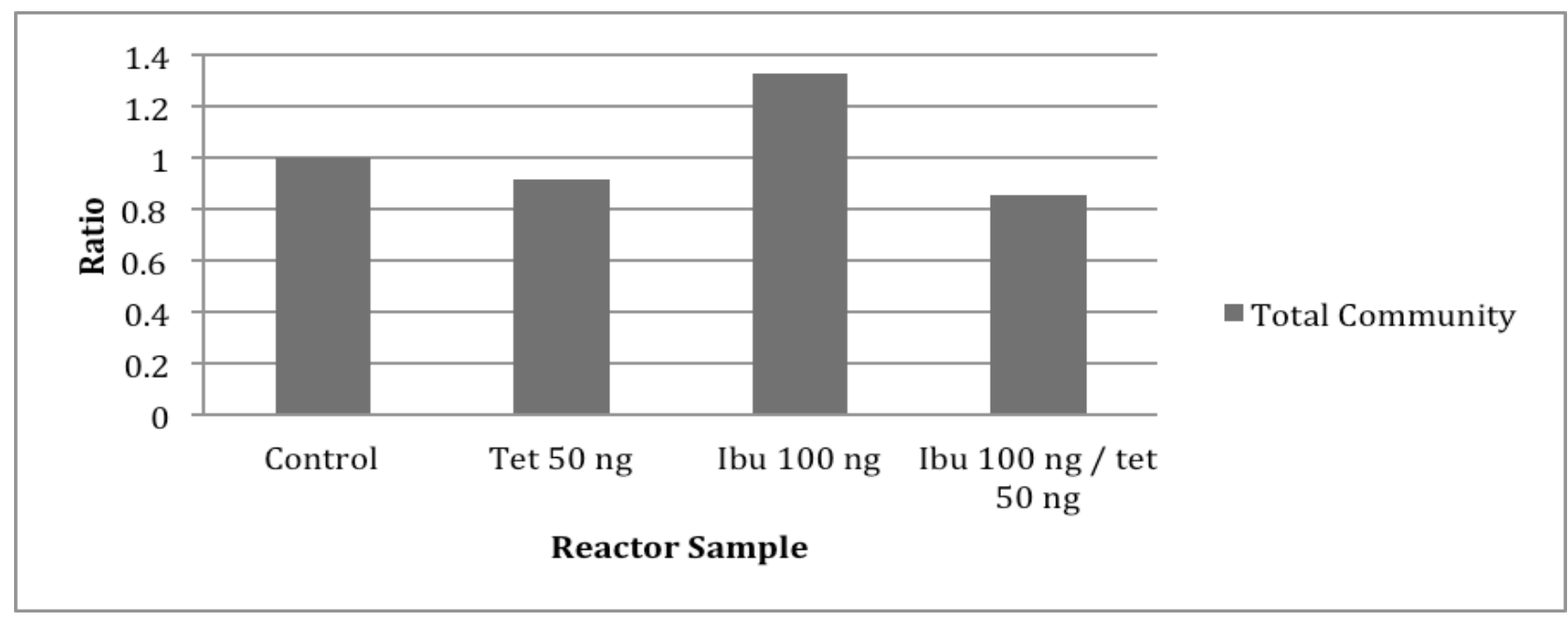

Figure 8B: Using the relative abundance of the protozoan population vs. the bacterial population calculated using the relative expression formula for all day 15 reactors after the addition of no pharmaceuticals (control), tetracycline $(50 \mathrm{ng} / \mathrm{ml})$, Ibuprofen $(100 \mathrm{ng} / \mathrm{ml})$, and a combination of Ibuprofen $(100 \mathrm{ng} / \mathrm{ml})$ and tetracycline $(50 \mathrm{ng} / \mathrm{ml})$. Using the protozoa and bacterial ratios to calculate a single community ratio for each reactor.

Figure $8 \mathrm{~B}$ shows an overall community change. Using the relative abundance values from Figure $8 \mathrm{~A}$, a simple ratio of protozoa to bacteria $(\mathrm{P}: \mathrm{B})$ was calculated to examine the entire microbial community for each sample. Although the control shows a 1:1 ratio, in reality there are millions of bacteria per protozoa. The 1:1 control ratio is simply a reference point at which the total community is seen as being in a normal state, that is in the absence of pharmaceuticals. The following sample ratios increase and decrease with respect to the pharmaceutical in which the 
total population is effected. A lower ratio represents an increase of bacteria relative to protozoa. It does not mean that bacteria has increased relative to the control, instead it represents more bacteria compared to protozoa than there is in the control. Whereas an increased ratio implies a higher protozoa population relative to bacteria, it does not mean that there are more protozoa than bacteria but rather more protozoa compared to bacteria than in the control. Figure 10B reflects a similar understanding of the ratio calculation.

Compared to the control, the reactors containing $50 \mathrm{ng} / \mathrm{ml}$ of tetracycline and $100 \mathrm{ng} / \mathrm{ml}$ of ibuprofen with the addition of $50 \mathrm{ng} / \mathrm{ml}$ of tetracycline have shown an overall decrease of the microbial community due to the decrease of the protozoan population, as seen in Figure $8 \mathrm{~A}$. However, the reactor containing $100 \mathrm{ng} / \mathrm{ml}$ of ibuprofen has shown an increases in total microbial community, this is due to the increase of the protozoan population seen in Figure 8A. 


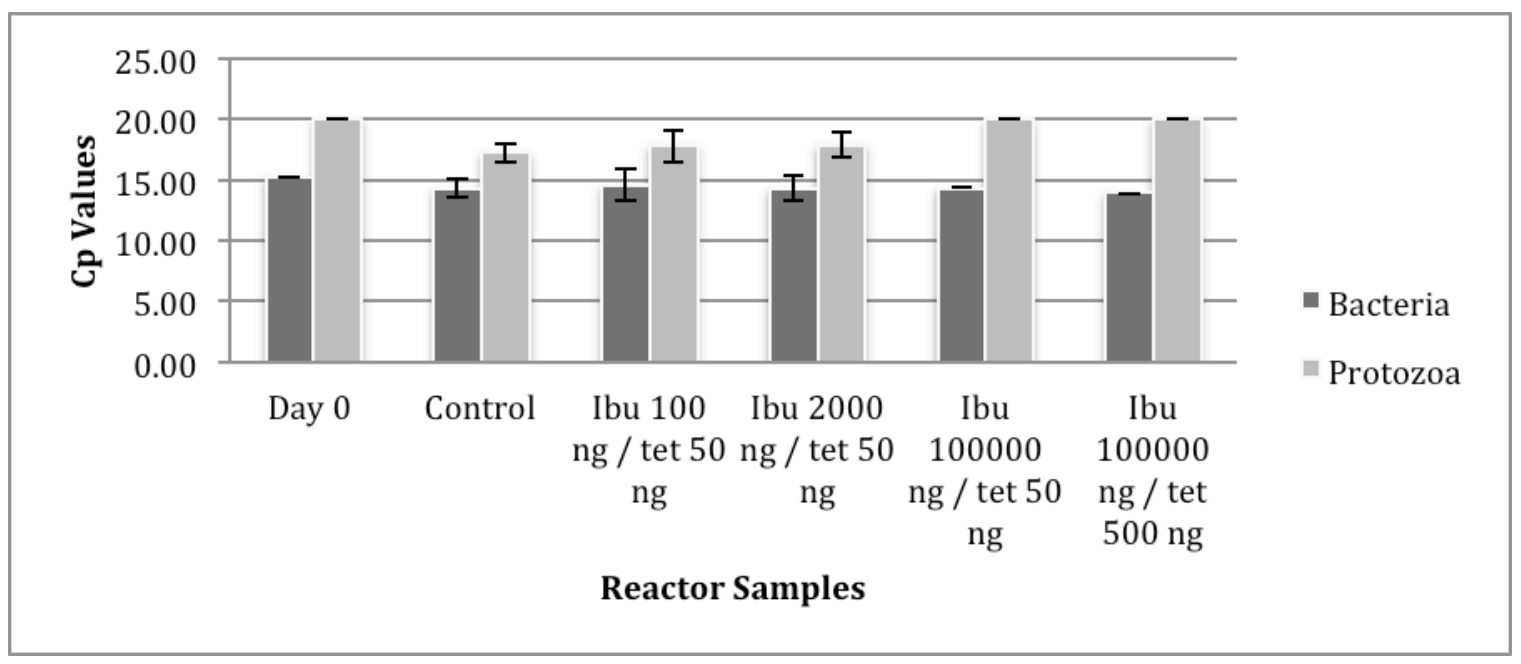

Figure 9: The relative abundance of the bacterial and protozoan populations in each reactors at time zero and then after 15 days after the addition of no pharmaceuticals (control), ibuprofen $(100 \mathrm{ng} / \mathrm{ml})$ plus tetracycline $(50 \mathrm{ng} / \mathrm{ml})$, Ibuprofen $(2000 \mathrm{ng} / \mathrm{ml})$, a combination of Ibuprofen $(100,000 \mathrm{ng} / \mathrm{ml})$ and tetracycline $(50 \mathrm{ng} / \mathrm{ml})$ and a combination of Ibuprofen $(100,000 \mathrm{ng} / \mathrm{ml})$ and tetracycline $(500 \mathrm{ng} / \mathrm{ml})$.

Figure 9 shows a similar pattern as Figure 7 when additional reactors were examined with higher concentrations of pharmaceuticals where the 18S rRNA gene had a higher Cp value than the 16S rRNA gene sequence. The $16 \mathrm{~S}$ rRNA gene $\mathrm{Cp}$ values seem to have had a negligible change throughout the 15 days, even with the high concentration of $500 \mathrm{ng} / \mathrm{ml}$ of tetracycline, which showed little to no major change. With regards to the $18 \mathrm{~S}$ rRNA gene, the Cp values increased as the concentrations of ibuprofen increased, representing lower 18S rRNA gene abundance. 


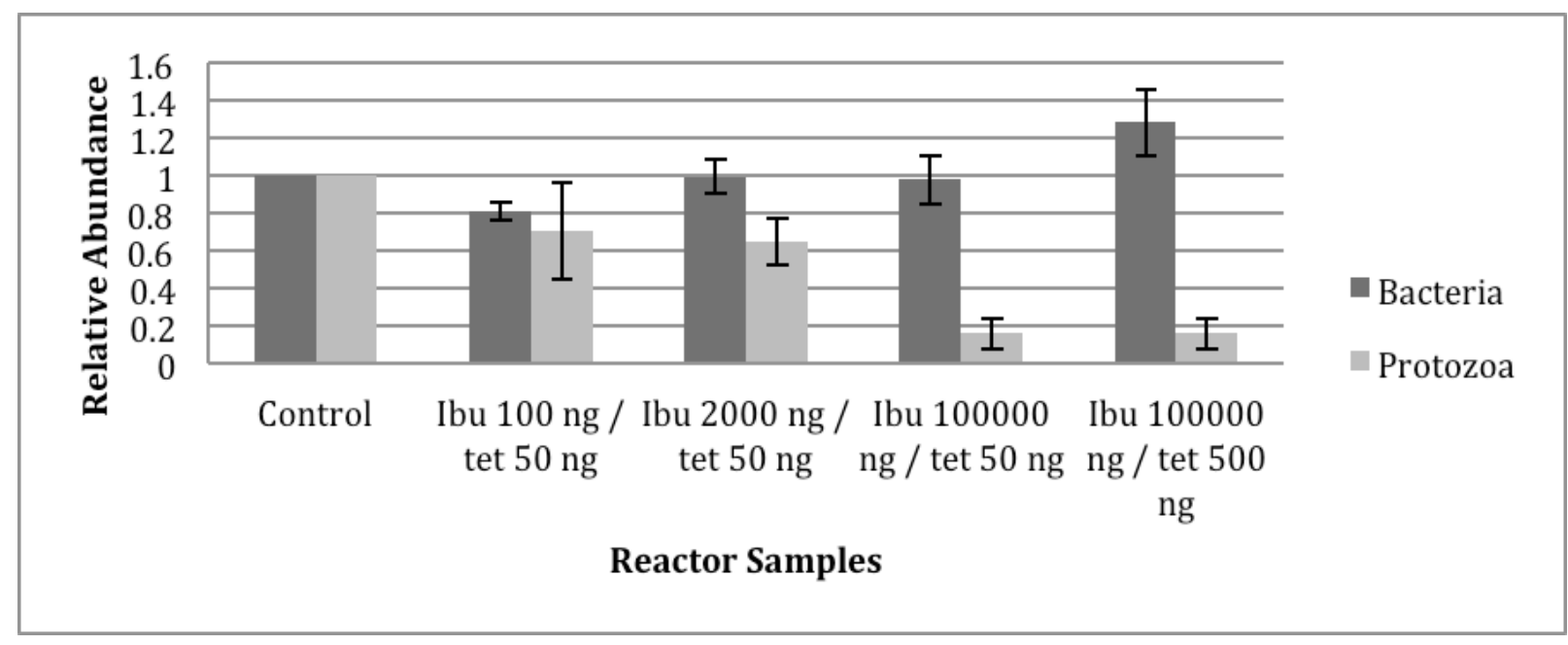

Figure 10A: The relative abundance of the bacterial and protozoan populations calculated using the relative expression formula for all day 15 reactors after the addition of no pharmaceuticals (control), Ibuprofen $(100 \mathrm{ng} / \mathrm{ml})$ and tetracycline $(50 \mathrm{ng} / \mathrm{ml})$, Ibuprofen $2000 \mathrm{ng} / \mathrm{ml}$ and tetracycline $(50 \mathrm{ng} / \mathrm{ml})$, Ibuprofen $(100,000 \mathrm{ng} / \mathrm{ml})$ and tetracycline $(50$ $\mathrm{ng} / \mathrm{ml})$, and Ibuprofen $(100,000 \mathrm{ng} / \mathrm{ml})$ and tetracycline $(500 \mathrm{ng} / \mathrm{ml})$. Ratios are relative to their own control and the control values are not $1: 1$ ratio.

Figure 10A follows the same calculation approach as demonstrated for Figure 8A. Figure 10A shows a comparison of the abundance of each population for control and reactors with pharmaceuticals at extreme concentrations. The values were calculated using the formula $\mathrm{R}=2^{\Delta \mathrm{Cp}}$. The standard deviations were calculated for the triplicates set of the $\mathrm{Cp}$ values for both the 16S rRNA gene and 18S rRNA gene. For bacteria, a decrease was observed for reactors containing $100 \mathrm{ng} / \mathrm{ml}$ of Ibuprofen and $50 \mathrm{ng} / \mathrm{ml}$ tetracycline, which confirmed the results found in the earlier experiment, both showing a major difference in comparison to their controls. Using Observations showed a decrease in the bacterial population under reactor sample containing 100 $\mathrm{ng} / \mathrm{ml}$ of Ibuprofen and $50 \mathrm{ng} / \mathrm{ml}$ tetracycline and increase for 100,000 $\mathrm{ng} / \mathrm{ml}$ of Ibuprofen and 50 $\mathrm{ng} / \mathrm{ml}$ tetracycline. In regards to the protozoan population a major decrease is seen in all reactors with greater decrease with concentrations of $100,000 \mathrm{ng} / \mathrm{ml}$ of ibuprofen. 


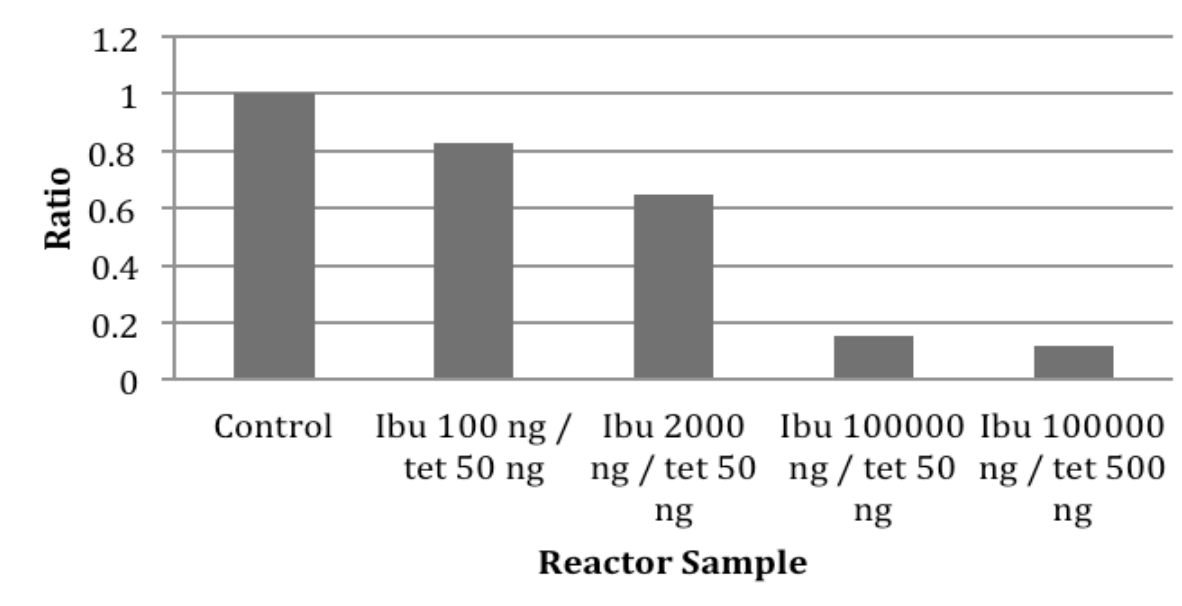

- Total Community

Figure 10B: Using the relative abundance of the protozoan population vs the bacterial population calculated using the relative expression formula for all day 15 reactors after the addition of no pharmaceuticals (control), Ibuprofen $(100 \mathrm{ng} / \mathrm{ml})$ and tetracycline (50 $\mathrm{ng} / \mathrm{ml})$, Ibuprofen $2000 \mathrm{ng} / \mathrm{ml}$ and tetracycline $(50 \mathrm{ng} / \mathrm{ml})$, Ibuprofen $100,000 \mathrm{ng} / \mathrm{ml}$ and tetracycline $(50 \mathrm{ng} / \mathrm{ml})$, and Ibuprofen $(100,000 \mathrm{ng} / \mathrm{ml})$ and tetracycline $(500 \mathrm{ng} / \mathrm{ml})$. Using the protozoa and bacterial ratios to calculate a single community ratio for each reactor.

Figure 10B shows an overall microbial community change using ratios calculated for Figure 10A. Using the relative abundance values, a single ratio was produced to examine the entire microbial community change. Compared to the control, the reactors demonstrated a continuous decrease in protozoan to bacterial ratio as the concentrations of ibuprofen and tetracycline increased for each reactor. The reactors containing $100,000 \mathrm{ng} / \mathrm{ml}$ of ibuprofen showed the largest change in community structure due to the major reduction of protozoa.

The protozoan community profiles were generated by amplifying the $18 \mathrm{~S}$ rRNA gene and running the amplicons on a DGGE gel. The DGGE gel image is seen in Figure 12. The control lane (lane 3) represents the community on Day zero. Lanes 1 and 2 represent the community on day 15 after being incubated with the pharmaceuticals for that time period. Major differences 
between control and the other lanes is the disappearance of bands 2,3,4,5, and 12 . There are also other faint bands that did not get tested but can be seen in the control and missing in the lanes with higher ibuprofen concentrations. Bands 6 and 7 appear more prominent in the control and lesser in the other two lanes. Band 8 is present in lanes 1 and 2 but is not observable in the control lane. Band 1 appears faint in the control lanes but prominent in lanes 1 and 2 under band 9 and 10. Disappearance of bands from lanes 1 and 2 can be attributed to the high concentrations of ibuprofen, while the faint bands observed in lane 1 that appear more prominent in lane 2 can be attributed to the high concentration of tetracycline. Bands that were faint or unobservable in the control but can be observed in lanes 1 and 2 can be attributed to the loss of other species allowing the rise of the few to increase.

DNA bands in the 18S rRNA gene lanes were extracted, re-amplified and cleaned, then sent for sequencing to identify the major genera that comprised the protozoan population. Figure 13 shows image of isolated DNA bands extracted from DGGE gel. 


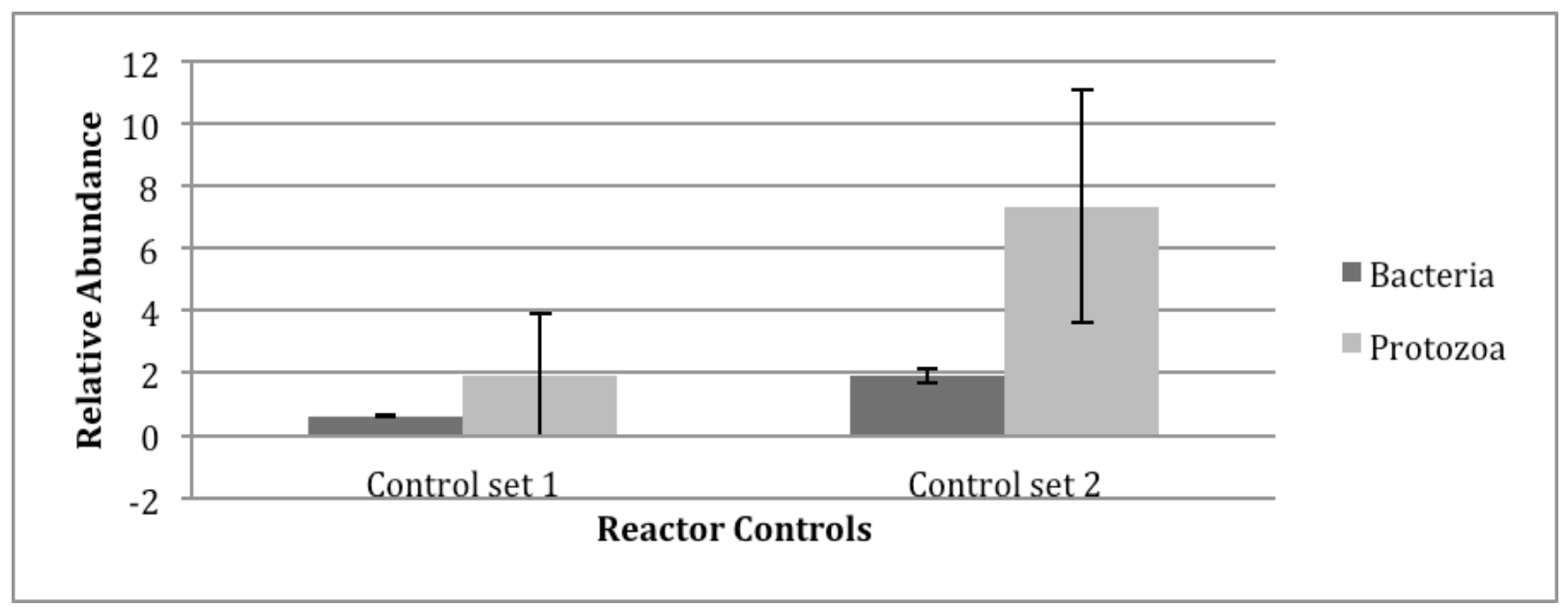

Figure 11: The relative abundance of the bacterial and protozoan populations for two sets of day 0 and day 15 controls. Ratios are relative to their own control and the control values are not 1:1 ratio.

Figure 11 follows the same calculation approach using the relative quantification formula. Figure 11 shows a comparison of the abundance of each population for two sets of day 0 and day 15 controls using $\mathrm{R}=2^{\Delta \mathrm{Cp}}$. The standard deviations were calculated for the triplicates set of the Cp values for both 16S rRNA gene and 18S rRNA gene. For the low concentration control batch, bacteria observed no change while protozoa doubled. For the high concentration control batch, bacteria doubled while protozoa increased $7 \mathrm{x}$ compared to the day 0 sample. The protozoan populations appeared to highly increase relative to the bacterial population. Both sets observed the same trend. 


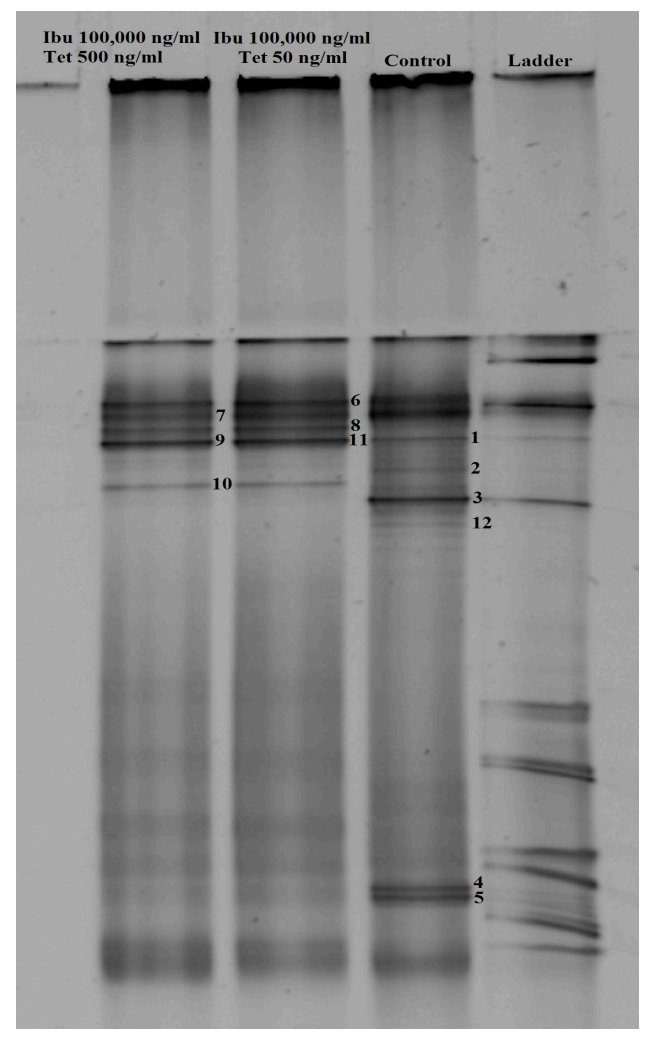

Figure 12: DGGE profile of protozoan population in the reactors with various tetracycline and ibuprofen contractions. From right to left; MW marker ladder, control population, profile from reactors with Ibu $100,000 \mathrm{ng} / \mathrm{ml}$ and tet $50 \mathrm{ng} / \mathrm{ml}$, profile from reactors with Ibu 100,000 $\mathrm{ng} / \mathrm{ml}$ and tet $500 \mathrm{ng} / \mathrm{ml}$. The bands present qPCR fragments generated with the $18 S$ rRNA gene primers.

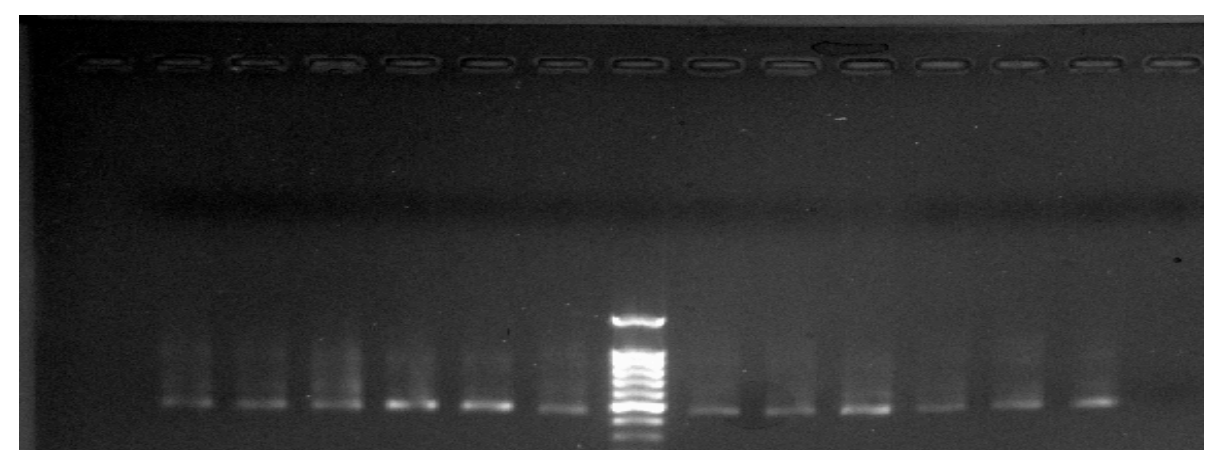

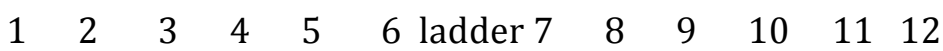

Figure 13: PCR gel image of isolated DNA bands cut from DGGE gel. Image shows DNA bands 1-6, ladder and 7-12. Bands show approximately 500 base pairs. 
Table 6: Analyzed nucleotide sequences from DGGE samples 1-12 obtained from ACGT Inc. Using the Basic Local Alignment Search Tool (BLAST) from National Center For Biotechnology Information (NCBI), a compiled list of possible species with their identity percentage is produced. (Altschul et al., 1997)

\begin{tabular}{|c|c|c|c|}
\hline Number & Species & Identities & Environment \\
\hline 1 & Lamproderma sp. & $86 \%$ & NA \\
\hline \multirow[t]{3}{*}{2} & Slavina appendiculata & $99 \%$ & Aquatic \\
\hline & Paranais litoralis & $99 \%$ & Aquatic, brackish \\
\hline & Nais communis & $99 \%$ & Aquatic \\
\hline \multirow[t]{3}{*}{3} & Slavina appendiculata & $99 \%$ & Aquatic \\
\hline & Paranais litoralis & $99 \%$ & Aquatic, brackish \\
\hline & Nais communis & $99 \%$ & Aquatic \\
\hline 4 & Arcella vulgaris & $95 \%$ & Aquatic \\
\hline \multirow[t]{2}{*}{5} & Arcella hemisphaerica & $98 \%$ & Aquatic \\
\hline & Arcella gibbosa & $97 \%$ & Aquatic \\
\hline \multirow[t]{2}{*}{6} & Uncultured eukaryote & $95 \%$ & Cold desert \\
\hline & Invertebrate & $92 \%$ & NA \\
\hline 7 & Cercozoa sp. & $95 \%$ & Soil, freshwater, aquatic \\
\hline \multirow[t]{2}{*}{8} & Uncultured Cryptomycota & $92 \%$ & Aquifer, freshwater, aquatic \\
\hline & Lamproderma sp. & $85 \%$ & NA \\
\hline \multirow[t]{3}{*}{9} & Uncultured Cryptomycota & $93 \%$ & Aquifer, freshwater, aquatic \\
\hline & Lamproderma sp. & $86 \%$ & NA \\
\hline & Eimeriidae environmental sample clone & $84 \%$ & Soil \\
\hline 10 & Uncultured eukaryote & $95 \%$ & Aquatic \\
\hline \multirow[t]{2}{*}{11} & Uncultured Cryptomycota & $90 \%$ & Aquifer, freshwater, aquatic \\
\hline & Lamproderma sp. & $86 \%$ & NA \\
\hline \multirow[t]{4}{*}{12} & Uncultured eukaryote & $98 \%$ & Karst spring \\
\hline & Slavina appendiculata & $97 \%$ & Aquatic \\
\hline & Paranais litoralis & $97 \%$ & Aquatic, brackish \\
\hline & Nais communis & $97 \%$ & Aquatic \\
\hline
\end{tabular}

Using the nucleotide sequences obtained from ACGT Inc., a collection of best possible identity match of species was compiled in Table 6 . Some of the sequences were identified as uncultured samples but the cultured sample with the highest identity match has been included in Table 6. Identity matching percentage ranged from as low as $84 \%$ to as high as $99 \%$ match. The samples that ranged in the mid 80 's percentile were compiled with an identity match in the 90 's, 
reason for that is to show a cultured along with an uncultured specie. Nucleotide sequences that were used to identify the species have been compiled and are listed in the appendix. Although all of these species were identified using the $18 \mathrm{~S}$ rRNA gene and are classified under eukaryote, while most were identified as protozoan others had different classifications. Lamproderma, which was identified under samples 1, 8, 9, and 11, is an Amoebozoa, which is under the kingdom protozoa. The genus Arcella, identified under samples 4 and 5 is amoebozoa, which is under the kingdom protozoa. Cercozoa identified under sample 7 is a group of protist. Lastly, Slavina appendiculata, Paranais litoralis, and Nais communis, identified under samples 2, 3, and 12, are an animalia, a type of worm. The rest of the samples contain uncultured eukaryotic samples. Nearly all of these eukaryotes have been previously found in aqueous environments. 


\section{CHAPTER 5 DISCUSSION}

\subsection{RESEARCH EXAMINATION}

The focus of this research is to study the effects of both ibuprofen and tetracycline independently and in combination, on activated sludge microorganisms in relation to sustainability and community composition. Since the focus of this study is the microbial community, it is important to differentiate between natural and toxic variations within the microbial community. A natural variation would be represented by the control where no pharmaceutical is added and only the effects of time and natural uncontrollable events occur, whereas, toxic variations represent the introduction of a contaminant such as pharmaceuticals. Thus, this study was conducted with replicate trials and reactor sets. Throughout the trials, $\mathrm{Cp}$ values for reactor samples containing the same pharmaceutical concentrations exhibited the same increasing and decrease trends, indicating consistency.

The microbial communities present in the activated sludge were investigated under the influence of tetracycline and ibuprofen in a semi-batch reactor system containing activated sludge extracted from the secondary wastewater treatment process. Specifically, the study examined the relative abundance of prokaryotes and eukaryotes using $16 \mathrm{~S}$ rRNA gene and 18S rRNA gene primers to monitored the impact of tetracycline and ibuprofen on the communities that are important in secondary wastewater treatment process. The study was expected to show a decrease in the bacterial population due to the antibiotic, and possible an inhibitory effect of ibuprofen on the eukaryotic population. 
The study was designed to examine the effects of these contaminants at two ranges of concentrations of both pharmaceutical compounds in which one was the environmentally relevant concentration and other was an extremely high concentration. Concentrations of $100 \mathrm{ng}$, $2000 \mathrm{ng} .100,000 \mathrm{ng}$, per $\mathrm{ml}$ of ibuprofen and $50 \mathrm{ng}$, and $500 \mathrm{ng}$, per $\mathrm{ml}$ of tetracycline were used.

Quantitative PCR and DGGE were reliable in monitoring changes in the systems caused by the different concentrations of tetracycline and ibuprofen. Analysis of the communities was conducted through DNA extraction, qPCR of 16S rRNA gene and 18S rRNA gene sequences, PCR of $18 \mathrm{~S}$ rRNA gene, and DGGE of $18 \mathrm{~S}$ rRNA gene amplicons from the eukaryotic community.

The overall change of the relative abundance of microbial communities in the presence of the two pharmaceuticals was measured through qPCR. It is difficult to calculate an exact number of the microorganisms present. A relative calculation was used in order to monitor change in comparison to the control. As to the actual amount of organism per ml, one can use past studies with calculated population numbers. Previous studies showed the bacterial population ranging from as low as 9.5 million to as high as 6 billion cells per $\mathrm{ml}$ of effluent, and the protozoan population to be from as low as 3000 to as high as several hundred thousand cells per ml. If one was to use the optimal values or lowest values of both, an ratio can be produced. Example of such ratio can be created using 3000 cells per $\mathrm{ml}$ of protozoa compared to 9.5 million cells of bacteria per $\mathrm{ml}$ to achieve a ratio of $3 \times 10^{-5}$ that can be used to represent the relative community 
composition.

In the current study, a physical DNA extraction method, bead beating, was used to reduce the possible introduction of biases related to chemical and enzymatic methods because eukaryotes have a diverse cell structures. The choice of primers and their annealing temperatures are essential parameters in obtaining the desired qPCR amplified products. The chosen $16 \mathrm{~S}$ rRNA gene forward primer F341 and reverse primer V3R, and 18S rRNA gene forward primer 3NDF and reverse primer V4_euk_R2 were selected for this research because of their efficiency, and have been verified by others (Muyzer et al., 1993; Lin et al., 2014). One of the reasons for selecting the primers used is due to their success in identifying $18 \mathrm{~S}$ rRNA gene species. A limitation of identifying $18 \mathrm{~S}$ rRNA gene sequences can be attributed to public databases containing a limited quantity of sequences derived from eukaryotes in wastewater treatment plants (Matsunaga et al., 2014). Possibly due to the aforementioned reason, many of the identified species were uncultured eukaryotes. Using different primer sets can increase the identification of the eukaryotic community.

The purpose of DGGE is that DNA fragments of the same length can be separated based on differences in their nucleic acid sequence. Since the target sequence in this study is the $18 \mathrm{~S}$ rRNA gene fragment containing organism specific strands, the number of DGGE bands ideally represents the number of organisms in the system, in this case eukaryotes, and the intensity of the bands represents the abundance of that organism. Eichner et al. (1999), suggested that one species is able to produce more than a single DGGE band and a single band can represent more than a single species, thus the number and intensity of any band may not reflect the actual 
number and abundance of a particular species within a given community. Due to the aforementioned reason, the intensity, presence and absence of a band was the target of the DGGE, and was looked upon as a cause and effect of the contaminant, in this case it was the concentration of ibuprofen. As seen in Figure 12, band presence and frequency changes from one reactor to the next as ibuprofen increases. Despite certain limitations of DGGE, the results showed a relationship between high concentrations of toxins, i.e. ibuprofen and tetracycline, and decrease in the eukaryotic community in different activated sludge samples.

\subsection{PERFORMANCE OF THE SEMI-BATCH REACTORS}

It is important that certain environment conditions are met in order to simulate and environment similar to that in a WWTP in order to achieve a realistic outcome to the tests conducted on the microorganism. To achieve a successful biological treatment, the dissolved oxygen (DO) concentration must be between 1-2mg/L (EPA, 1997). The pH must also be monitored in order to achieve to determine whether greater concentrations would affect $\mathrm{pH}$ levels of activated sludge. When tested, the difference in the $\mathrm{pH}$ levels for the control reactor and high concentration of ibuprofen and tetracycline reactors were negligible. The activated sludge process is found to occur at temperatures ranging from $15-25^{\circ} \mathrm{C}$ (Viessman and Hammer, 1998). The temperatures were fairly constant throughout the experiments since reactors were conduct in the same environment and did not differ between reactors. The semi-batch reactor system used in this experiment was similar in design in a previous study by Islam (2013). 
Pogue, (2001), showed that in a semi-batch reactor system, the microbial community can be sustained roughly one to two weeks, although without the addition of nutrients the process would eventually fail. The advantage of using a semi-batch reactor system over a batch system allows for fresh synthetic feed or organic load to be added to the reactors, which in theory would sustain and prolong the microbial community long enough to perform the required tests. A limitation of the reactor is the evaporation of water caused by the aeration. The reactors consisting of $100,000 \mathrm{ng} / \mathrm{ml}$ of ibuprofen were observed to evaporate at a higher rate. The reason could be attributed to the foaming caused by the high volume of ibuprofen, the foaming can be seen in Figure 6B. The constituents in the ibuprofen capsules could have possibly caused the foaming. Another limitation could be attributed to the aeration component, as it was difficult to ensure all reactors received the same amount of aeration due to the lack of a controlling unit that could monitor airflow rates. Nevertheless, airflow was monitored manually and adjusted as needed. Simulating aeration tank conditions and expecting the microbial community to behave in a similar manor in a laboratory environment can be challenging, because wastewater treatment plants have a continuous inflow of effluent containing high concentrations of nutrients for the microbial community while the tested community is limited to the conditions of a set nutrient schedule.

\subsection{NON-STEROIDAL ANTI-INFLAMMATORY DRUGS}

There is not extensive data in the literature with regards to the effects of NSAIDs particularly on eukaryotic protozoa. Some NSAIDs have been tested on different microbial such 
as different bacteria and more often eukaryotic algae than other eukaryotes, and have been found to produce growth inhibiting capabilities in eukaryotic species. Abdul Hussein and Al-Janabi (2011), tested Diclofenac, Naproxen and Aspirin which showed a great ability to inhibit dermatophytes growth. Another study tested other NSAIDs (Diflunisal, Piroxicam, Diclofenac, Mefenamic acid and Ibuprofen), in concentrations of $100,000 \mathrm{ng} / \mathrm{ml}$ on different cultures of cyanobacteria and eukaryotic algea. Cyanobateria were slightly effected but showed more tolerence to the NSAIDs than eukaryotic algea, which had growth reductions caused by all NSAIDs tested (Bácsi et al., 2016).

Ibuprofen is a NSAID that has been exhibited to significantly affect the growth of numerous fungal and bacterial species (Sanyal et al., 1993; Chowdhury et al., 1996). Furthmore, ibuprofen could possess stimulatory effect on bacteria (Pomati et al., 2004). In the study by Pomati (2004) showed that both Lemna and Synechocystis were inhibited by freshly added ibuprofen but exhibited growth stimulation after the second day, however after further addition exhibited an inhibitory effect by the fifth day (Pomati et al., 2004). This could explain why in Figure 6A, protozoa increased under the $100 \mathrm{ng} / \mathrm{ml}$ of ibuprofen, possibly due to its stimulating effect while showing a major decrease under higher concentrations of 2000 and $100,000 \mathrm{ng} / \mathrm{ml}$. As for Figure 10A, the increase in bacteria could be attributed to the stimulating affects of high concentration ibuprofen, but a most likely possibility for the increase is likely due to the decrease in protozoan population or the inability for the protozoa to graze.

Some of the eukaryotes present in the control are absent under higher concentrations of ibuprofen. Figure 12, shows various effects of ibuprofen on eukaryotes. The results show that 
while some protists such as amoebozoa are affected by high concentrations of ibuprofen, others are not. Slavina appendiculata, is a eukaryote that has a high identity match. It was present in the control but absent due to the high levels of ibuprofen. Cercozoa is a protist that has a brighter band in the control, the brighter band has often been associated with intensity due to higher concentrations of DNA. While Cercozoa was present throughout, the intensity of the band decreases with increased amounts of ibuprofen. It is clear that ibuprofen can either have an extreme effect or minor effect depending on the species present.

\subsection{ANTIBIOTIC TETRACYCLINE}

Tetracycline is a broad-spectrum antibiotic that is active against prokaryotes through its inhibition of protein synthesis by inhibiting the association of aminoacyl-tRNAs with the bacterial ribosomes (Pomati et al., 2004). Although tetracycline has inhibitory capabilities, in this study, minor affects have been observed. Even in the presence of $10 \mathrm{x}$ the relative concentrations, tetracycline appeared to display no effects. This observation could be attributed to resistance gained by the prokaryotic species found in activated sludge. Figures 10A and 10B show a major increase in the reactor that contained $500 \mathrm{ng} / \mathrm{ml}$ tetracycline / 100,000 $\mathrm{ng} / \mathrm{ml}$ ibuprofen in comparison to the reactor that contained $50 \mathrm{ng} / \mathrm{ml}$ tetracycline / 100,000 $\mathrm{ng} / \mathrm{ml}$ ibuprofen. Some studies have shown that antibiotic resistant bacteria have the capability to use antibiotics as a carbon source. Dantas et al., (2008), penicillin resistant soil bacteria were found to contain the capability of utilizing and degrading penicillin as the sole carbon source. Walsh et al., (2013) found that antibiotics were detoxified by bacteria through a resistance mechanisms 
and enzyme degradation. This could be the reason for the increase shown for the reactor with $500 \mathrm{ng} / \mathrm{ml}$ of tetracycline, where the bacteria could possibly use the high concentration of tetracycline as its carbon source, and that coupled with the inhibited protozoa could cause the change in abundance.

\subsection{EQUATIONS AND EXPECTATIONS}

The chosen mathematical model for relative quantification for $\mathrm{qPCR}$ is $\mathrm{R}=\mathrm{E}^{\text {(control-sample) }}$ which translates to $\mathrm{R}=2^{\Delta \mathrm{Cp}}$ ("Real-Time", 2006). This model assumes certain conditions. First

condition is $100 \%$ efficiency of the qPCR process, where $\mathrm{E}=10^{-1 / \text { slop }}$ is not calculated but rather assumes a perfect doubling efficiency $(\mathrm{E}=2)$ of the target DNA during each performed qPCR cycle (Livak, 1997, 2001; Livak and Schmittgen, 2001). Second condition, requires accurate quantification of starting material which in this case its assumed each sample started with 50 $\mathrm{ng} / \mu \mathrm{l}$ of DNA. A limitation of the Cp values obtained from the qPCR is the upper limit of 20 , which represents the highest number of cycles needed to reach the crossing point. Possibly, under different qPCR protocol settings, such as the increased number of cycles, a higher upper limit can be achieved in order to observe the $18 \mathrm{~S} \mathrm{Cp}$ values without limitations.

\subsection{RESEARCH PROJECT APPLICATION AND FUTURE PROSPECTIVE}

The investigation revealed the impact of ibuprofen and tetracycline on the microbial community present in the secondary wastewater treatment activated sludge. Research can be extended to examine the varying effects on microorganisms through different NSAIDs at 
varies concentrations, both independently and combination. Furthermore, testing the contaminants during low, medium, and high organic loading may show increased or reduced contaminant effect on the microbial community. Current major antibiotics may also be tested through the same method. Low concentration of tetracycline showed no effect, insight to the extent of varies antibiotic resistance could be beneficial.

Through literature exploration, limited information was available particularly in the last decade in regards to studies examining community populations in wastewater treatment plants in Canada. It could be beneficial to examine the microbial community and study the population sizes of all species, prokaryotic, eukaryotic and archaea. Research can also examine the populations during low, medium, and high organic load in order to establish population ratios. Benefits of such a study can be beneficial when examining effects of toxins and observing community changes in relation to documented population sizes as well as determining domestic levels of antimicrobial resistance.

Improvements to the semi-batch reactors would be beneficial. Evaporation reduction technique can be improved. Saran wrap and aluminum foil top covers were used to reduce evaporation, but failed to meet expectations. Construction of fitted cover top can be fashioned with organic load accessibility. Furthermore, reactors can be constructed to examine open verses closed systems and observe environmental change. Further improvements of sludge settling can be reduced, stir rods can be used to maintain internal effluent flow and reduce settling. 


\subsection{CONCLUSION}

The exploration of effects of tetracycline and ibuprofen separately and in combination, at low and high doses on microbial communities were examined. For this purpose semi-batch reactors containing activated sludge extract from the Humber wastewater secondary treatment plant were used. The relative abundance of prokaryotes and eukaryotes were monitored via $16 \mathrm{~S}$ rRNA gene and 18S rRNA gene primer sets as well as DGGE. It was concluded that low doses show no inhibitory effect in relation to the prokaryotic community, while high doses of ibuprofen showed an inhibitory effect on the eukaryotic community. Examination of the $18 \mathrm{~S}$ rRNA genes of the eukaryotic community screened using DGGE showed a reduction of species in reactors containing high dose of ibuprofen while high concentrations of tetracycline showed no effect. 


\section{APPENDIX A: STANDARD DGGE PROTOCOL}

Standard Operating Protocol

Denaturing Gradient Gel Electrophoresis System

\section{Denaturant Gradient Gel}

1. Assemble the glass plates with spacers and clamps. Make sure that the spacers and glass plates are flush against the sides of the clamps. Secure the plates on the casting stand.

2. Clamp (or tape) needle between the glass plates (middle/top) so that it will inject the gel solution between the plates.

3. Set pump at 99. Level the casting stand and the gradient former.

4. Add to the required amount of $0 \%$ denaturant and $80 \%$ denaturant to two $50 \mathrm{ml}$ Falcon tubes (Low and High).

5. Add $115 \mu \mathrm{l}$ of $10 \%$ fresh ammonium persulfate $(w / v)$ to each tube. Mix gently by inversion. Be carefull not to introduce air in the solution.

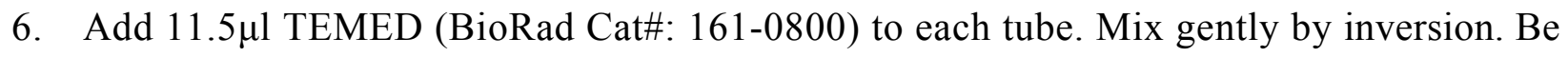
careful not to introduce air in the solution.

7. Add the low denaturant solution gently to the left chamber (Low). Remove air bubble from transfer tube by opening the valve stem quickly until the transfer tube is full of low denaturant solution and you see the solution entering the chamber on the right (High).

8. Transfer the excess low denaturant solution from the right chamber back to the left chamber.

9. Add the high denaturant solution gently to the right chamber (High).

10. Turn on mixer. 
11. Turn on pump (setting at 99).

12.Open the valve stem. Let the solution enter the glass plates. DO NOT TILT THE GRADIENT FORMER.

13. Cover the top of the gel with a piece of plastic wrap to prevent it from drying out. See step 16 before you go have a coffee!

14. Let gel polymerize for 1.5 hour at room temperature.

\section{$\underline{\text { Buffer }}$}

1.Add $6 \mathrm{~L}$ of $1 \mathrm{x}$ TAE to gel tank (i.e., fill to the FILL line).

2. Insert the lid and turn on. Let the buffer warm up until the temperature reaches 60 degrees. This takes more than an hour, so you should do this $30 \mathrm{~min}$ after pouring the gel.

\section{Spacer Gel}

1. Using filter paper, remove the water on top of the polymerized gel.

2. Insert gel comb fully.

3. Mix $3.75 \mathrm{ml}$ of $8 \%$ acrylamide- $0 \%$ denaturant with $1.25 \mathrm{ml}$ of $1 \mathrm{X}$ TAE and with $45 \mu \mathrm{l}$ of $10 \%$ (wlv) APS and $4.5 \mu 1$ TEMED.

4. Add this to the top of the denaturant gradient with a pipet.

5. Let polymerize for 0.5 hour.

\section{Loading and Running Gel}

1. Assemble the plates on the core. Pour approximately $350 \mathrm{ml} 1 \mathrm{X}$ TAE in the upper chamber to check the integrity of the seal. If buffer is leaking, discard the buffer, 
disassemble, lubricate the gasket, reassemble the plates onto the core and test again. Insert into $60^{\circ} \mathrm{C}$ lx TAE buffer (tank).

2. Let equilibrate for $15 \mathrm{~min}$.

3. Wash wells with syringe using the $1 \mathrm{X}$ TAE buffer from the tank.

4. Load wells with samples diluted in $2 \mathrm{X}$ gel loading buffer (max volume $-45 \mu \mathrm{l})$.

5. Run gel at $80 \mathrm{~V}$ for $16 \mathrm{~h}$. at $60^{\circ} \mathrm{C}$.

\section{Staining Gel}

1. Stain gel for 0.5 hour in 1:10000 dilution of SYBR Gold (Invitrogen Cat\# S11494) with gentle shaking (25 I.11 of SYBR Gold in $250 \mathrm{ml}$ of $1 \mathrm{X}$ TAE).

2. De-stain for $10-15 \mathrm{mins}$ in $250 \mathrm{ml}$ of $1 \mathrm{X} \mathrm{TAE}$ with gentle shaking.

\section{Solutions}

1. Ammonium Persulfate-APS (10\%) (BioRad cat\#: 161-0700)

Add $100 \mathrm{mg}$ of dry APS to $1 \mathrm{ml}$ of ultrapure $\mathrm{H}_{2} \mathrm{O}$, vortex to dissolve. This is used immediately and then discarded.

2. Acrylamide - Denaturant Solutions (BioRad cat\#: 161-0148)

The acrylamide solutions are only stable for one month. All glassware should be rinsed with ultrapure water.

$\mathbf{8 \%}$ acrylamide - $\mathbf{0 \%}$ denaturant: to make $\mathbf{1 0 0} \quad \mathbf{m l}$ of solution $20 \mathrm{ml} \quad 40 \%$ Acrylamide/Bisacrylamide (37.5:1) (BioRad) 
$2 \mathrm{ml} 50 \mathrm{X}$ TAE prepared with ultrapure $\mathrm{H}_{2} \mathrm{O}$ and ultrapure reagents $78 \mathrm{ml}$ ultrapure $\mathrm{H}_{2} \mathrm{O}$

Sterilize through a $0.22 \mathrm{um}$ filter $(150 \mathrm{~mL}$ filtration unit). Degas for $5 \mathrm{~min}$ (pump) or 10-15 min (lab set up). Store at $4^{\circ} \mathrm{C}$ in a brown bottle for approx. 1 month.

$8 \%$ acrylamide $-80 \%$ denaturant: to make $100 \mathrm{ml}$ of solution

$20 \mathrm{ml} \mathrm{40 \%} \mathrm{Acrylamide/Bisacrylamide} \mathrm{(37.5:1)} \mathrm{(BioRad)}$

$2 \mathrm{ml} 50 \mathrm{X}$ TAE prepared with ultrapure $\mathrm{H} 2 \mathrm{O}$ and ultrapure reagents $32 \mathrm{ml}$ deionized Formamide (see recipe below)

33.6 g Ultrapure Urea (Fluka-Sigma/Aldrich cat\#:51456)

Adjust volume to $100 \mathrm{ml}$

Mix and sterilize through a $0.22 \mathrm{um}$ filter (150 mL filtration unit). Degas for $5 \mathrm{~min}$ (pump) or 10-15 min (lab set up). Store at $4^{\circ} \mathrm{C}$ in a brown bottle for approx. 1 month. 
Table 7: Full experiment 1 Cp values, standard deviation and relative abundance ratios for 16S rRNA gene and 18S rRNA gene for; day 0 , no pharmaceuticals (control), tetracycline $(50 \mathrm{ng} / \mathrm{ml})$, Ibuprofen $(100 \mathrm{ng} / \mathrm{ml})$, and a combination of Ibuprofen $(100 \mathrm{ng} / \mathrm{ml})$ and tetracycline $(50 \mathrm{ng} / \mathrm{ml})$. Experiment $2 \mathrm{Cp}$ values, standard deviation and relative abundance ratios for $16 \mathrm{~S}$ rRNA gene and 18S rRNA gene; day 0 , no pharmaceuticals (control), ibuprofen $(100 \mathrm{ng} / \mathrm{ml})$ plus tetracycline $(50 \mathrm{ng} / \mathrm{ml})$, Ibuprofen $(2000 \mathrm{ng} / \mathrm{ml})$, a combination of Ibuprofen $(100,000 \mathrm{ng} / \mathrm{ml})$ and tetracycline $(50 \mathrm{ng} / \mathrm{ml})$ and a combination of Ibuprofen $(100,000 \mathrm{ng} / \mathrm{ml})$ and tetracycline $(500 \mathrm{ng} / \mathrm{ml})$

\begin{tabular}{|c|c|c|c|c|c|c|c|c|c|c|c|}
\hline $\begin{array}{l}\text { Environmentally } \\
\text { relative concentrations }\end{array}$ & $\begin{array}{l}\text { CP } \\
16 \mathrm{~S}- \\
1 \\
\end{array}$ & $\begin{array}{l}\text { CP } \\
16 \mathrm{~S}- \\
2 \\
\end{array}$ & $\begin{array}{l}\text { CP } \\
16 \mathrm{~S}- \\
3 \\
\end{array}$ & $\begin{array}{l}\text { Average } \\
\text { s Cp } 1\end{array}$ & $\begin{array}{l}\text { Average } \\
\text { s Cp } 2\end{array}$ & $\begin{array}{l}\text { Average } \\
\text { s Cp } 3\end{array}$ & $\begin{array}{l}\text { Avg } 1 \\
R=2^{\Delta C p}\end{array}$ & $\begin{array}{l}\text { Avg } 2 \\
\mathrm{R}=2^{\Delta \mathrm{Cp}}\end{array}$ & $\begin{array}{l}\text { Avg } \\
3 R=2^{\Delta C}\end{array}$ & $\begin{array}{l}\text { Average } \\
\text { Ratio }\end{array}$ & $\begin{array}{l}\text { Stand } \\
\text { Dev. }\end{array}$ \\
\hline \multicolumn{12}{|l|}{ Bacteria $16 \mathrm{~S}$} \\
\hline Day 0 & 13.75 & 13.86 & 13.83 & 13.79 & 13.83 & 13.71 & 0.64 & 0.60 & 0.64 & 0.63 & 0.02 \\
\hline Day $0(2)$ & 13.92 & 13.96 & 13.68 & & & & & & & & \\
\hline Day 0 (Experiment 2) & 13.76 & 14.06 & 13.93 & & & & & & & & \\
\hline $\begin{array}{l}\text { Day } 0 \text { (Experiment 2) } \\
\text { (2) }\end{array}$ & 13.72 & 13.43 & 13.38 & & & & & & & & \\
\hline Control & 14.47 & 14.11 & 14.01 & 14.42 & 14.56 & 14.36 & & & & & \\
\hline Control (2) & 13.46 & 14.03 & 13.71 & & & & & & & & \\
\hline Control (Experiment 2) & 15.01 & 15.15 & 15.00 & & & & & & & & \\
\hline $\begin{array}{l}\text { Control (2) (Experiment } \\
\text { 2) (2) }\end{array}$ & 14.75 & 14.96 & 14.70 & & & & & & & & \\
\hline Tet $50 \mathrm{ng}$ & 14.49 & 14.52 & 14.38 & 14.41 & 14.94 & 14.34 & 1.01 & 0.77 & 1.01 & 0.93 & 0.14 \\
\hline
\end{tabular}




\begin{tabular}{|c|c|c|c|c|c|c|c|c|c|c|c|}
\hline $\begin{array}{l}\text { Tet } 50 \mathrm{ng} \text { (Experiment } \\
\text { 2) }\end{array}$ & 14.57 & 16.12 & 14.56 & & & & & & & & \\
\hline $\begin{array}{l}\text { Tet } 50 \mathrm{ng} \text { (Experiment } \\
\text { 2) (2) }\end{array}$ & 14.60 & 14.71 & 14.42 & & & & & & & & \\
\hline Ibu 100 ng & 14.01 & 14.79 & 13.85 & 14.41 & 14.53 & 14.34 & 1.01 & 1.02 & 1.01 & 1.01 & 0.01 \\
\hline Ibu 100 ng (2) & 14.38 & 13.70 & 14.39 & & & & & & & & \\
\hline $\begin{array}{l}\text { Ibu } 100 \mathrm{ng} \text { (Experiment } \\
\text { 2) }\end{array}$ & 14.69 & 14.65 & 14.55 & & & & & & & & \\
\hline $\begin{array}{l}\text { Ibu } 100 \mathrm{ng} \text { (Experiment } \\
\text { 2) (2) }\end{array}$ & 14.57 & 14.98 & 14.58 & & & & & & & & \\
\hline Ibu $100 \mathrm{ng} /$ tet $50 \mathrm{ng}$ & 14.84 & 14.76 & 14.50 & 14.65 & 14.71 & 14.47 & 0.85 & 0.90 & 0.92 & 0.89 & 0.04 \\
\hline $\begin{array}{l}\text { Ibu } 100 \mathrm{ng} / \text { tet } 50 \mathrm{ng} \\
\text { (2) }\end{array}$ & 14.49 & 14.20 & 14.39 & & & & & & & & \\
\hline $\begin{array}{l}\text { Ibu } 100 \mathrm{ng} / \text { tet } 50 \mathrm{ng} \\
\text { (Experiment } 2 \text { ) }\end{array}$ & 14.67 & 14.87 & 14.51 & & & & & & & & \\
\hline $\begin{array}{l}\text { Ibu } 100 \mathrm{ng} / \text { tet } 50 \mathrm{ng} \\
\text { (Experiment 2) (2) }\end{array}$ & 14.60 & 15.00 & 14.47 & & & & & & & & \\
\hline Protozoa $18 \mathrm{~S}$ & & & & & & & & & & & \\
\hline Day 0 & 18.15 & 20.00 & 20.00 & 18.85 & 20.00 & 19.46 & 3.57 & 4.77 & 0.92 & 3.09 & 1.97 \\
\hline Day 0 (2) & 20.00 & 20.00 & 20.00 & & & & & & & & \\
\hline Day 0 (Experiment 2) & 19.85 & 20.00 & 20.00 & & & & & & & & \\
\hline $\begin{array}{l}\text { Day } 0 \text { (Experiment 2) } \\
\text { (2) }\end{array}$ & 17.39 & 20.00 & 17.84 & & & & & & & & \\
\hline Control & 17.50 & 17.97 & 20.00 & 17.01 & 17.75 & 19.58 & & & & & \\
\hline Control (2) & 16.96 & 17.72 & 19.13 & & & & & & & & \\
\hline Control (Experiment 2) & 17.20 & 17.90 & 19.93 & & & & & & & & \\
\hline $\begin{array}{l}\text { Control (2) (Experiment } \\
\text { 2) (2) }\end{array}$ & 16.38 & 17.40 & 19.24 & & & & & & & & \\
\hline Tet $50 \mathrm{ng}$ & 16.58 & 17.22 & 19.65 & 17.25 & 17.91 & 19.91 & 0.85 & 0.89 & 0.79 & 0.84 & 0.05 \\
\hline
\end{tabular}




\begin{tabular}{|c|c|c|c|c|c|c|c|c|c|c|c|}
\hline Tet 50 ng (2) & 17.25 & 17.54 & 20.00 & & & & & & & & \\
\hline $\begin{array}{l}\text { Tet } 50 \text { ng (Experiment } \\
\text { 2) }\end{array}$ & 17.43 & 18.34 & 20.00 & & & & & & & & \\
\hline $\begin{array}{l}\text { Tet } 50 \text { ng (Experiment } \\
\text { 2) (2) }\end{array}$ & 17.73 & 18.55 & 20.00 & & & & & & & & \\
\hline Ibu $100 \mathrm{ng}$ & 16.72 & 17.45 & 18.11 & 16.87 & 17.79 & 18.42 & 1.30 & 1.09 & 2.81 & 1.73 & 0.94 \\
\hline Ibu $100 \mathrm{ng}(2)$ & 15.78 & 16.00 & 15.58 & & & & & & & & \\
\hline $\begin{array}{l}\text { Ibu } 100 \mathrm{ng} \text { (Experiment } \\
\text { 2) }\end{array}$ & 17.20 & 18.47 & 20.00 & & & & & & & & \\
\hline $\begin{array}{l}\text { Ibu } 100 \mathrm{ng} \text { (Experiment } \\
\text { 2) (2) }\end{array}$ & 17.77 & 19.24 & 20.00 & & & & & & & & \\
\hline Ibu $100 \mathrm{ng} /$ tet $50 \mathrm{ng}$ & 16.88 & 18.16 & 20.00 & 17.24 & 18.26 & 20.00 & 0.85 & 0.70 & 0.74 & 0.77 & 0.08 \\
\hline $\begin{array}{l}\text { Ibu } 100 \mathrm{ng} / \text { tet } 50 \mathrm{ng} \\
\text { (2) }\end{array}$ & 17.06 & 16.73 & 20.00 & & & & & & & & \\
\hline $\begin{array}{l}\text { Ibu } 100 \mathrm{ng} / \text { tet } 50 \mathrm{ng} \\
\text { (Experiment } 2 \text { ) }\end{array}$ & 17.85 & 19.83 & 20.00 & & & & & & & & \\
\hline $\begin{array}{l}\text { Ibu } 100 \mathrm{ng} / \text { tet } 50 \mathrm{ng} \\
\text { (Experiment 2) (2) }\end{array}$ & 17.17 & 18.32 & 20.00 & & & & & & & & \\
\hline & \multicolumn{2}{|c|}{ High Concentration } & & & & & & & & & \\
\hline Bacteria $16 \mathrm{~S}$ & & & & & & & & & & & \\
\hline Day 0 & 15.63 & 16.03 & 16.04 & 14.93 & 15.40 & 15.35 & 1.71 & 1.93 & 2.14 & 1.92 & 0.22 \\
\hline Day $0(2)$ & 14.23 & 14.76 & 14.66 & & & & & & & & \\
\hline Control & 14.16 & 14.43 & 14.13 & 14.16 & 14.45 & 14.25 & & & & & \\
\hline Control (2) & 14.16 & 14.47 & 14.37 & & & & & & & & \\
\hline $\mathrm{Ibu} 100 \mathrm{ng} /$ tet $50 \mathrm{ng}$ & 14.43 & 14.51 & 14.43 & 14.53 & 14.67 & 14.60 & 0.78 & 0.86 & 0.79 & 0.81 & 0.05 \\
\hline $\begin{array}{l}\text { Ibu } 100 \mathrm{ng} / \text { tet } 50 \mathrm{ng} \\
\text { (2) }\end{array}$ & 14.62 & 14.82 & 14.76 & & & & & & & & \\
\hline Ibu $2000 \mathrm{ng} /$ tet $50 \mathrm{ng}$ & 14.06 & 14.13 & 14.26 & 14.17 & 14.34 & 14.40 & 0.99 & 1.08 & 0.90 & 0.99 & 0.09 \\
\hline Ibu $2000 \mathrm{ng} /$ tet $50 \mathrm{ng}$ & 14.28 & 14.54 & 14.54 & & & & & & & & \\
\hline
\end{tabular}




\begin{tabular}{|c|c|c|c|c|c|c|c|c|c|c|c|}
\hline (2) & & & & & & & & & & & \\
\hline $\begin{array}{l}\text { Ibu } 100000 \mathrm{ng} / \text { tet } 50 \\
\text { ng }\end{array}$ & 13.89 & 14.03 & 14.08 & 14.30 & 14.28 & 14.41 & 0.91 & 1.13 & 0.90 & 0.98 & 0.13 \\
\hline $\begin{array}{l}\text { Ibu } 100000 \mathrm{ng} / \text { tet } 50 \\
\text { ng (2) }\end{array}$ & 14.70 & 14.53 & 14.73 & & & & & & & & \\
\hline $\begin{array}{l}\text { Ibu } 100000 \mathrm{ng} / \text { tet } 500 \\
\text { ng }\end{array}$ & 14.03 & 13.91 & 13.91 & 14.01 & 13.90 & 13.90 & 1.11 & 1.46 & 1.28 & 1.28 & 0.18 \\
\hline $\begin{array}{l}\text { Ibu } 100000 \mathrm{ng} / \text { tet } 500 \\
\text { ng (2) }\end{array}$ & 13.99 & 13.89 & 13.88 & & & & & & & & \\
\hline & & & & & & & & & & & \\
\hline Protozoa 18S & & & & & & & & & & & \\
\hline Day 0 & 20.00 & 20.00 & 20.00 & 20.00 & 20.00 & 20.00 & 6.66 & 4.01 & 11.39 & 7.35 & 3.74 \\
\hline Day 0 (2) & 20.00 & 20.00 & 20.00 & & & & & & & & \\
\hline Control & 17.36 & 18.25 & 16.62 & 17.27 & 18.00 & 16.49 & & & & & \\
\hline Control (2) & 17.17 & 17.74 & 16.36 & & & & & & & & \\
\hline Ibu $100 \mathrm{ng} /$ tet $50 \mathrm{ng}$ & 17.54 & 19.36 & 16.59 & 17.53 & 19.29 & 16.70 & 0.84 & 0.41 & 0.87 & 0.70 & 0.26 \\
\hline $\begin{array}{l}\text { Ibu } 100 \mathrm{ng} / \text { tet } 50 \mathrm{ng} \\
\text { (2) }\end{array}$ & 17.51 & 19.21 & 16.80 & & & & & & & & \\
\hline Ibu $2000 \mathrm{ng} /$ tet $50 \mathrm{ng}$ & 17.22 & 17.90 & 16.77 & 17.85 & 18.95 & 16.88 & 0.67 & 0.52 & 0.76 & 0.65 & 0.12 \\
\hline $\begin{array}{l}\text { Ibu } 2000 \mathrm{ng} / \text { tet } 50 \mathrm{ng} \\
\text { (2) }\end{array}$ & 18.48 & 20.00 & 16.99 & & & & & & & & \\
\hline $\begin{array}{l}\text { Ibu } 100000 \mathrm{ng} / \text { tet } 50 \\
\text { ng }\end{array}$ & 20.00 & 20.00 & 20.00 & 20.00 & 20.00 & 19.96 & 0.15 & 0.25 & 0.09 & 0.16 & 0.08 \\
\hline $\begin{array}{l}\text { Ibu } 100000 \mathrm{ng} / \text { tet } 50 \\
\text { ng (2) }\end{array}$ & 20.00 & 20.00 & 19.91 & & & & & & & & \\
\hline $\begin{array}{l}\text { Ibu } 100000 \mathrm{ng} / \text { tet } 500 \\
\text { ng }\end{array}$ & 20.00 & 20.00 & 20.00 & 20.00 & 20.00 & 20.00 & 0.15 & 0.25 & 0.09 & 0.16 & 0.08 \\
\hline $\begin{array}{l}\text { Ibu } 100000 \mathrm{ng} / \text { tet } 500 \\
\text { ng (2) }\end{array}$ & 20.00 & 20.00 & 20.00 & & & & & & & & \\
\hline
\end{tabular}




\section{APPENDIX C: REAGENTS \& NUCLEIC ACID SEQUENCES}

Table 8: Reagents and concentrations used for $q P C R$

\begin{tabular}{|c|c|}
\hline Reagents & For $20 \mu$ l sample $(\mu \mathrm{l})$ \\
\hline Milli-Q $\mathrm{H}_{2} \mathrm{O}$ & 11.81 \\
\hline Bovine Serum Albumin (BSA) (100x, $10 \mathrm{mg} / \mathrm{ml})$ & 0.34 \\
\hline Dimethyl Sulfoxide (DMSO) & 1.25 \\
\hline Forward/Reverse $(5 \mu \mathrm{M})$ & 0.50 \\
\hline $\mathrm{MgCl}_{2}$ (conc?) & 1.60 \\
\hline Master Mix (FastStart PCR Master Mix) (co?) & 2.00 \\
\hline
\end{tabular}

Table 9: - Reagents and concentrations used for PCR

\begin{tabular}{|l|l|}
\hline Reagents & For $25 \boldsymbol{\mu l}$ sample $(\boldsymbol{\mu l})$ \\
\hline Milli-Q $\mathrm{H}_{2} \mathrm{O}$ & 8.90 \\
\hline Bovine Serum Albumin (BSA) $(100 \mathrm{x})$ & 0.34 \\
\hline Dimethyl Sulfoxide (DMSO) & 1.25 \\
\hline Forward $(10 \mu \mathrm{M})$ & 0.50 \\
\hline Reverse $(10 \mu \mathrm{M})$ & 0.50 \\
\hline Master Mix $($ FastStart PCR Master Mix) & 12.50 \\
\hline
\end{tabular}

Table 10: Synthetic Wastewater Composition (Liao et al., 2001)

\begin{tabular}{|r|r|c|c|c|}
\hline Nutrients & Compounds & Constituents & Concentration (mg/L) & Sources \\
\hline C-Source & Glucose & COD & $250(100 \mathrm{mg}$ C) & Sigma Chemical, Canada \\
\hline & Sodium Acetate & COD & $283.5(83.0 \mathrm{mg}$ C) & Sigma Chemical, Canada \\
\hline P-Source & KH2PO4 & P & $8,78(2.0 \mathrm{mg} \mathrm{P})$ & Sigma Chemical, Canada \\
& K2HPO4 & P & $11.24(2.0 \mathrm{mg}$ P $)$ & Sigma Chemical, Canada \\
\hline
\end{tabular}




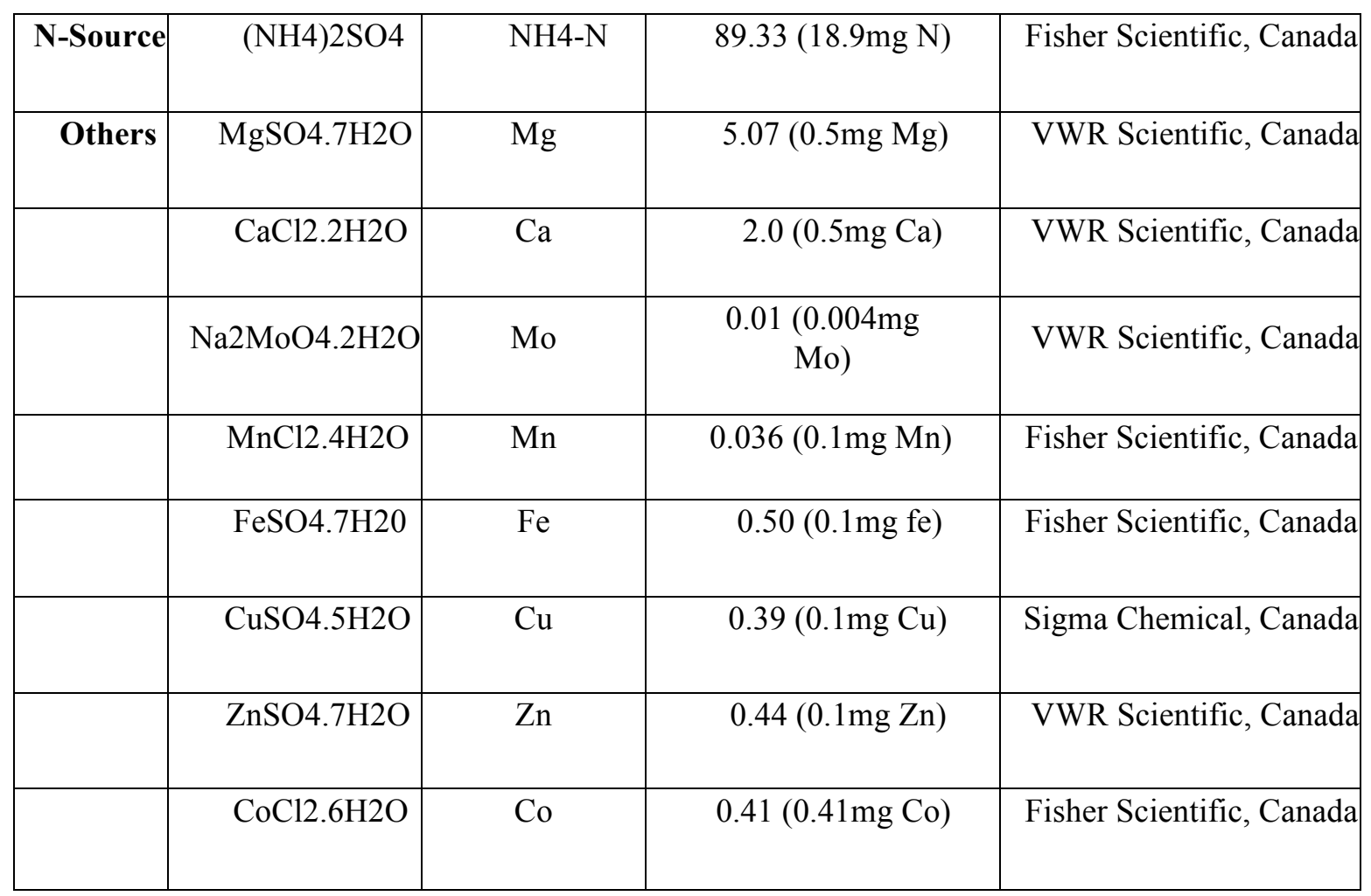

Nucleotide sequences from DGGE samples 1-12 obtained from ACGT Inc.

TEMPLATE NAME: 1

PRIMER NAME: 3NDF

NNNNNNNNNNNNNNNNTTNAANTTNTTGCAGTTAAAAAGCTCGTAGTTGNATNTCG GNNSNNGNCNNNCGGTNNGNCTNCNGGNNATNACTGNNCGNSCNGANYYWYMYYY CKRNKKWMNCNKNGTGCNCTTCNYYGNGTGCKYCGGGNGNCNNGNACGNTTACNT TGANAAAANTAGAGTGNTNAAAGCANGCNNACTGNCTGNACNTNNCGCATGGAAN TTGNNANNACNNNGNTCTNNNTTNNTTGGTTTTGAGGACCACTGTCATGNNNNTAN NNNNANTGNNGGCATTTTCNTCNGGNGTCNNAGGNGNNAAATTTGNANTGCNNNAN NANNCNANCTNNN

TEMPLATE NAME: 2

PRIMER NAME: 3NDF

NNNNNNNNNNNNATNNNNNNNNTNNTGCAGTTAAAAAGCTCGNAGTTGGATCTCG 
GGTCCAGGCTNGCNGNTNNNNTCGCGGCGATTACTGCNCGTCCTGACCTACCTCCCG GTTTTCCCTTGGTGCTCTTCGTTGAGTGCTTCGGGTGGCCGGAACGTTTACTTTGAAA AAATTAGAGTGCTCAAAGCAGGCGGACTGCCTGAATAATCGCGCATGGAATAATGG AATAGGACCTCGGTTCTATTTTGTTGGTTTTCGGAACTCGAGGTAATGATTAAGAGG GACAGACGGGGGCATTCGTATTACGGTGTTAGAGGTGAAATTCTTGGATCGCCGTAA GACGAACTACTGCGAAAGCATTTGCCAAGAATGTTTTCNTTAATCAAGAACGAAAG TNNGAGGTTCGAAGACGATCNGATACCNNNNN

TEMPLATE NAME: 2

PRIMER NAME: V4R2

NNNNNNNNNNNNNNNNNNNNNNTNTNGGNANTGCTTTCGCAGTAGTTCGTCTTNCG GCGATCCAAGAATTTCACCTCTAACACCGTAATACGAATGCCCCCGTCTGTCCCTCT TAATCATTACCTCGAGTTCCGAAAACCAACAAAATAGAACCGAGGTCCTATTCCATT ATTCCATGCGCGATTATTCAGGCAGTCCGCCTGCTTTGAGCACTCTAATTTTTTCAAA GTAAACGTTCCGGCCACCCGAAGCACTCAACGAAGAGCACCAAGGGAAAACCGGG AGGTAGGTCAGGACGNGCAGTAATCGCCGCGAGGCGAACCGCNAGCCTGGACCCG AGATCCAACTACNAGCTTTTTAACTGCAACAACTTTAATATACGCTATTGGAGCTGG AATTACCGCGGCTGCTGGCANNNACTTGCCAN

\section{TEMPLATE NAME: 3}

PRIMER NAME: 3NDF

NNNNNNNNNNNNNATATNAANGTTNTTGCAGTTAAAAAGCTCGTAGTTGGATCTCG GGTCCAGGCTNGCGGTTCGCCTCGCGGCGATTACTGCYCGTCCTGACCTACCTCCCG GTTTTCCCTTGGTGCTCTTCGTTGAGTGCTTCGGGTGGCCGGAACGTTTACTTTGAAA AAATTAGAGTGCTCAAAGCAGGCGGACTGCCTGAATAATCGCGCATGGAATAATGG AATAGGACCTCGGTTCTATTTTGTTGGTTTTCGGAACTCGAGGTAATGATTAAGAGG GACAGACGGGGGCATTCGTATTACGGTGTTAGAGGTGAAATTCTTGGATCGCCGTAA GACGAACTACTGCGAAAGCATTTGCCAAGAATGTTTTCATTAATCAAGAACGAAAG TNAGAGGTTCGAAGANNATNANATACCGN

TEMPLATE NAME: 3

PRIMER NAME: V4R2

NNNNNNNNNNNNNNNNNNNNTTCTTGNCNNNGCTTTCGCAGTAGTTCGTCTTACGG CGATCCAAGAATTTCACCTCTAACACCGTAATACGAATGCCCCCGTCTGTCCCTCTT AATCATTACCTCGAGTTCCGAAAACCAACAAAATAGAACCGAGGTCCTATTCCATTA TTCCATGCGCGATTATTCAGGCAGTCCGCCTGCTTTGAGCACTCTAATTTTTTCAAAG TAAACGTTCCGGCCACCCGAAGCACTCAACGAAGAGCACCAAGGGAAAACCGGGA GGTAGGTCAGGACGRGCAGTAATCGCCGCGAGGCGAACCGCRAGCCTGGACCCGAG ATCCAACTACGAGCTTTTTAACTGCAACAACTTTAATATACGCTATTGGAGCTGGAA TTACCGCGGCTGCTGGCACNNNNNTTGCCNCNGCTGCTGGCACCNGACTTGC

TEMPLATE NAME: 4 


\section{PRIMER NAME: 3NDF}

NNNNNNNNNNNNNNNGNACGTTNNNTTGCTGCAGTTAAAAAGCTCGTAGTTGAACG TNCGGGTTCCGCGGGACGGGGCCGCCCCGCGAGGGACGGCGCCGCCCYGGGGCYCG TGNNNTCYSATCTCGCCGCCCGTCGCGAGGCGGACGGAGGGANGGATGAGGTTACC TGGAAAAAATCGGGGCGATCTAGGCGGGCGAACCTCGCCAACGAACGATMGGACA TGGGATAACGGAAGAGGGCRTCGGCTCGACTTCGTCGGTTCCTCGNGCYGAGGCAC GTACGGTGAATAGGGACGGTCGGGGCCGCCCGTACCGGGTCGYGAGAGGTGAAATT CTAGGATCGACCCGAGACGAACCGCCGCGAAAGCATTCGGCAAGGACGCTTTCATT AATCAAGAACGAAAGTCGGGGGATCGAAGANGANNANATACCGNNN

TEMPLATE NAME: 4

PRIMER NAME: V4R2

NNNNNNNNNNNNNNNNGANNCGTCCTTGCCGAATGCTTTCGCGGCGGTTCGTCTCG GGTCGATCCTAGAATTTCACCTCTCNCGACCCGGTACGGGCGGCCCCNACCGTCCCT ATTCNCCGTACGTGCCTCNGCNCGAGGAACCNACNAAGTCNAGCCNANGCCCTCNT CCGTTATCCCATGTCCNATCGTTCGTTGGCGAGGTTCNCCCGCCTAGATCGCCCCGA TTTTTTCCAGGTAACCTCATCCNTCCCTCCGTCCGCCTCGCGACGGGCGGCGAGATSR GATNNCACGRGCCCCNGGGCGGCGCCGTCCCTCGCGGGGCGGCCCCGTCCCGCGGA ACCCGNACGTTCAACTACGAGCTTTTTAACTGCAGCAACTTTAACGTACGCTATTGG AGCTGGAATTACCGCGGCTGCTGGCANNNACTTGCN

TEMPLATE NAME: 5

PRIMER NAME: 3NDF

NNNNNNNGNGNACGTNNNNNTGCTGCAGTTAAAAAGCTCGTAGTTGAACGTCCGGG TTCCGCGGGACGGGGCCGCCCCGCGAGGGACGGCGCCGCCCYGGGGCCCGTGGGAT CCNATCTCGCCGCCCGTCGCGAGGCGGACGGAGGGACGGATGAGGTTACCTGGAAA AAATCGGGGCGATCTAGGCGGGCGAACCTCGCCAACGAACGATMGGACATGGGAT AACGGAAGAGGGCNTCGGCTCGACTTCGTCGGTTCCTCGNGCYGAGGCACGTACGG TGAATAGGGACGGTCGGGGCCGCCCGTACCGGGTCGCGAGAGGTGAAATTCTAGGA TCGACCCGAGACGAACCGCCGCGAAAGCATTCGGCAAGGACGCTTTCATTAATCAA GAACGAAAGTCGGGGGATCGAAGNNGN

TEMPLATE NAME: 5

PRIMER NAME: V4R2

NNNNNNNNNNNNNNNNNCCTTGCCGAANGCTTTCGCGGCGGTTCGTCTCGGGTCGA TCCTAGAATTTCACCTCTCNCGACCCGGTACGGGCGGCCCCGACCGTCCCTATTCAC CGTACGTGCCTCNGCTCGAGGAACCGACGAAGTCGAGCCGATGCCCTCTTCCGTTAT CCCATGTCCTATCGTTCGTTGGCGAGGTTCGCCCGCCTAGATCGCCCCGATTTTTTCC AGGTAACCTCATCCGTCCCTCCGTCCGCCTCGCGACGGGCGGCGAGATCNGATCCCA CGGGCCCCNGGGCGGCGCCGTCCCTCGCGGGGCGGCCCCGTCCCGCGGAACCCGGA 
CGTTCAACTACGAGCTTTTTAACTGCAGCAACTTTAACGTACGCTATTGGAGCTGGA ATTACCGCGGCTGCTGGCNNNNACTTG

TEMPLATE NAME: 6

PRIMER NAME: V4R2

\begin{abstract}
NNNNNNNNNNNNANNNNTTGNNNANGCTTTCGCATTAGTTAGTCTTcAAtAAATC CAAGAATTTCACCTCTGACTATTGAATACTAATGCCCCCAACTGTCCCTATTAAT CATTACTTTGGTCCTCAAAMCMAMMAAATAAAAMCMAAGTCCTATCATGWTAT TCCMTGSTAACGKATTCAAGCATAAGCCTGCTTTAAACACTCTAATTTCCTCAAG GTAARGCTCGGTTCCCTASCGCACCGAASCACGACTAGCTCCCCGAAKGTGAGGC RCAGCGATCCCAGTACACCCAGAGGGTGACCAGGCCGCCTTGCCTAAAGTCCAA CTACRAGCTTTTTAACTGCAACAACTTTAATATACKCTATTGGAGCTGGAATTAC CGCGGCTGCTGGCACCWGACTTGCCNGNNNNNNNNNNN
\end{abstract}

TEMPLATE NAME: 7

PRIMER NAME: 3NDF

NNNNNNNNNNNNNNNNNNNTGTTGCAGTTAAAAAGCTCGTAGTTGAATaTCTGG TATARCGTACCTGGCCCGCAGCCTTTAGGCTTGKGTGTGCCGGCGCACGTTTGCC ATCTTTCTAGAAAACGGSTCTGCCATTARCTTGGTGGGTTCGGGATCTAGATCATT TACTTTGAAAAAATTAKAGTGTTTAAAGCAAGCAATTGCTCTGAATACATTARCA TGRAATAATAATCTAGGACTTCKGTTCTATTTTGTTGGTTTCTAAAACTGAARTAA TGATTGATAGGGACAGTTGGGGGTGCTAGTATTGRCCGGMCAKAGGTGAAATTC TTGRATTCGGTCAAGACTAACTTATGCGAAAGCATTCRCCAAGGATGTCTTCTTT AATCAAKAACGAAAGTTGGGRGATCRAARACSATYAGATACCGA

TEMPLATE NAME: 8

PRIMER NAME: 3NDF

NNNNNNNNNGNANANNANNNTTGTTGCAGTTAAAAAGCTCGTAGTTGAATTTCG GACGAGGACGTCCGGTCTGGCTTCTGGTCRGCAcTGGACGGGCCGAGTCTTACTT CTAGGGAAGCGGCGKGCCCTTCACCGGGTGCGCCGGGGAACTAGGACGATTACC TTGAGAAAAATARAGTGTTTAAAGCAAGCCGATGCTTGAATACGTTAGCATGGA ATAATAGAATAGGACCTTGGTCTTATTTTGTTGGTTTTGAGGACCACTGTCATGA TGAATAGGGACAGTTGGGGGCATTAGTATTCTGGCGTCAGAGGTGAAATTCTTGG ATTGCCAGAARACTAACTAGTGCGAAAGCATTTGCCAAGGATGTTTTCATTAATC AAGAACGAAAGTTAGGGGATCGAARACRANNNATNCC

TEMPLATE NAME: 9

PRIMER NAME: 3NDF

NNNNNNNNNNNGNGNATATNNNNTTGTTGCAGTTAAAAAGCTCGTAGTTGAATTTC 
GGACGAGGACGTCCGGTCTGGCTTCTGGTCAGCACTGGACGGGCCGAGTCTTACTTC TAGGGAAGCGGCGTGCCCTTCACCGGGTGCGCCGGGGAACTAGGACGATTACCTTG AGAAAAATAGAGTGTTTAAAGCAAGCCGATGCTTGAATACGTTAGCATGGAATAAT AGAATAGGACCTTGGTCTTATTTTGTTGGTTTTGAGGACCACTGTCATGATGAATAG GGACAGTTGGGGGCATTAGTATTCTGGCGTCAGAGGTGAAATTCTTGGATTGCCAGA AGACTAACTAGTGCGAAAGCATTTGCCAAGGATGTTTTCATTAATCAAGAACGAAA GTTNGGGGNTCGAAGNNNNNNNNTACCG

TEMPLATE NAME: 9

PRIMER NAME: V4R2

NNNNNNNNNNNNNNNNCNTTGNNNNNGCTTTCGCACTAGTTAGTCTTCTGGCAATC CAAGAATTTCACCTCTGACGCCAGAATACTAATGCCCCCAACTGTCCCTATTCATCA TGACAGTGGTCCTCAAAACCAACAAAATAAGACCAAGGTCCTATTCTATTATTCCAT GCTAACGTATTCAAGCATCGGCTTGCTTTAAACACTCTATTTTTCTCAAGGTAATCGT CCTAGTTCCCCGGCGCACCCGGTGAAGGGCACGCCGCTTCCCTAGAAGTAAGACTC GGCCCGTCCAGTGCTGACCAGAAGCCAGACCGGACGTCCTCGTCCGAAATTCAACT ACGAGCTTTTTAACTGCAACAACTTTAATATACGCTATTGGAGCTGGAATTACCGCG GCTGCTGGCNCNNNCTTGCCNNN

TEMPLATE NAME: 10

PRIMER NAME: V4R2

NNNNNNNNNNNNNNNNTGGCGATGCTTTCGCACTAGTTAGTCTTCCGGCAANCCAA GAATTTCACCTCTGACGCCGGAATACTAATGCCCCCAACTGTCCCTATTCATCATGA CAYTGGTCCTCAAAMCMAMMMAAWWAAAACCAMGKYCTWWTYTWWTWWTYC MWGGYWAWGRATYYMAGCMAGAAGCCTGCTTTGAACACTCTGTTTTCCTCAAGGT AATCGTCCTGGTTCCCCGGCGCGCCCAGYRAAGGACACGCCGCTTCCCCAGAAGTA AGACTCGACCCGCGSCGTCGAGGCCGAARCCACACGCCGCGCTCTCGCCCSATGMTC MAMTACSARCTTTTTAACTGCARCAACHTTAATGTGTGCTATTGGARCTGGAATTAC CGCGGCTGSTGGCACCGAMTTGCCAAGACTTGCNNNCTTTAATATNCNCNNTTGGAG CTGGAATTANCGCGGCTGNNNNN

TEMPLATE NAME: 11

PRIMER NAME: V4R2

NNNNNNNNNNNNNNNNNNCCTTGGcAATGCTTTCGCACTAGTTMGTCTTCTGGMAA TCCAAGAATTTCACCTCTGACKCCRGAATACTAATGCCCCCAACTGTCCCTATTCAT CATGACAKTGGTCCTYAAAACCAACAAAATAARACCAARGTCCTATTYTATTATTCC ATGCTAACGTATTCAAGCAWMRGCTTGCTTTRAACACTCTATTTTTCTCAAGGTAAT CGTCCTRGTTCCCCGGCGCACCCGGTGAAGGGCACSCCGCTTCCCTAGAARWAAGA 
CTCGRCCCGYCCAGTGCTGACCARAAGCCARACCGGACGTCCTCGTCCGAAATTCAA CTACGAGCTTTTTAACTGCAACAACTTTAATATACGCTATTGGAGCTGGAATTACCG CGGCTGSTGGCACCANACTNNNNNNNN

\section{TEMPLATE NAME: 12}

PRIMER NAME: 3NDF

NNNNNNNNNNNNANANNNNNTTNNTGCAGTTAAAAAGCTCGTAGTTGGATCTCGGG TCCAGGCTNGCGGTTCGCCTCGCGGCGATTACTGCYCGTCCTGACCTACCTCCCGGT TTTCCCTTGGTGCTCTTCGTTGAGTGCTTCGGGTGGCCGGAACGTTTACTTTGAAAAA ATTAGAGTGCTCAAAGCAGGCGGACTGCCTGAATAATCGCGCATGGAATAATGGAA TAGGACCTCGGTTCTATTTTGTTGGTTTTCGGAACTCGAGGTAATGATTAAGAGGGA CAGACGGGGGCATTCGTATTACGGTGTTAGAGGTGAAATTCTTGGATCGCCGNAAG ACGAACTACTGCGAAAGCATTTGCCAAGAATGTTTTCATTAATCAAGAACGAAAGT NNGAGGTTCGAAGACGATCNNATACCNNNNN

\section{TEMPLATE NAME: 12}

\section{PRIMER NAME: V4R2}

NNNNNNNNNNNNNNNNNNNNNNNNGNNNNNNCTTTCGCAGNAGTTCGTCTTNCGG CGATCCAAGAATTTCNCNNNNAACACCGTAATACGAATGCCCCCGTCTGTCCCTCTT NATCATTACCTCGAGTTCCGAAAACCAACAAAATAGAACCGAGGTCCTATTCCATTA TTCCATGCGCGATTATTCAGGCAGTCCGCCTGCTTTGAGCACTCTAATTTTTTCAAAG TAAACGTTCCGGCCACCCGAAGCACTCAACGAAGAGCACCAAGGGAAAACCGGGA GGTAGGTCAGGACGNGCAGTAATCGCCGCGAGGCGAACCGCNAGCCTGGACCCGA GATCCAACTACGAGCTTTTTAACTGCAACAACTTTAATATACGCTATTGGAGCTGGA ATTACCGCGGCTGCTGGCANNNACTTGCNNNN 


\section{REFERENCES:}

Abdul Hussein, A., \& Al-Janabi, S. (2011). Investigation of anti-dermatophytic effects of nonsteroidal anti-inflammatory drugs on trichophyton mentagrophytes and epidermophyton floccosum. Iranian Journal of Pharmaceutical Research : IJPR, 10(3), 547.

Allen, L. A. (1944). The bacteriology of activated sludge. The Journal of Hygiene, 43(6), 424431.

Altschul, S. F., Madden, T. L., Schäffer, A. A., Zhang, J., Zhang, Z., Miller, W., \& Lipman, D. J. (1997). Gapped BLAST and PSI-BLAST: A new generation of protein database search programs. Nucleic Acids Research, 25(17), 3389-3402

Aslam, N., \& Bushra, R. (2010). An overview of clinical pharmacology of ibuprofen. Oman Medical Journal, 25(3), 153-154.

Basnyat, P. (2010). Evaluation of Toxicity of Pharmaceuticals to the Activated Sludge Treatment Plant. Tampere University of Technology, 1-66.

Beychok, M. R. (1967). Aqueous Wastes from Petroleum and Petrochemical Plants. John Wiley \& Sons Ltd.

Buser, H.R., Poiger, T., \& Muller, M.D., (1999). Occurrence and environmental behavior of the 
chiral pharmaceutical drug ibuprofen in surface waters and in wastewater. Environ. Sci. Technol. 33 (15), 2529-2535.

Bácsi, I., B-Béres, V., Kókai, Z., Gonda, S., Novák, Z., Nagy, S. A., \& Vasas, G. (2016). Effects of non-steroidal anti-inflammatory drugs on cyanobacteria and algae in laboratory strains and in natural algal assemblages. Environmental Pollution, 212, 508-518.

Carballa, M., Omil, F., Lema, J.M., Llompart, M., Garcia-Jares, C., Rodriguez, I., Gomez, M., \& Ternes, T., (2004). Behavior of pharmaceuticals, cosmetics and hormones in a sewage treatment plant. Water Research. 38 (12), 2918-2926.

Chopra, I., \& Roberts, M. (2001). Tetracycline antibiotics: Mode of action, applications, molecular biology, and epidemiology of bacterial resistance. Microbiology and Molecular Biology Reviews, 65(2), 232-260.

Chowdhury, B., Roy, D., Chavan, U., \& Mukhopadhyay, S., (1996). The anti-inflammatory, antipyretic, analgesic compound ibuprofen also has antibacterial activity against Gram-positive bacteria. Med. Sci. Res. 24, 801-802.

City of Toronto. (2015). Humber Wastewater Treatment Plant 2014 Annual Report.

Curds, C.R. \& Fey, GJ. (1969). The effect of ciliated protozoa on fate of Escherichia coli in the activated sludge process. Water Research, 3, 853-867. 
Curds, C. R. (1973). The role of protozoa in the activated-sludge process. American Zoologist, 13(1), 161-169.

Curds, C.R. (1975) Protozoa. In: Curds CR, Hawkes HA (eds) Ecological aspects of usedwater treatment.Academic Press, London, 203.

Curds, C. R. (1982). The ecology and role of protozoa in aerobic sewage treatment processes. Annual Review of Microbiology, 36(1), 27-28.

Curds, C. R., \& Cockburn, A. (1970). Protozoa in biological sewage-treatment processes-I. A survey of the protozoan fauna of British percolating filters and activated-sludge plants. Water Research, 4(3), 225,IN1,229-228.

Curds, C. R., \& Cockburn, A. (1970). Protozoa in biological sewage-treatment processes-II. Protozoa as indicators in the activated-sludge process. Water Research, 4(3), 237-249.

Curds CR. (1975). Protozoa. In: Curds CR, Hawkes HA, editors. Ecological aspects of usedwater treatment. London: Academic Press. pp. 203-268.

Dantas G., Sommer M.O.A., Oluwasegun R.D., \& Church G.M., (2008). Bacteria subsisting on antibiotics. Science. 320:100-103. 
Daughton, C. G., \& Ternes, T. A. (1999). Pharmaceuticals and personal care products in the environment: Agents of subtle change? Environmental Health Perspectives, 107(12), 907.

Deblonde, T., Cossu-Leguille, C., \& Hartemann, P. (2011). Emerging pollutants in wastewater: A review of the literature. International Journal of Hygiene and Environmental Health, 214(6), 442.

Dieffenbach, C. W., \& Dveksler, G. S. (1995). PCR primer: A laboratory manual. Plainview, NY: Cold Spring Harbor Laboratory Press.

Do Bugs Need Drugs? (2014). Antibiotic Utilization in the Province of British Columbia. Vancouver (BC): B.C. Centre for Disease Control, 3-106.

Eichner, C. A., Erb, R. W., Timmis, K. N., \& Wagner-Döbler, I. (1999). Thermal gradient gel electrophoresis analysis of bioprotection from pollutant shocks in the activated sludge microbial community. Applied and Environmental Microbiology, 65(1), 102-109.

Environmental Protection Agency (EPA). (1997) Wastewater treatment manuals: Primary, secondary and tertiary treatment. Published by EPA, Ardcavan, Wexford, Ireland. http://www.epa.ie/downloads/advice/water/wastewater/ accessed July 10, 2016

Ferrando-Climent, L., Collado, N., Buttiglieri, G., Gros, M., Rodriguez-Roda, I., RodriguezMozaz, S., \& Barceló, D. (2012). Comprehensive study of ibuprofen and its metabolites in 84 
activated sludge batch experiments and aquatic environment. The Science of the Total Environment, 438, 404-413.

Gros, M., Petrović, M., Ginebreda, A., \& Barceló, D. (2010). Removal of pharmaceuticals during wastewater treatment and environmental risk assessment using hazard indexes. Environment International, 36(1), 15-26.

Gujarathi, N. P., Haney, B. J., \& Linden, J. C. (2005). Phytoremediation potential of myriophyllum aquaticum and pistia stratiotes to modify antibiotic growth promoters, tetracycline, and oxytetracycline, in aqueous wastewater systems. International Journal of Phytoremediation, 7(2), 99.

Gutiérrez, M., Etxebarria, J., \& de las Fuentes, L. (2002). Evaluation of wastewater toxicity: Comparative study between microtox ${ }^{\circledR}$ and activated sludge oxygen uptake inhibition. Water Research, 36(4), 919-924.

Health Canada (2015), Summary Safety Review - Prescription Oral Ibuprofen (Non-Steroidal Anti-inflammatory Drug) - Risk of Serious Heart and Stroke Adverse Events at High Doses. CA: Health Canada

Heberer, T. (2002). Occurrence, fate, and removal of pharmaceutical residues in the aquatic environment: A review of recent research data. Toxicology Letters, 131(1), 5-17 
Islam, G. I. (2013). Impact of tetracycline on microbial communities in the secondary treatment process of wastewater treatment systems. Master Thesis, Ryerson University.

Jenkins, D., M. G. Richard, \& G. T. Daigger, (1993). Manual on the Causes and Control of Activated Sludge Bulking and Foaming, Ridgeline Press, Lafayette, CA.

Jill E. Clarridge III. (2004). Impact of 16S rRNA gene sequence analysis for identification of bacteria on clinical microbiology and infectious diseases. Clinical Microbiology Reviews, 17(4), $840-862$.

Kimura, K., Hara, H., \& Watanabe, Y. (2005). Removal of pharmaceutical compounds by submerged membrane bioreactors (MBRs). Desalination, 178(1), 135-140.

Liao B.Q., Allen D.G., Droppo I.G., Leppard G.G. \& Liss S.N. (2001) Surface properties of sludge and their role in bioflocculation and settleability. Water Research. 35, 339-350.

Lin, W., Yu, Z., Zhang, H., \& Thompson, I. P. (2014). Diversity and dynamics of microbial communities at each step of treatment plant for potable water generation. Water Research, 52, 218

Lindqvist, N., Tuhkanen, T., \& Kronberg, L., (2005). Occurrence of acidic pharmaceuticals in raw and treated sewages and in receiv- ing waters. Water Res. 39, 2219-2228. 
Livak. K.J., (1997 \& 2001). ABI Prism 7700 Sequence detection System User Bulletin \#2 Relative quantification of gene expression. ABI company publication.

Livak, K.J., \& Schmittgen, T.D., (2001). Analysis of relative gene expression data using realtime quantitative PCR and the $2 \Delta \Delta \mathrm{C}(\mathrm{T})$ Method. Methods 25 (4), 402-408.

Madoni P. (1994a). Quantitative importance of ciliated protozoa in activated sludge and biofilm. Bioresource Technology 48:245-249.

Madoni, P. (2003). Protozoa as indicators of wastewater treatment efficiency. Handbook of Water and Wastewater Microbiology, 361-371.

Madoni, P. (2011). Protozoa in wastewater treatment processes: a mini review. Italian Journal of Zoology, 78(1), 3-11

Mallory, L. M., Yuk, C. S., Liang, L. N., \& Alexander, M. (1983). Alternative prey: A mechanism for elimination of bacterial species by protozoa. Applied and Environmental Microbiology, 46(5), 1073-1079.

Matsunaga, K., Kubota, K., \& Harada, H. (2014). Molecular diversity of eukaryotes in municipal wastewater treatment processes as revealed by $18 \mathrm{~S}$ rRNA gene analysis. Microbes and Environments, 29(4), 401-407. 
Metcalfe, C. D., Koenig, B. G., Bennie, D. T., Servos, M., Ternes, T. A., \& Hirsch, R. (2003). Occurrence of neutral and acidic drugs in the effluents of Canadian sewage treatment plants. Environmental Toxicology and Chemistry / SETAC, 22(12), 2872 - 2880.

Miège, C., Choubert, J. M., Ribeiro, L., Eusèbe, M., \& Coquery, M. (2009). Fate of pharmaceuticals and personal care products in wastewater treatment plants - conception of a database and first results. Environmental Pollution, 157(5), 1721-1726.

Muyzer, G., E C de Waal, \& Uitterlinden, A. G. (1993). Profiling of complex microbial populations by denaturing gradient gel electrophoresis analysis of polymerase chain reactionamplified genes coding for 16S rRNA gene. Applied and Environmental Microbiology, 59(3), $695-700$.

Nelson, M. L., \& Levy, S. B. (2011). The history of the tetracyclines. Annals of the New York Academy of Sciences, 1241(1).

Nesc. (2003). National Small Flows Clearinghouse. Pipeline, Explaining the Activated Sludge Process. Pipeline, 14(2)

Ormerod, K. S., \& H. Efraimsen, (1988), 'Testing for toxicity and adaptation in communities of heterotrophic microorganisms" In Toxicity Screening Procedures Using Bacterial Systems, D. Liu, and B. J. Dutka, editors, Marcel Dekker, Inc., New York, 195-212. 
Ovez, S., \& Orhon, D. (2005). Microbial ecology of bulking and foaming activated sludge treating tannery wastewater. Journal of Environmental Science and Health. Part A, Toxic/hazardous Substances \& Environmental Engineering, 40(2), 409-422.

Pauli, W., Jax, K., \& Berger, S. (2015). Protozoa in Wastewater Treatment: Function and Importance. The Handbook of Environmental Chemistry Biodegradation and Persistance, 203252

Petropoulos, P., \& Gilbride, K. A. (2005). Nitrification in activated sludge batch reactors is linked to protozoan grazing of the bacterial population. Canadian Journal of Microbiology, 51(9), 791-791.

Pike EB (1975) Aerobic bacteria. In: Curds C R, Hawkes HA (eds) Ecological aspects of usedwater treatment.Academic Press, London

Pogue, A. J., \& Gilbride, K. A. (2007). Impact of protozoan grazing on nitrification and the ammonia- and nitrite-oxidizing bacterial communities in activated sludge. Canadian Journal of Microbiology, 53(5), 559-559.

Pomati, F., Netting, A. G., Calamari, D., \& Neilan, B. A. (2004). Effects of erythromycin, tetracycline and ibuprofen on the growth of synechocystis sp. and lemna minor. Aquatic Toxicology, 67(4), 387-396. 
Prado, T., Gaspar, A. M. C., \& Miagostovich, M. P. (2014). Detection of enteric viruses in activated sludge by feasible concentration methods. Brazilian Journal of Microbiology, 45(1), 343-349.

Quintana, J.B., Weiss, S., \& Reemtsma, T., (2005). Pathways and metabo- lites of microbial degradation of selected acidic pharmaceutical and their occurrence in municipal wastewater treated by a mem- brane bioreactor. Water Res. 39, 2654-2664.

Rainsford, K. D. (2011). Fifty years since the discovery of ibuprofen. Inflammopharmacology, 19(6), 293-297.

Rang, H. P., Dale, M. M., Ritter, J. M., \& Moore, P. K. (2003). Pharmacology. Edinburgh: Churchill Livingstone.

Ratsak, C.H., Maarsen, K.A. \& Kooijman, S. (1996). Effects of protozoan on carbon mineralization in activated sludge. Water Research, 30, 1-12.

Real-Time PCR Applications Guide. (2006). Bio-Rad Laboratories.

Roberts, P.H., \& Thomas, K.V., (2005). The occurrence of selected phar- maceuticals in wastewater effluent and surface waters of the lower Tyne catchment. Sci. Total Environ.

Salvadò H., Mas M., Menéndez S, \& Gracia M.P., (2001). Effects of shock loads of salt on 90 
protozoan communities of activated sludge. Acta Protozoologica 40, 177-185.

Sanyal, A. K., Roy, D., Chowdhury, B., \& Banerjee, A. B. (1993). Ibuprofen, a unique antiinflammatory compound with antifungal activity against dermatophytes. Letters in Applied Microbiology, 17(3), 109-111.

Sengupta, A. (2014). Remediation of tetracycline from water sources using vetiver grass (chrysopogon zizanioides L. nash) and tetracycline-tolerant root-associated bacteria, Michigan Technological University

Strenn, B., Clara, M., Gans, O., \& Kreuzinger, N., (2004). Carba- mazepine, diclofenac, ibuprofen and bezafibrate-investigations on the behaviour of selected pharmaceuticals during wastewater treatment. Water Sci. Technol. 50 (5), 269-276.

Sydenham, D. H. J. (1971). A re-assessment of the relative importance of ciliates, rhizopods and rotatorians in the ecology of activated sludge. Hydrobiologia, 38(3-4), 553-563.

Tauxe-Wuersch, A., de Alencastro, L.F., Grandjean, D., \& Tarradellas, J., (2005). Occurrence of several acidic drugs in sewage treatment plants in Switzerland and risk assessment. Water Res. $39,1761-1772$.

Ternes, T. A. (2001). Analytical methods for the determination of pharmaceuticals in aqueous environmental samples. Trends in Analytical Chemistry, 20(8), 419-434. 
Thomas, P.M., \& Foster, G.D., (2004). Determination of nonsteroidal anti-inflammatory drugs, caffeine, and triclosan in wastewater by gas chromatography-mass spectrometry. J. Environ. Sci. Health A 39 (8), 1969-1978

Thomson, A. J., Giannopoulos, G., Pretty, J., Baggs, E. M., \& Richardson, D. J. (2012).

Biological sources and sinks of nitrous oxide and strategies to mitigate emissions. Philosophical Transactions of the Royal Society of London. Series B, Biological Sciences, 367(1593), 1157 1168.

Viessman, W., \& Hammer, M. J. (1998). (6th ed.) Addison Wesley.

Wada, Y., Gleeson, T., \& Esnault, L. (2014). Wedge approach to water stress. Nature Geoscience Nature Geosci, 615-617.

Walsh F., Amyes, S.G.B., \& Duffy, B., (2013). Challenging the concept of bacteria subsisting on antibiotics . Int. J. Antimicrob. Ag . 41:558- 563.

Wang, P., He, Y., \& Huang, C. (2011). Reactions of tetracycline antibiotics with chlorine dioxide and free chlorine. Water Research, 45(4), 1838-1846.

WHO (2006). WHO collaborating centre for Drug Statistics and methodology. Available at: http://www.whocc.no/. 
WHO - The World Health Organization (2011). Pharmaceuticals in Drinking-water.

Wisconsin department of natural resources (2010) Introduction to activated sludge study guide, bureau of science services.

Yang, S., Cha, J., \& Carlson, K. (2005). Simultaneous extraction and analysis of 11 tetracycline and sulfonamide antibiotics in influent and effluent domestic wastewater by solid-phase extraction and liquid chromatography-electrospray ionization tandem mass spectrometry. Journal of Chromatography A, 1097(1), 40-53.

Yin, Z., Wang, Y., Whittell, L. R., Jergic, S., Liu, M., Harry, E.. . \& Oakley, A. J., (2014). DNA replication is the target for the antibacterial effects of nonsteroidal anti-inflammatory drugs. Chemistry \& Biology, 21(4), 481-487.

Yu, J., Zhou, X., Yang, S., Liu, W., \& Hu, X. (2013). Design and application of specific 16S rDNA-targeted primers for assessing endophytic diversity in dendrobium officinale using nested PCR-DGGE. Applied Microbiology and Biotechnology, 97(22), 9825-9836.

Zhang, Y., Geißen, S., \& Gal, C. (2008). Carbamazepine and diclofenac: Removal in wastewater treatment plants and occurrence in water bodies. Chemosphere, 73(8), 1151-1161. 